\title{
The Architecture of Emotional Drawings
}

by

Jeniffer Milburn

A thesis submitted to the Faculty of Graduate and Postdoctoral Affairs in partial fulfillment of the requirements for the degree of

Master of Architecture

in

Azrieli School of Architecture and Urbanism

Carleton University

Ottawa, Ontario

(c) 2017

Jeniffer Milburn 
$M$ 


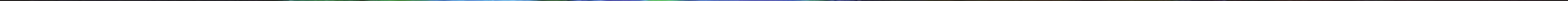


Architecture is a story which unfolds through drawing. The experience of architecture affects us, it stimulates people and can affect their wellbeing. Thus, happiness is the foremost significant emotion in the architecture of emotional drawings. Drawing can reveal what the spoken word cannot, it can bequeath wellbeing as it is an expression of conscious and unconscious desires.

Drawings are essentially constructed of subjective artistic experiences; whilst healthcare is grounded in objective scientific research. To explore the context of drawing and wellbeing at the Children's Hospital of Eastern Ontario CHEO, it is necessary to consider both frameworks. It is the scope of this thesis to research a qualitative phenomenological approach, revealed through drawings, to express how one experiences happiness and by connecting it to existing evidencebased and quantitative research. How can drawing become a way of imagining the new addition at CHEO; a cultivated place which can stimulate an environment of happiness and wellbeing. 


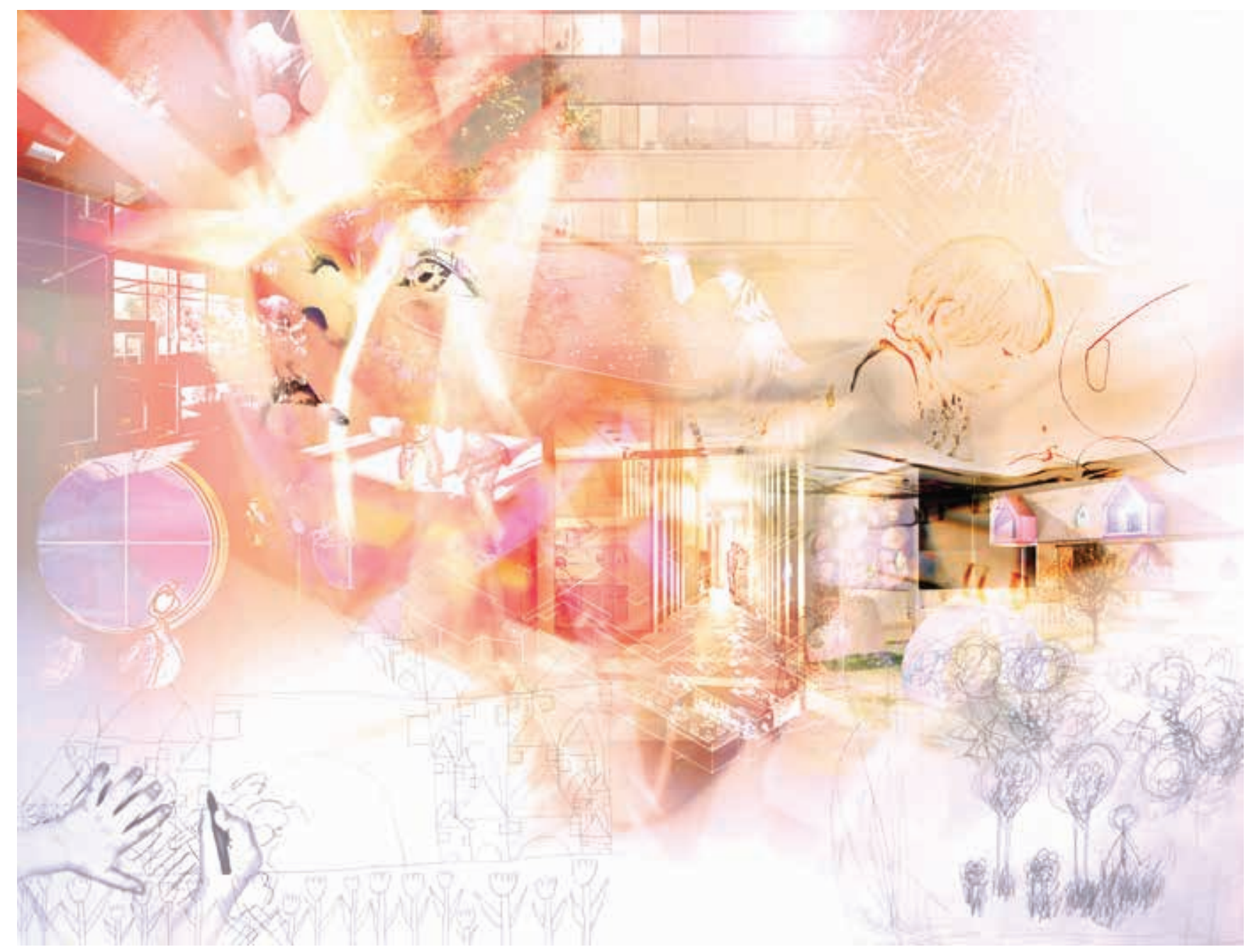




\section{ACKNOWLEDGMENTS}

First and foremost, I would like to thank my parents and sister because you are at the root of my accomplishments, my strength and courage. Thank you to Dylan, to all my dearest friends, and especially Carolyn, I couldn't have done the last six years without you.

Thank you to everyone listed on the subsequent page for letting me use your drawings to inspire the design in this thesis. Thank you to the amazing artists and ladies at H'Art, the four weeks that I spent with you flew by, you truly filled my heart with joy. Most importantly I must thank the executive director of H'Art, thank you Lin Rowsell, without you this wouldn't have been possible, your enthusiasm in the project will be forever appreciated.

Thank you to all the visiting guests whom guided us throughout the entire process, to Professor Claudio Sgarbi and Registered Nurse Kim McMillan for inspiring me at the very beginning of this journey. Thank you to Professor Greg Andonian for teaching me colour theory, it has very much influenced my work in a positive way.

I owe the utmost of gratitude and thanks to my academic advisor Federica Goffi whom has supported me in my endeavors and always encouraged me to achieve my best. I have learned so much from her and I am forever grateful. 


\section{DEDICATED TO}

\begin{tabular}{ll} 
- & Elaine \\
- & Bella \\
- & Michard \\
- & Ada \\
- & Anna \\
- & Megan \\
- & Julie \\
- & Jenny \\
- & Doug \\
- & Christopher \\
- & Christine \\
- & Mike \\
- & Henry \\
- & Jessie H \\
- & Alixe \\
- & Caroline \\
- & Tracey \\
- & Analisa \\
- & Frances \\
& Andre \\
\hline
\end{tabular}

- Amanda

- Chris M

- Jessie M

- Claire

- Jake

- Alanna

- Debbie

- Marika

- Alexa

- Nadia

- Jessica W

- Suzan

- Tanya

- Kelly

- Kelsey

- Sarah

- Arron

- Karina

- Achilla

- Millan

- Oliver 
iv-V

vi-vii

viii-x

xi

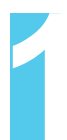

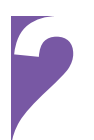

Abstract

Acknowledgments

Contents

List of Illustrations

List of Appendices

DRAWING ON MY WONDROUS EXPERIENCE

1

DRAWING RESEARCH

Drawings of Happiness: A Design Tool

Drawing Imagination from the Archive
5

\section{CONTENTS}

8

vi 
DRAWING OUT EVIDENCE

The Language of Drawing

Drawing from Neurology in Architecture

ARCHITECTURAL PROPOSITION

Drawing the Line

Emotional Drawings in $\mathrm{CHEO}$

Drawing on top of CHEO

The Architecture of Emotional Drawings 


\section{LIST OF ILLUSTRATIONS}

Figure 1

Figure 2

Figure 3

Figure 4

Figure 5

Figure 6

Quilt 1

Quilt 2

Quilt 3

Quilt 4

Figure 7

Quilt 5

Quilt 6

Quilt 7

Quilt 8

Quilt 9

Quilt 10

Figure 8

Figure 9

Quilt 11

Quilt 12

Quilt 13

Quilt 14

Quilt 15

Figure 10

Figure 11
Entering the Drawing of Another-Caroline, Christine, Henry ........................... i

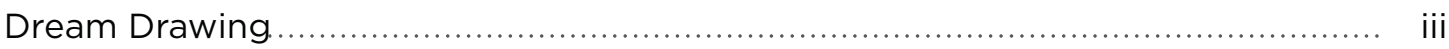

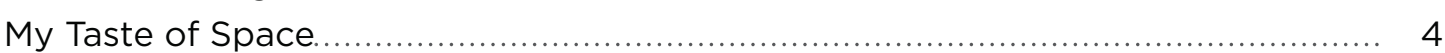

Drawing Exercise Pamphlet.............................................................................. 6

Draw a Space Where You Feel Happy - Henry ......................................................... 9

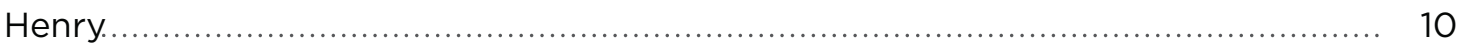

Henry, Kelsey, Elaine, Jenny, Jessica, Analisa................................................ 11

Richard, Nadia, Marika, Christine, Kelly ............................................................ 13

Tracey, Jessica, Tanya, Julie ......................................................................... 15

Amanda, Megan, Ada, Oliver, Andre ................................................................ 17

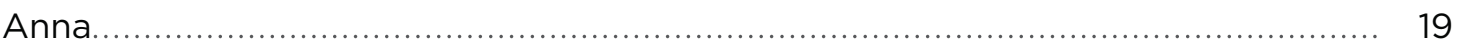

Anna, Caroline, Andre, Malinda, Jessica, Alixe, Sarah........................................ 21

Michael, Debbie, Jenny, Ada, Julie............................................................... 23

Analisa, Kelly, Marika, Suzan, Tracey ............................................................... 25

Frances, Jessica, Alanna, Christine ........................................................... 27

Achilla, Chris, Millan, Jake, Nadia.................................................................... 29

Claire, Jessie, Karina, Elaine, Doug, Alexa.............................................................. 31

Draw What Happiness Looks Like To You - Julie ............................................. 33

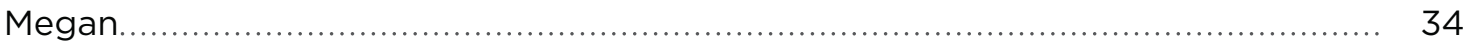

Frances, Alanna, Sarah, Marika, Alixe, Amanda................................................. 35

Karina, Millan, Debbie, Oliver, Alexa................................................................... 36

Christine, Amanda, Kelsey, Claire, Bella, Jake, Doug.......................................... 37

Julie, Malinda, Christopher, Andre, Alixe, Anna, Jake ......................................... 38

Caroline, Alixe, Achilla, Richard, Tanya, Jessie, Suzan ......................................... 39

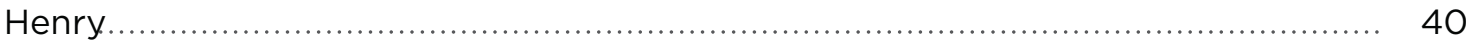

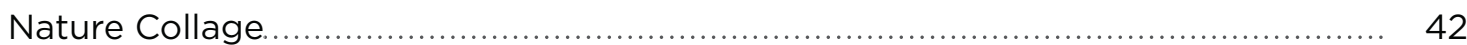


Figure 12

Figure 13

Figure 14

Figure 15

Figure 16

Figure 17

Figure 18

Figure 19

Figure 20

Figure 21

Figure 22

Figure 23

Figure 24

Figure 25

Figure 26

Figure 27

Figure 28

Figure 29

Figure 30

Figure 31

Figure 32

Figure 33

Figure 34

Figure 35

Figure 36

Figure 37

Figure 38

Figure 39

Figure 40

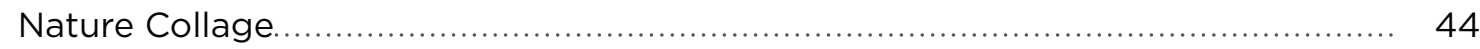

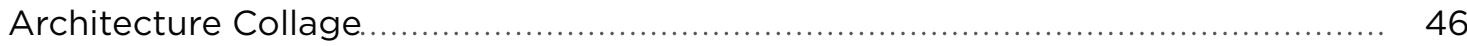

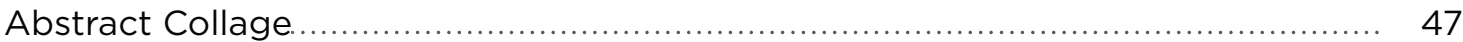

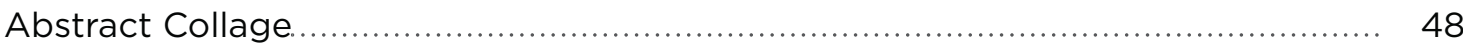

CHEO Rooftop, Source: Google Maps........................................................... 58

CHEO Rooftop with children cut out façade,

Source: Google Maps, Photo: Jeniffer Milburn.................................................. 58

Section of level 4,5,6 looking down onto roof............................................ 59

Level four to six is in the 'tower' of CHEO ...................................................... 60

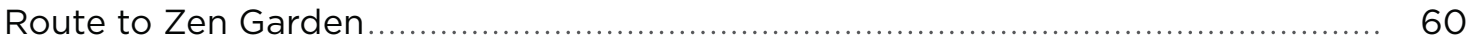

CHEO Façade, Photo: Jeniffer Milburn .......................................................... 61

Drawings in railing at CHEO, Photo: Jeniffer Milburn........................................ 62

Drawings on façade at CHEO, Photo: Jeniffer Milburn....................................... 62

Sculpture at CHEO, Photo: Jeniffer Milburn ................................................... 62

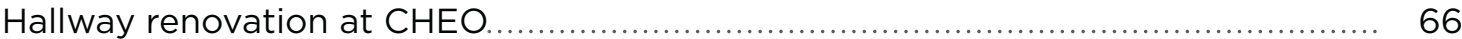

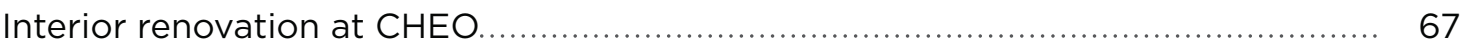

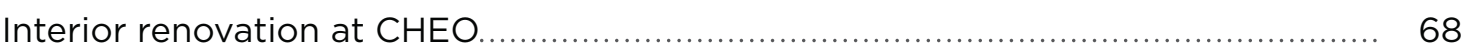

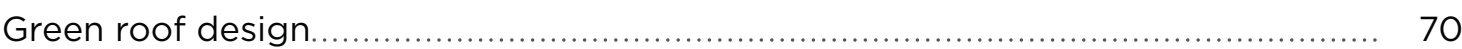

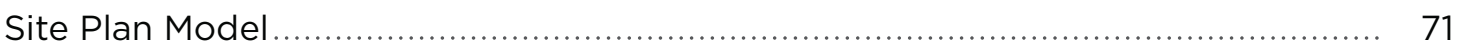

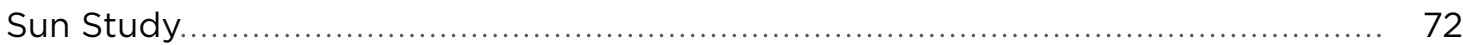

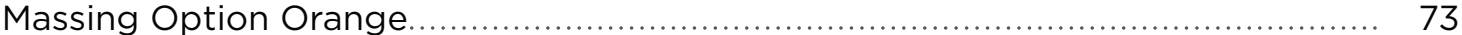

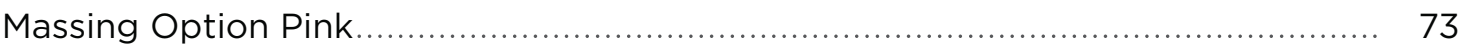

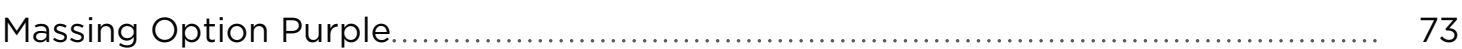

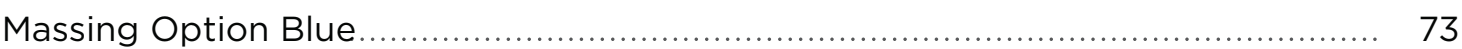

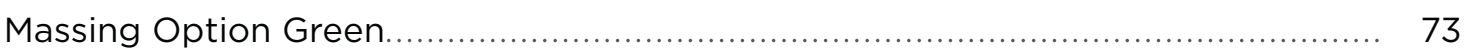

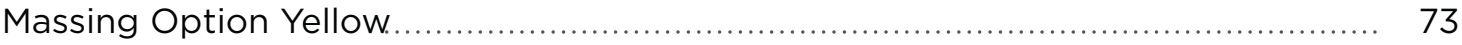

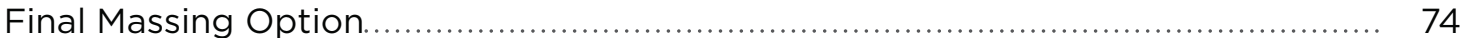

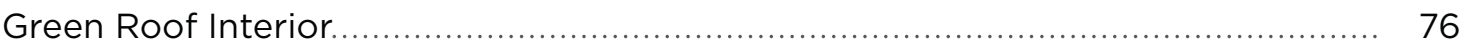

Exterior View of Addition...................................................................... 77

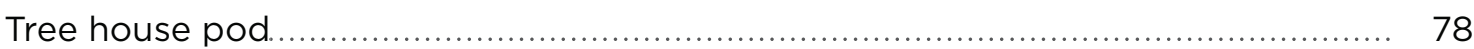


Figure 41

Figure 42

Figure 43

Figure 44

Figure 45

Figure 46

Figure 47

Figure 48

Figure 49

Figure 50

Figure 51

Figure 52

Figure 53

Figure 54

Figure 55

Figure 56

Figure 57

Figure 58

Figure 59

Figure 60

Figure 61

Figure 62

Figure 63

Figure 64

Figure 65

Figure 66

Figure 67

Figure 68

Figure 69

Figure 70

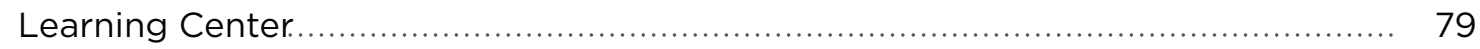

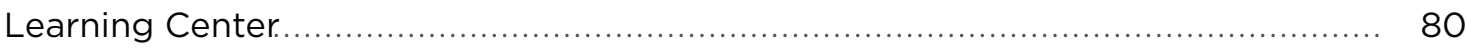

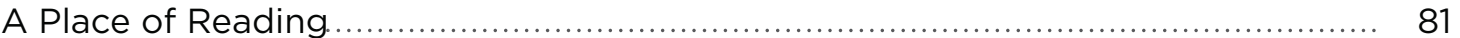

Site Plan.............................. 83

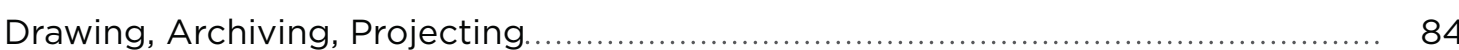

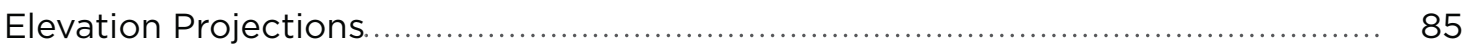

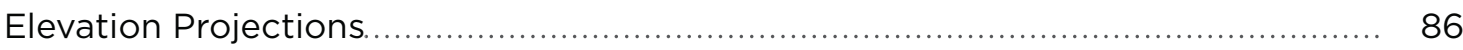

Connected by the Digital Quilt.......................................................... 88

Green roof

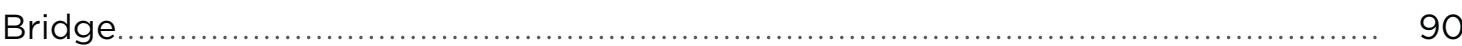

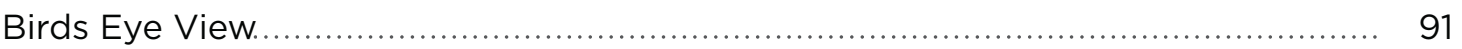

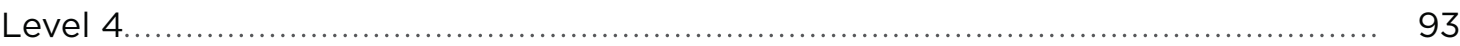

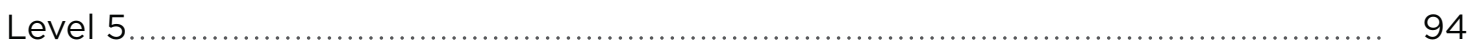

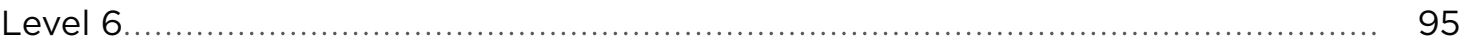

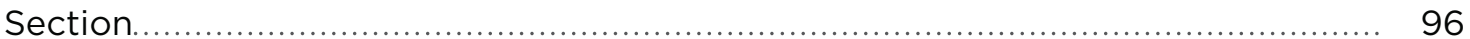

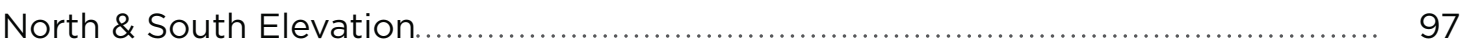

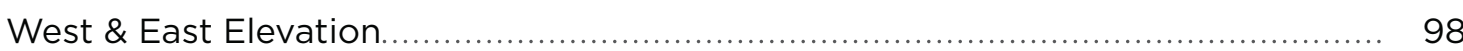

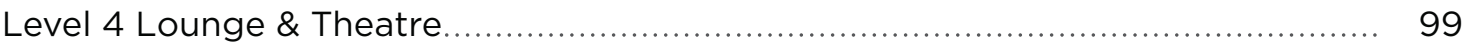

Level 4 Central Atrium.................................................................................. 100

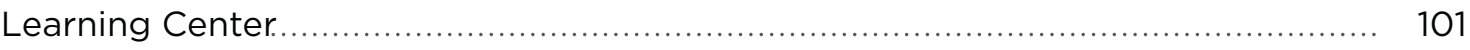

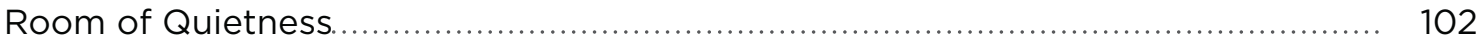

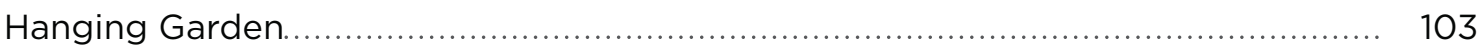

View from Sixth Floor ............................................................................... 104

Fifth Floor Reading Room........................................................................... 105

Sixth Floor Reading Room........................................................................... 106

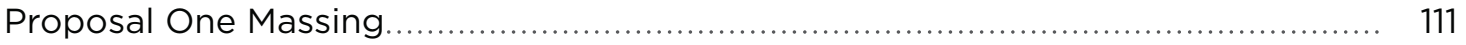

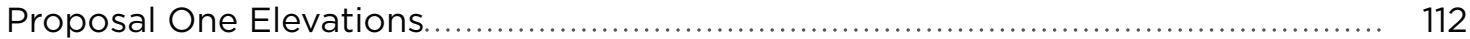

Interior Renovation Diagram..................................................................... 112

Children's Design Volume Massing............................................................... 112

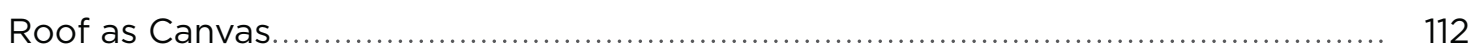


ARCHIVING PROPOSAL ONE

ETHICS CLEARANCE

\section{LIST OF APPENDICES}

APPENDIX

i

APPENDIX 


\title{
DRAWING ON MY WONDROUS EXPERIENCE
}

\author{
Read Happily,
}

Drawing is an inception of architecture; it is where we enter the wondrous space of our minds. Architecture communicates and draws out emotions, it shapes us and our wellbeing. Drawing is a visual language which can reveal glimpses into the subconscious mind. Drawing becomes the tool to imagine the architecture of emotional drawings and in turn, the new addition at the Children's Hospital of Eastern Ontario CHEO. This thesis looks at the relationship between space and emotion, and its interpretation through drawing. To draw conclusions on the qualitative research of this thesis, understanding and interpretation will be directed through readings of existing quantitative research; drawing together a transparency, a link between.

Advances in psychology and neuroscience now provide a scientific basis for considering the effects of space on emotions and wellbeing. ${ }^{1}$ The experience of architecture is uniquely coloured for everyone. The meaning things have in our embodied experiences, their appearances, and the way we experience things is defined as phenomenology. ${ }^{2}$ There are architectural nuances which can emit a positive or negative phenomenology. Physical surroundings can change the way one 
feels and thus, can change one's wellbeing. Communication between the brain and the immune system is very important. ${ }^{3}$ Awareness of space and place changes when we are ill, and changes yet again when we begin to heal. ${ }^{4}$ Healing and illness noticeably shapes our sense of place; it can paint our emotions. ${ }^{5}$ Drawing and neuroscience in architecture may seem poles apart but with growing insight the two disciplines both work together in their quest of knowledge, which in due course aids in the design of wellbeing in architecture. ${ }^{6}$

Both drawing and architecture communicate and uniquely draw out emotions through lived experiences. There is a relationship between space and emotion -- how can drawing help interpret this relationship. As a child, I have had a reoccurring experience, which now as an adult only visits intermittently. With this lived experience in mind I realize that it is extremely important to design the experience of architecture, particularly for children, to have a positive impact on their wellbeing because they are very vulnerable to the stimulus of their surroundings. The onset of this personal experience is difficult to describe with words. Typically, it would come into being while drawing, or while writing a math exam. Drawing and math remarkably are both non-verbal languages. My surroundings become intense by having the feeling that things become faster and louder than usual. My actions feel like they are sped up, when in reality they are moving at a very normal pace. The only thing that does not seem to move faster is time itself. 
Sounds during this time are loud as if someone turned up the volume of the universe. If there is music, it sounds like someone turned up the volume and pressed fast forward. This lived experience has a taste, which if I had to describe it would taste like lead, and this taste in turn also has a texture

(Figure 3). The experience of the whole room has a new feeling to it. Sharp corners juxtaposing smooth surfaces give off a different feeling. Sharp corners draw a kind of heavy pressure on my head while smooth curved shapes do not seem to affect me much. My surroundings draw out new emotions, which I did not notice on a conscious level previously. It is a perceived experience of space, time, sound, taste and texture.

If space affects our whole being, our senses, our emotions - can we expose an architecture of wellbeing through drawing happy emotions? What is the relationship between wellbeing and space, and its interpretation through drawing? Existing neurological research reinforces the qualitative approach of drawing positive emotion to generate architecture which in turn enhances wellbeing. Drawings in the form of happiness envision the addition at CHEO. 


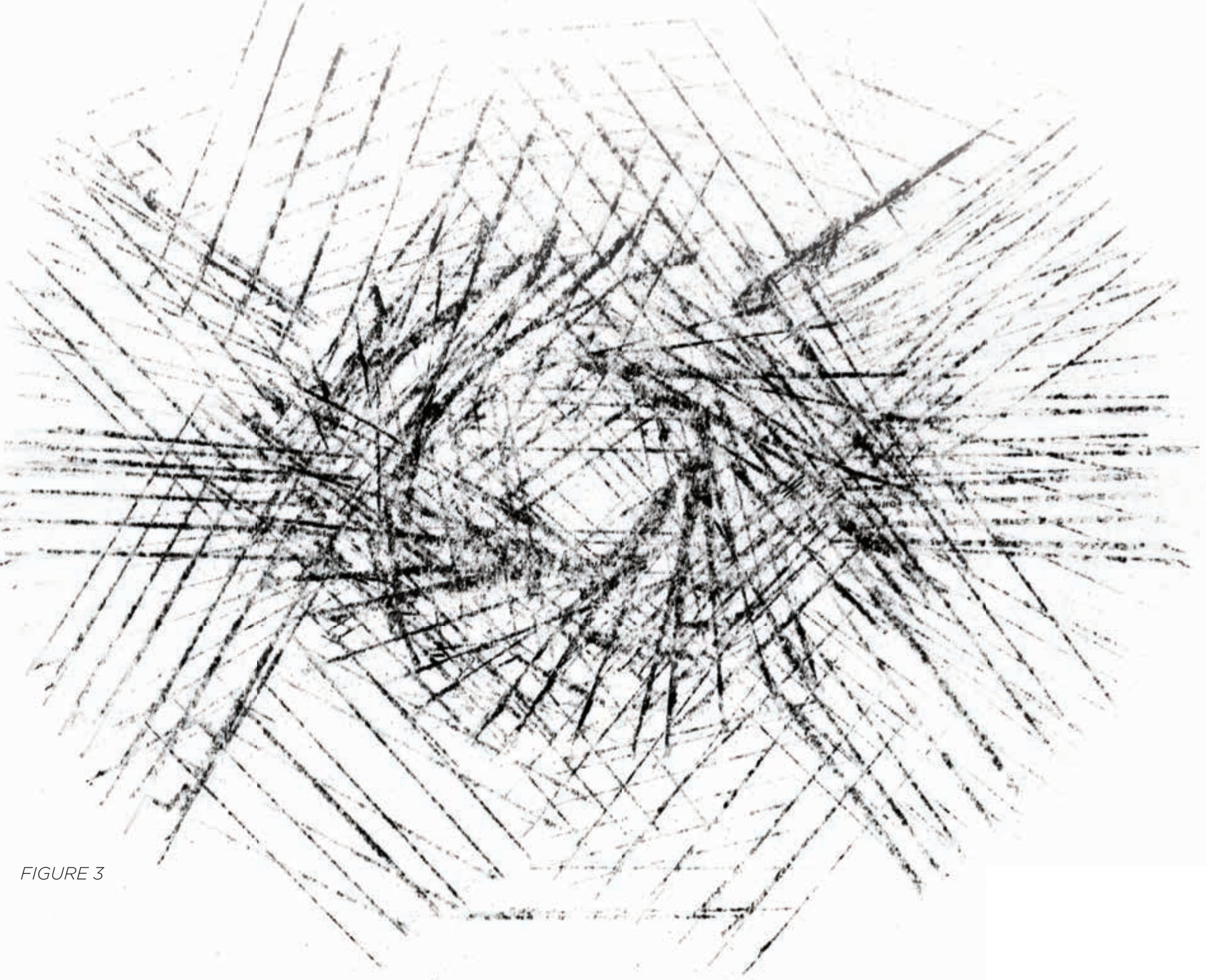




\section{DRAWING RESEARCH}

\section{DRAWINGS OF HAPPINESS: A DESIGN TOOL}

This research is conceptually concerned with considering human emotion from the informant's standpoint; it assumes a dynamic and transferred reality. Methodologically data are collected through participant's drawings. Data are analysed by themes from the drawings and descriptions by informants. Qualitative research is useful for studies at the individual level, and to find out, in depth, the ways in which people think or feel. ${ }^{7}$

This study aims to use drawing as a tool to design healthcare architecture to enhance wellbeing; an experience mapping of happiness. One must not only rely on scientific data, we must also create our own experiences. This study involves children and intellectually disabled individuals of varying ages drawing images, based on a series of drawing exercises. The two drawing exercises are:

1. Draw a space where you feel happy

2. Draw what happiness looks like to you 

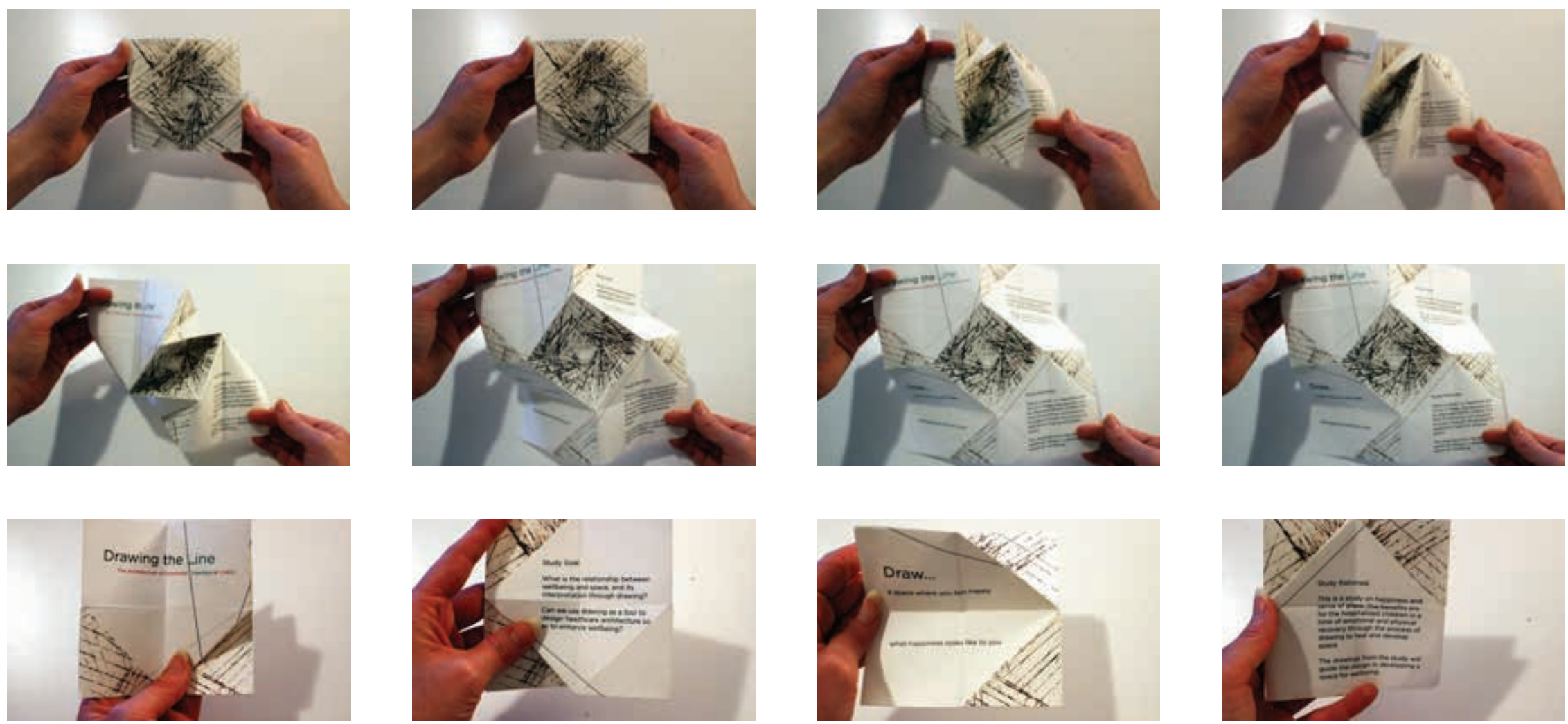

FIGURE 4

The drawings produced in the first exercise will help design 'what' the addition at CHEO will be about and the other exercise will determine 'how' the architecture of the addition will be shaped and coloured. The two drawing exercises have been fashioned to serve a needs assessment, as well as to transform themselves into architectural spaces. The drawing exercise guide embodies the idea of the drawing creating space and thus architecture (Figure 4). 
The drawing exercise was conducted with a few of the Professors children, of the Azrieli School of Architecture. However, most of the drawings were completed with intellectually disabled artists at H'Art of Ottawa as part of their curriculum. H'Art is an innovative art studio where sense of place is encouraged and celebrated for people with developmental disabilities. The artists have a great ability of communicating through the common language of art and self-expression. ${ }^{8}$ Most of the artists at H'Art are very familiar with CHEO, some of them have spent much of their childhood there. The artists are finding their voice and a place through art. At H'Art they are also enhancing their self-confidence and wellbeing while nurturing life-long learning through art. The artists contributed to this thesis in a very meaningful way. H'Art Studio is inspired by a strong belief that people with a developmental disability can be productive members of our society, and that through visual art they can realize their full potential. The artists have contributed a great wealth of knowledge to the research of this thesis.

Through drawing, and creative writing, the artists transform ideas, emotions and life experiences into works of art. There is a new group of people each day of the week at H'Art, thus I spent three 
amazing weeks there with them initially and one week in the end to show them the project that came about from their drawings of happiness. Sticking to their curriculum, at 9am we would start talking about what happiness is to each of us, to get the creativity flowing they would all write about the exercise, to put their words on paper, then they would draw what they said and wrote, and until about 3pm they would draw or paint. Using art as a vehicle and through personalized facilitation, participants were given the opportunity to explore their unique artistic expression in the two exercises. The children and the intellectually disabled artists that participated have fully embraced the creative process of the two exercises designed for them and the results are extraordinary.

DRAWING IMAGINATION FROM THE ARCHIVE

Herein are the results of the emotional drawings. These drawings capitalize on the desires to reflect upon and preserve experience and to actively create new ones. The drawings encourage design catered to wellbeing as they are an expression of happiness in a tangible form. They are exhibited in the form of a drawing quilt with a poetic quilt on the opposing page. 


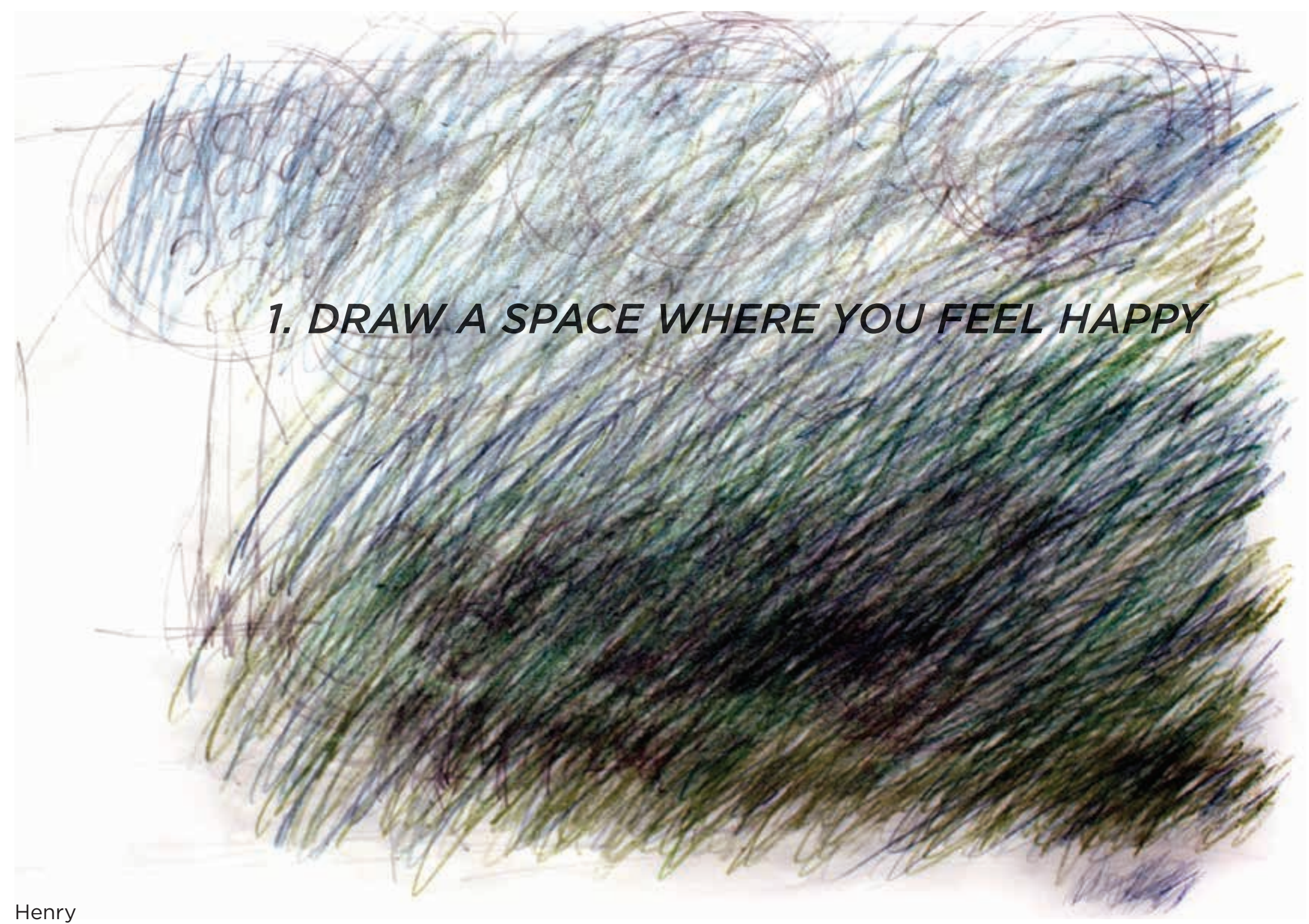

FIGURE 5 
NATURE

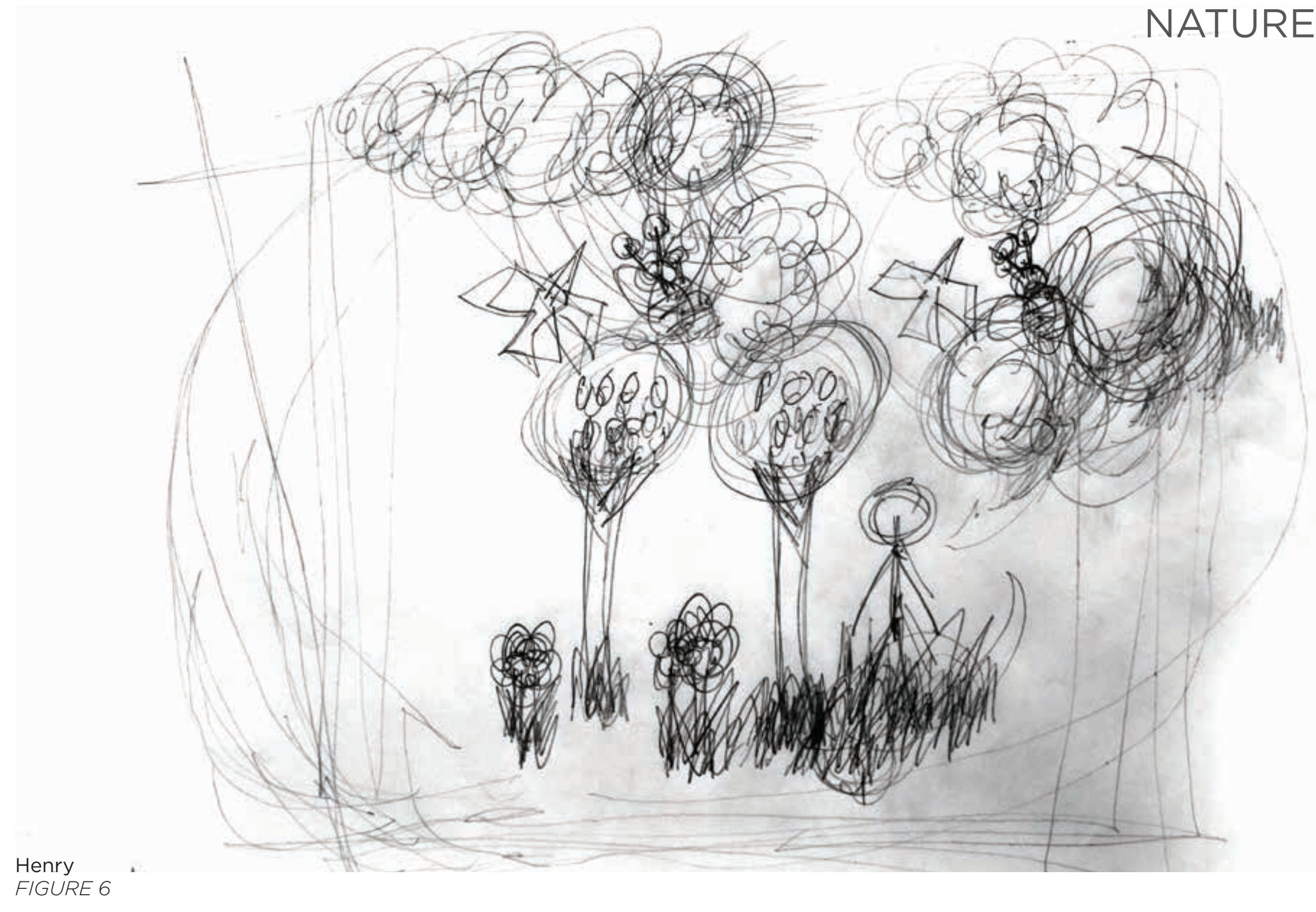




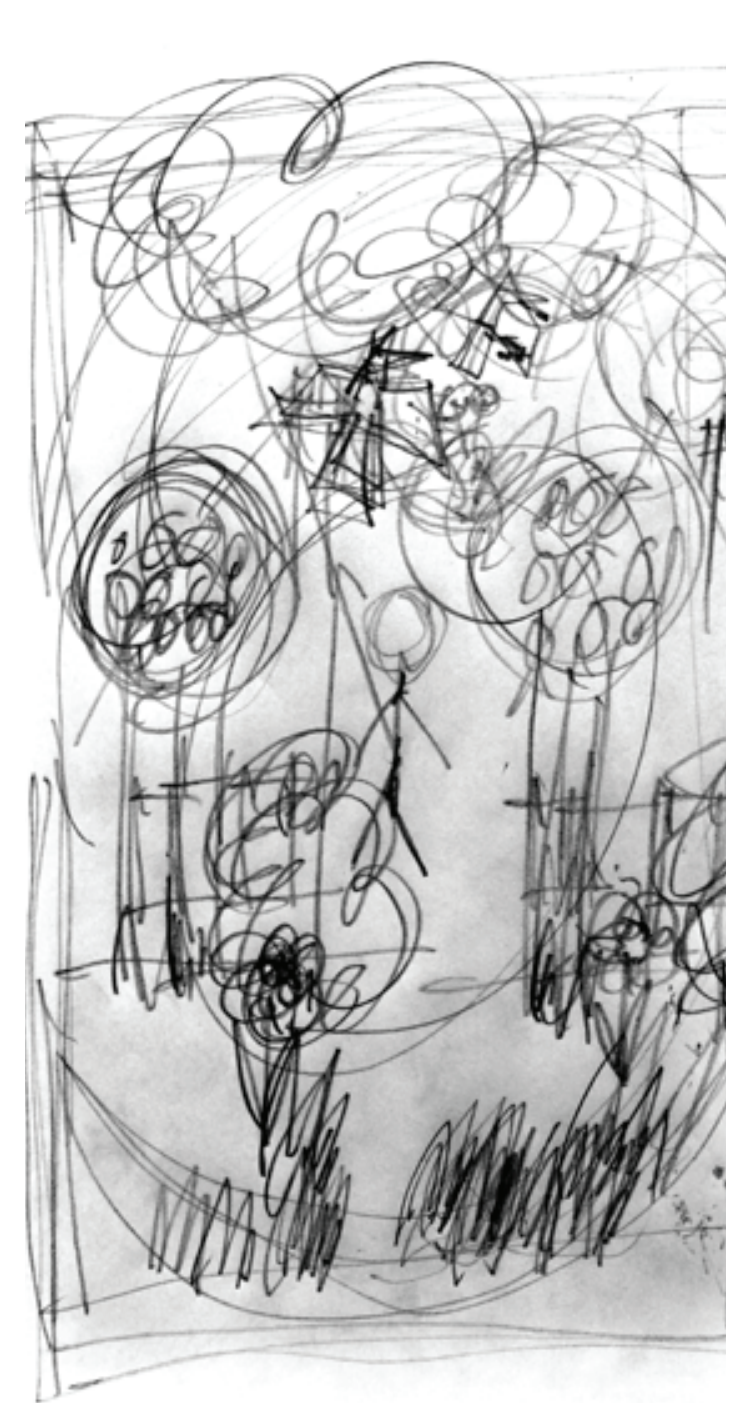

Henry

QUILT I
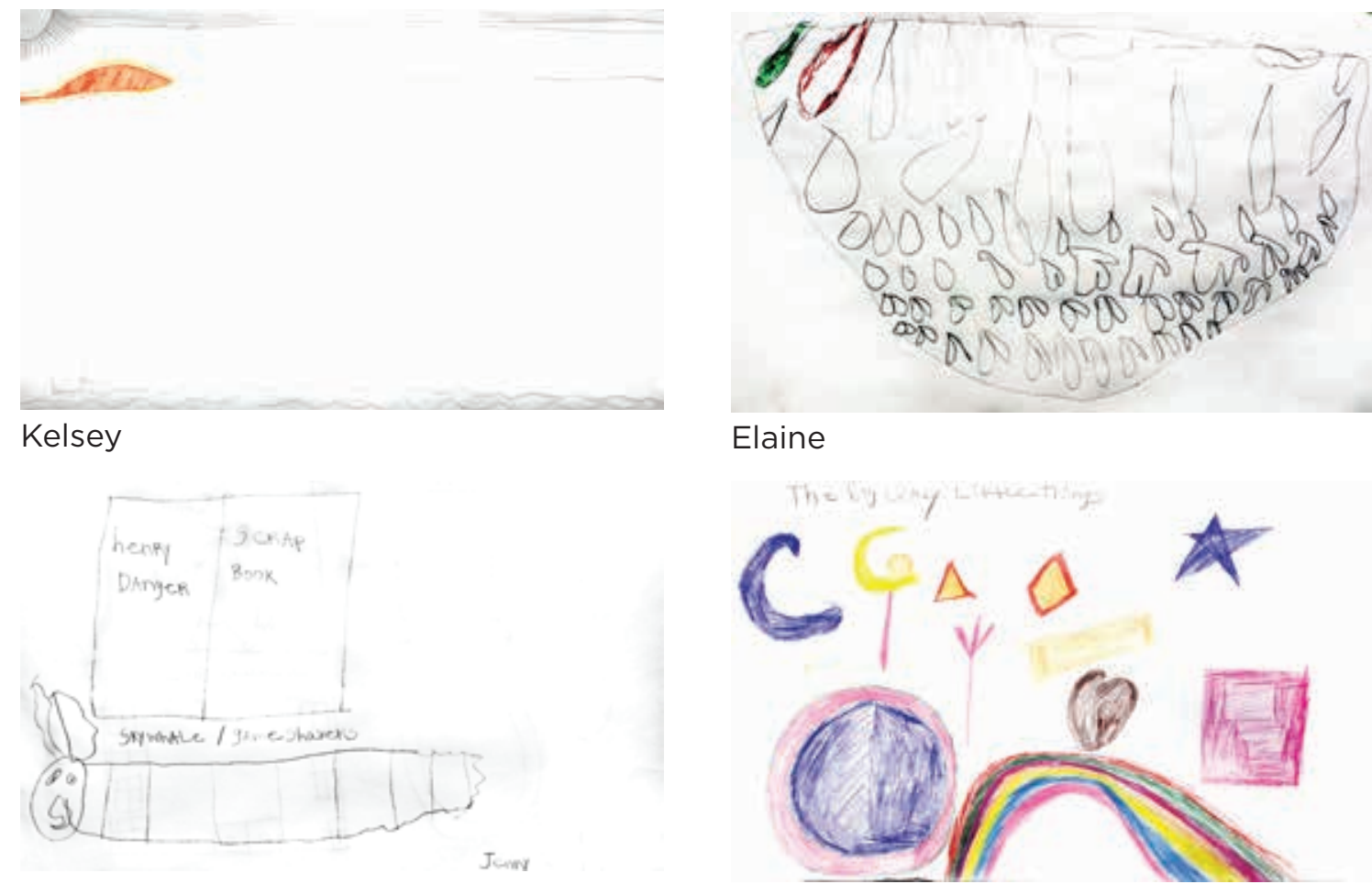

Jenny

Elaine
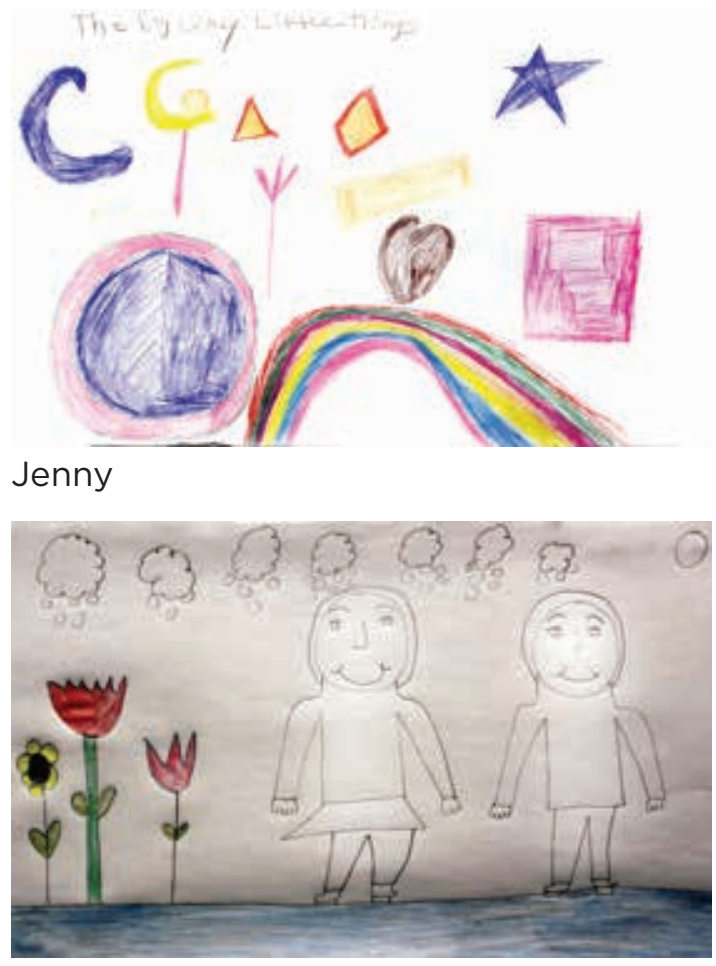

Analisa

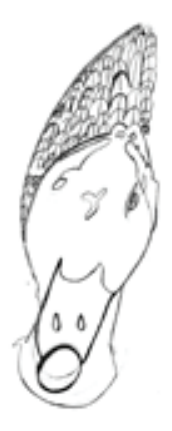

Jessica 
I feel happy when I'm in a quiet place, where there are flowers, trees and grass. There are birds and bees in the woods, there is sunshine and fresh air in this place. This place is peaceful when there is no noise or loud sounds. This can be very quiet, and nice and sunny or bright. My happy place where I am is happy and peaceful.

$$
\text { -- Henry }
$$
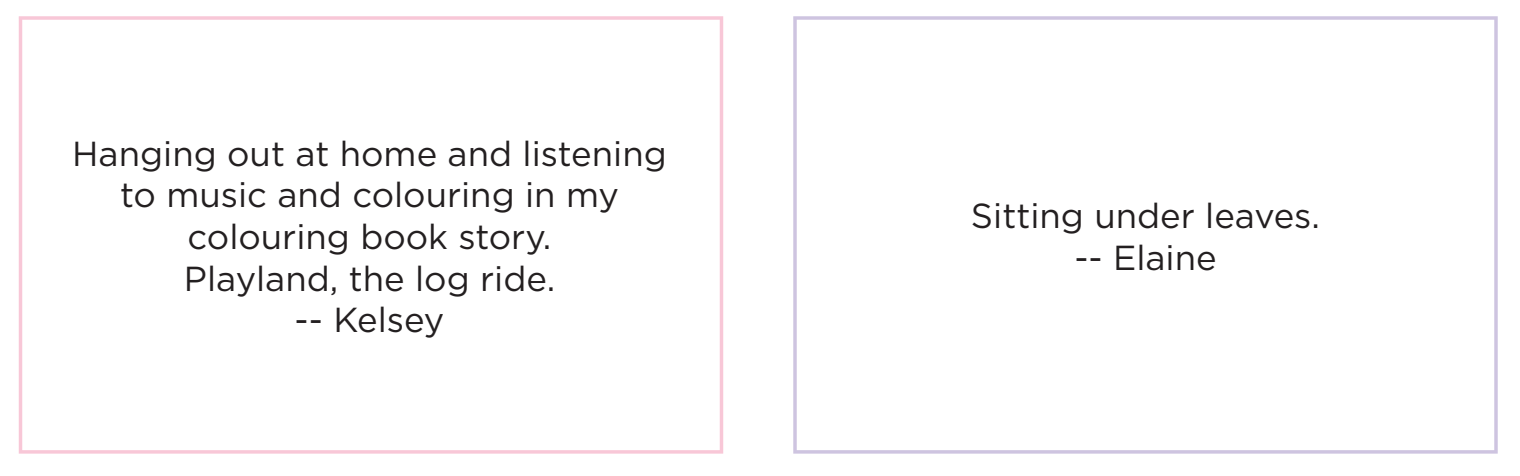

Picture of me on my wall, painting, a black dog. Windows of reflection at myself. The big crazy little things.

-- Jenny

My happy space looks good because my happy space makes me feel relaxed. I like feeding the geese down by the Rideau River. The walls are a waterfall, the

Flowers, clouds. water is blue. -- Jessica 


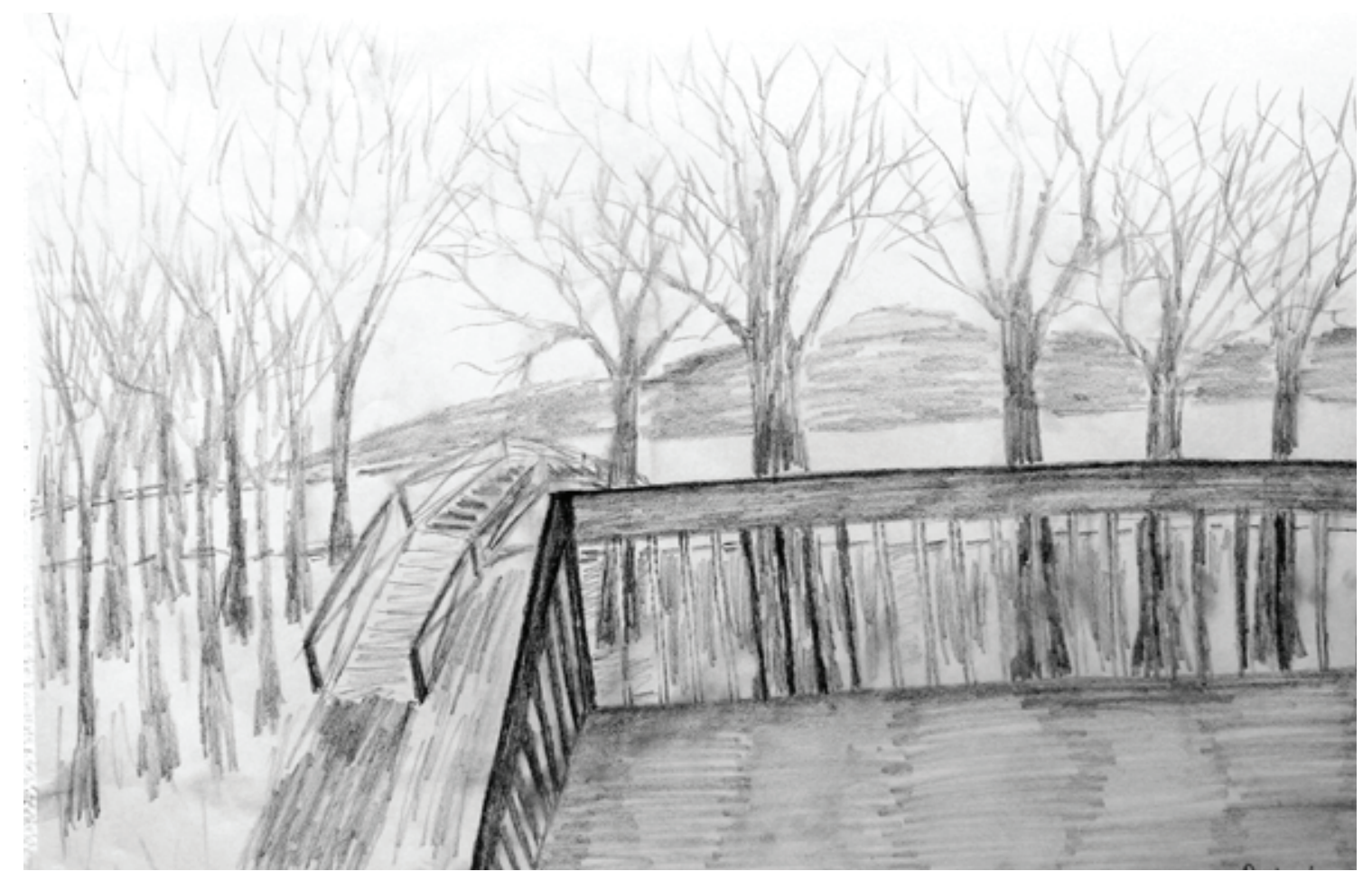

Richard

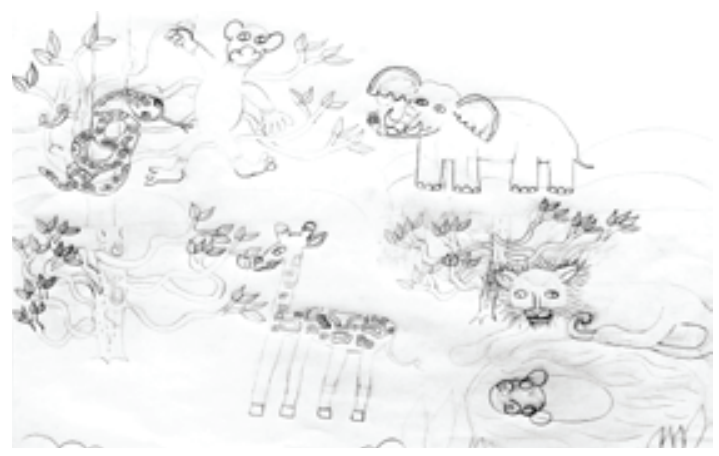

Christine

QUILT 2

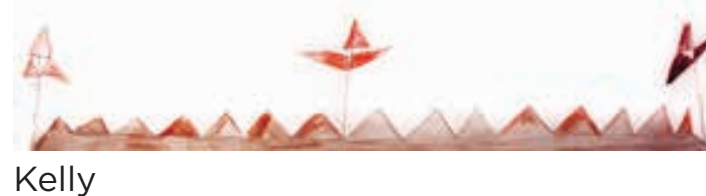

Kelly

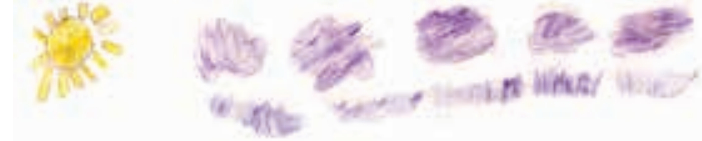

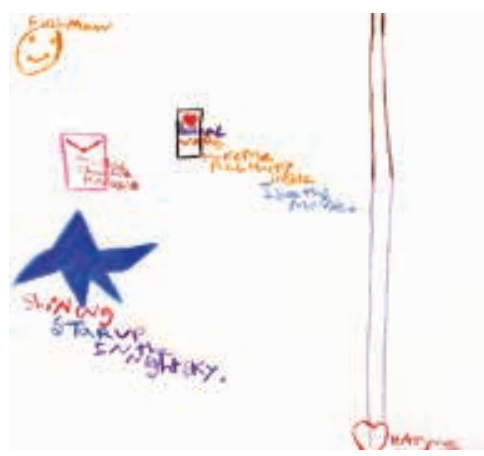

Nadia
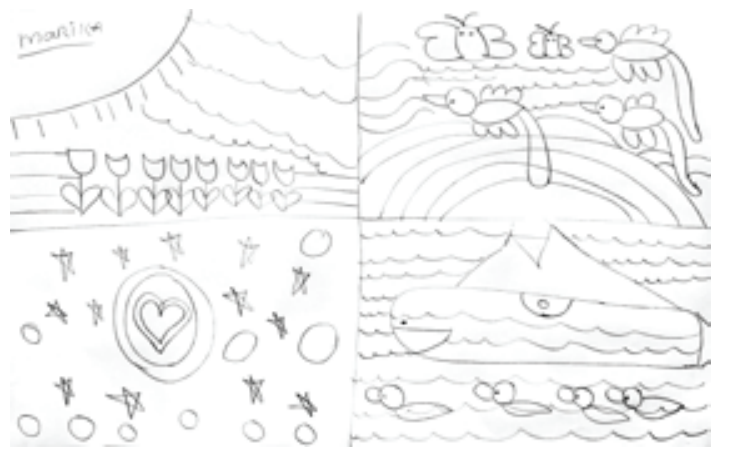

Marika

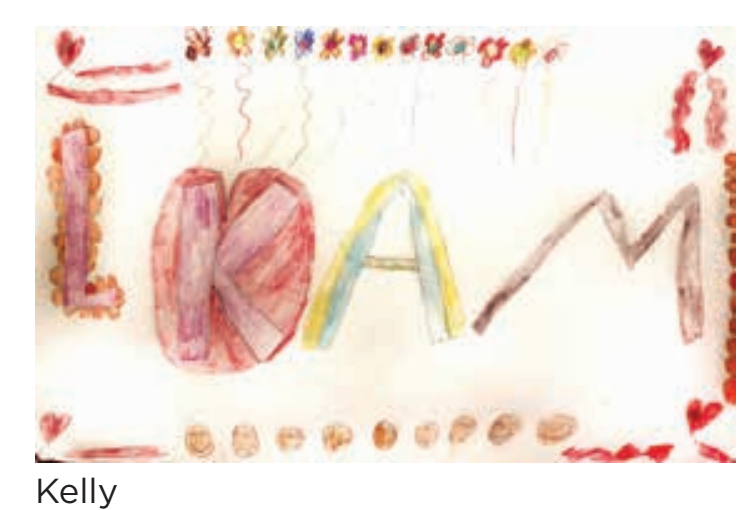

Kelly 
Good afternoon everyone, sincerely I would feel happy to find myself in small cottage in a forest overlooking a hill near a lake in which you could only hear nature in its purity. The perfect spot to replenish the body and mind and put away the stress, it would be the best therapy to feel better again. Being fully immersed in nature, there's nothing better to appreciate the good life.

-- Richard

Music in my room, when I talk loud and read my book.

-- Nadia

Where my parents pray with and for me. Dancing, hope, sunlight,

moon, earth. Like a bird to see the blue sky. In your dreams and night.

To see the sunlight so high in the

sky, to see the flowers.

-- Marika

Big and lots of room to move around, run and play. The ground would be hot like the sun, cracked like an old wooden boat and in some places is soft as an eagles feather and smooth like skin. It would have big green, wavey, fresh, healthy, grassy hills and it would have lots of long tall trees to keep my home cool from the hot sun.

-- Christine

Pyramid landscape, flowers.

$$
\text { -- Kelly }
$$



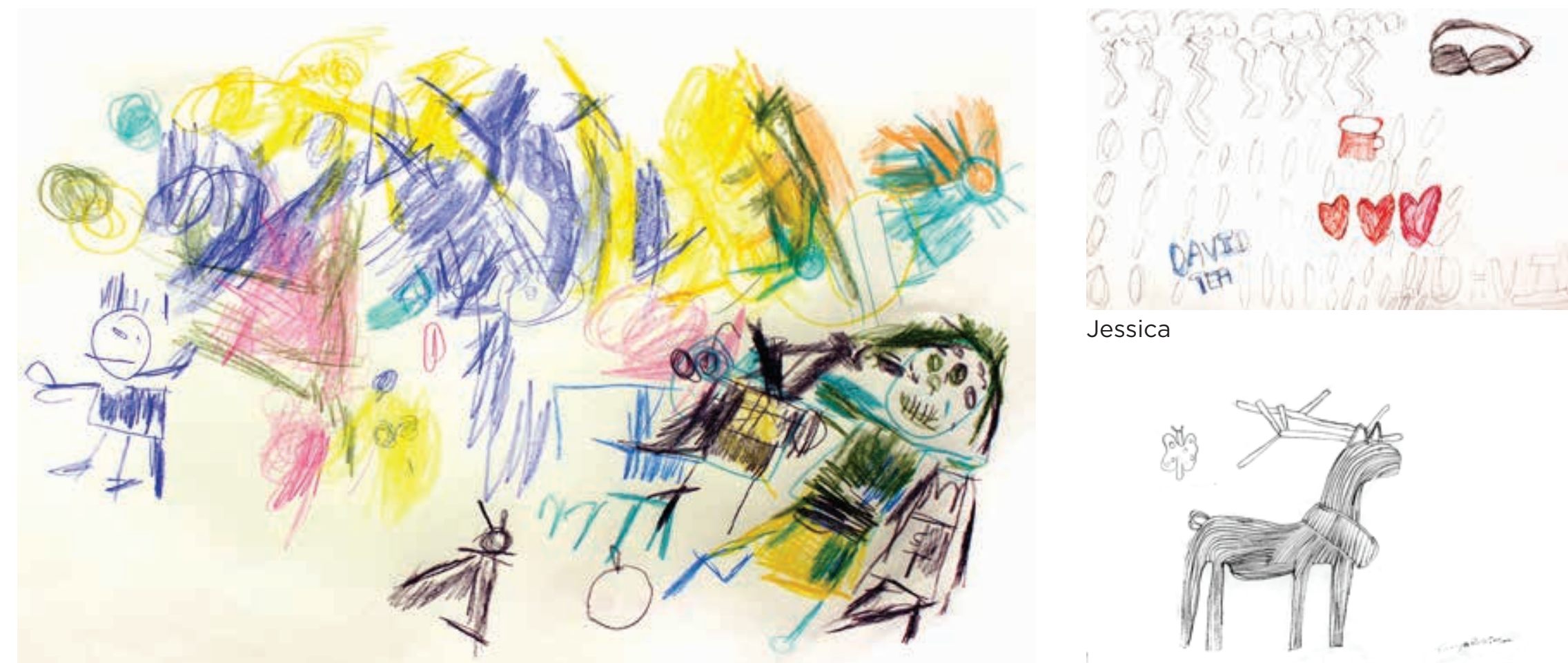

Tracey

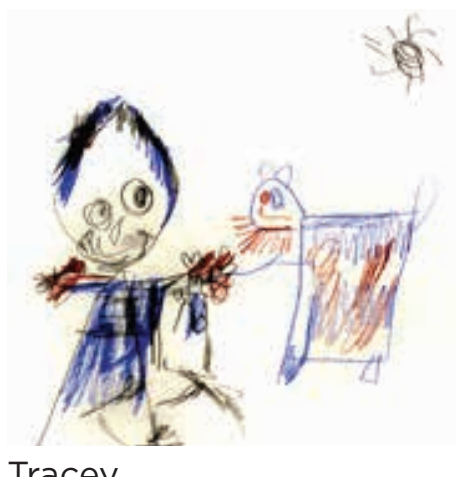

Tracey

QUILT 3

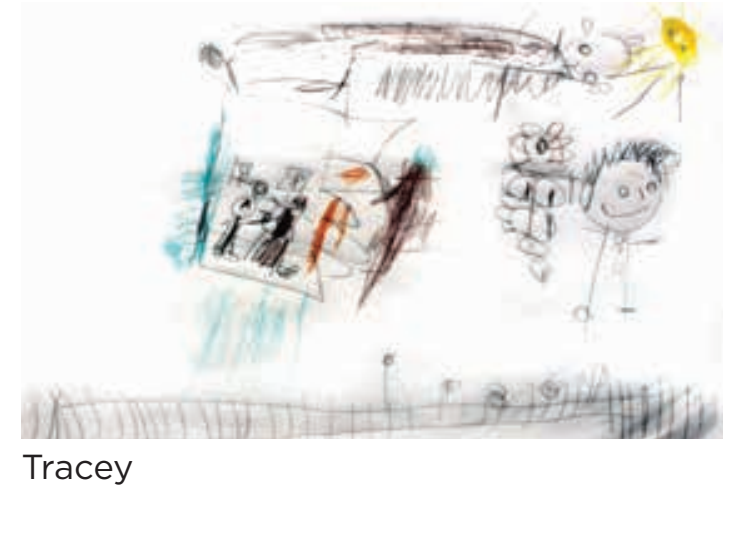

Tanya

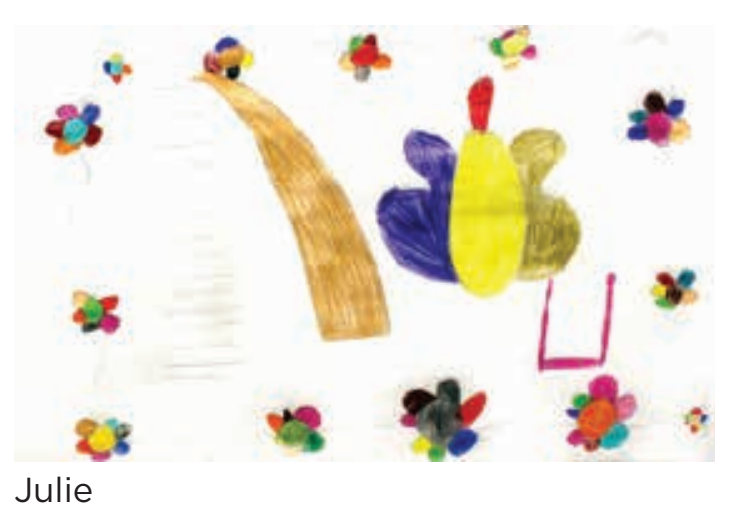


Baby at CHEO

Happy to go to school.

Party with cake. My mom makes me feel happy.

$$
\text { -- Tracey }
$$

I am a writer and I like to write.

My personal space feels safe and happy. Raining tea.

-- Jessica

Family, art, walking, dancing, computers, movies, friends, sitting in a circle talking, ballroom dance, lights, Cinderella, canopy, flowers, butterflies, castle, sun, horse farm, Disney, happy ever after. -- Tanya

I love being happy all the time, the music helps me to feel calm and be in the happy place. I'm very interested to be a song writer myself because music comes from the heart and song writing comes from your feelings, you have to feel and I love.

$$
\text { -- Julie }
$$



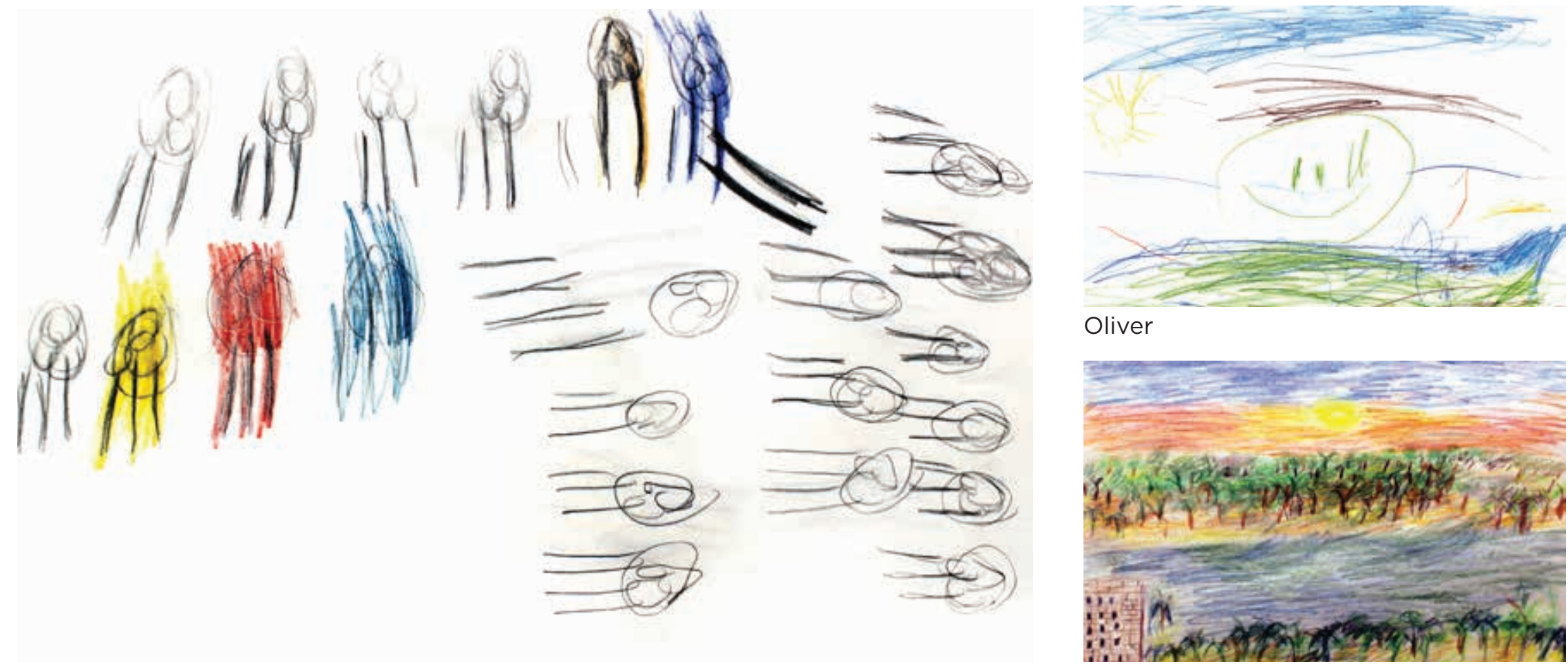

Amanda
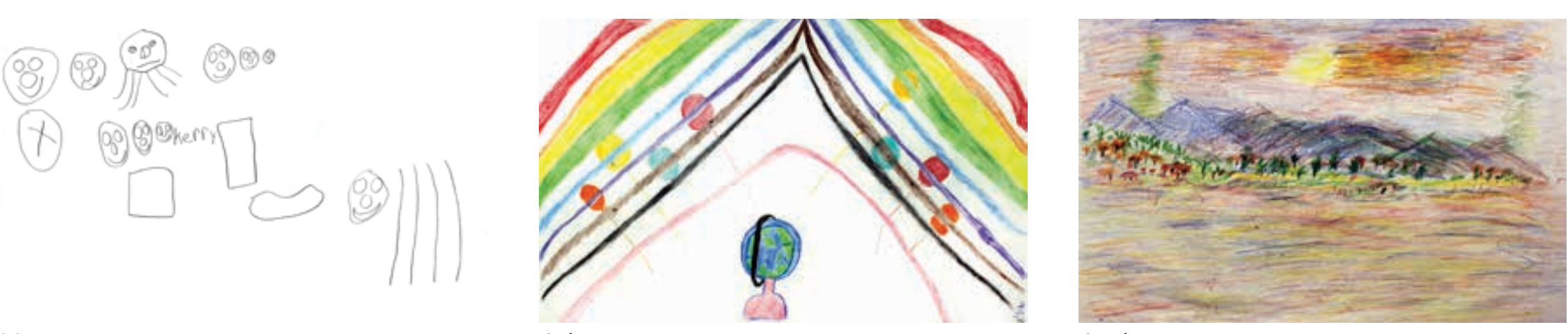

Andre 
My place where I am happy, I am really happy with my dad. I love going to Disney with him. When we go to the ballet I am happy. I love to listen to the orchestra at the NAC. Sometimes dad and I go for a walk, I like to be outside.

$$
\text { -- Amanda }
$$

A place where I can breathe, the earth, riding the waterfalls. Ballet dance, feeling music.

-- Megan
Everyone united;

Rainbow. I like dancing, music and animals, even nature. Draw or paint murals.

$$
\text { -- Ada }
$$

Playing in the spring.

-- Oliver

Trees, nature, colours, water, sunshine.

-- Andre 


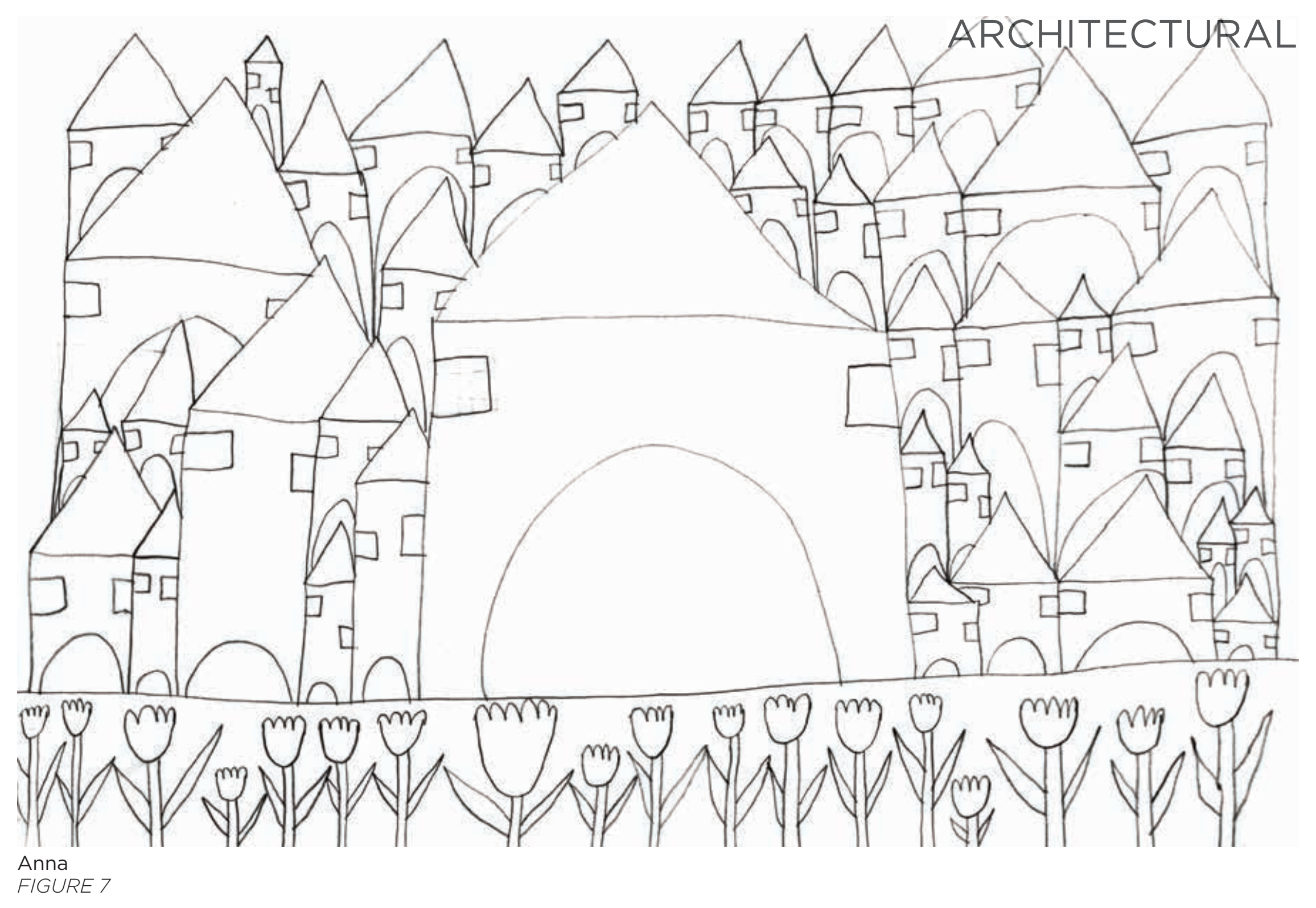


"When I think about it, I don't know what it looks like, when I draw it I see it" -- Jake

This quote from Jake at H'Art embodies the scope of this thesis. To materialize what is unseen, to project something other than the bare walls of the hospital, to bring out dreams and imagination into part of reality through drawing. These are the dream images that are incorporated into a physical architecture. 


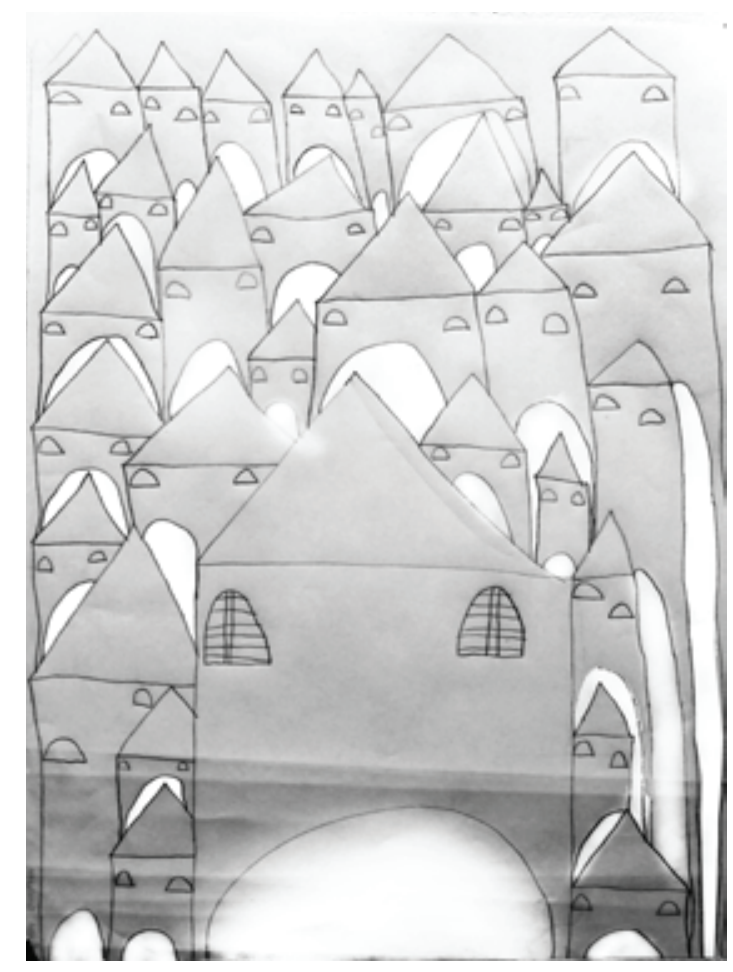

Anna

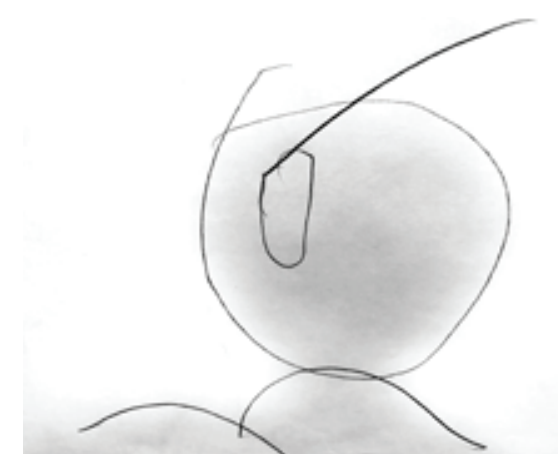

Alixe

QUILT 5
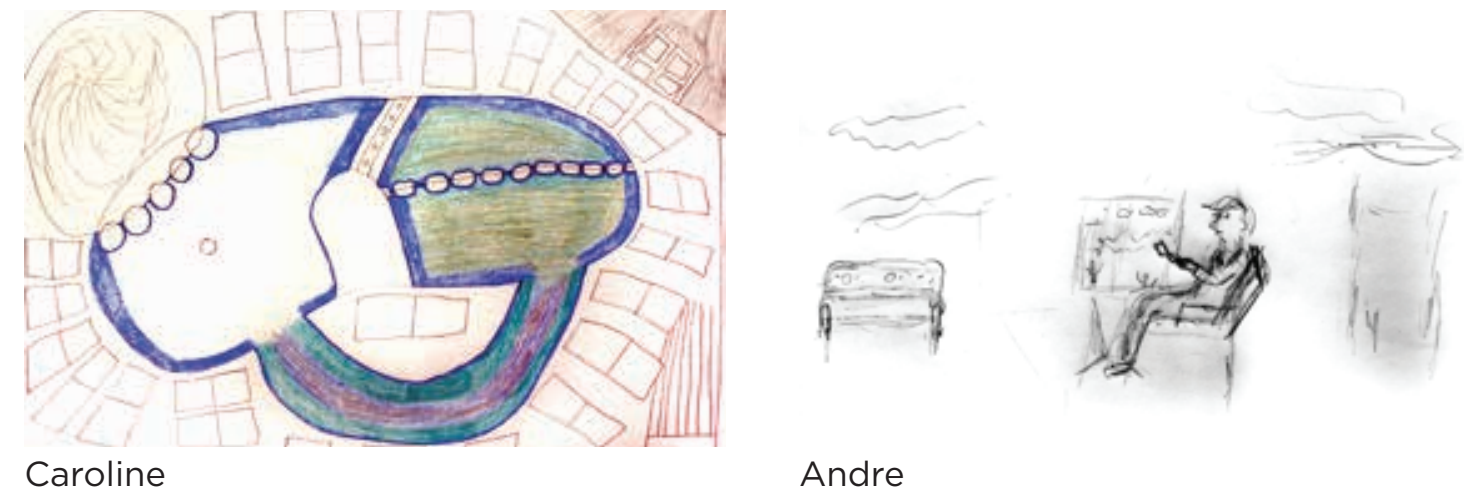

Andre

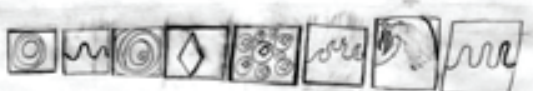

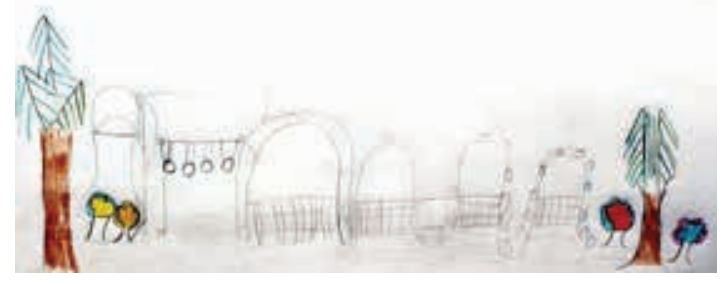

Malinda

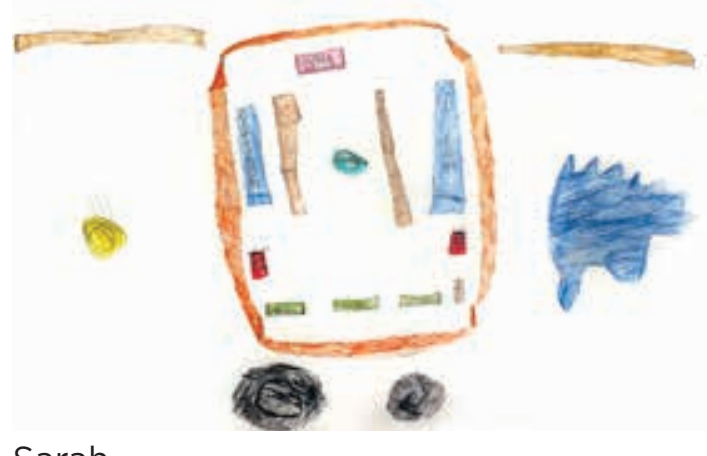

Sarah

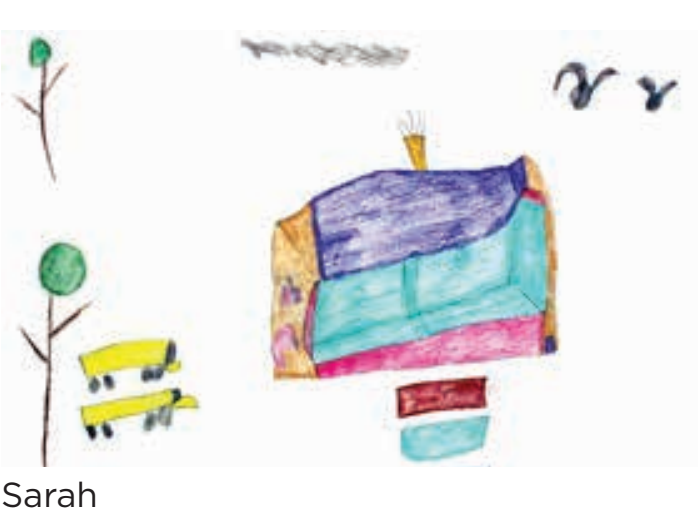


My happy space would be peaceful and calm with colourful tulips in a garden outside. Classical music would play as I create. I'd like to be beside a stream to listen to. My space is part of a magic castle.

$$
\text { -- Anna }
$$

New planet, Astronaut.
All the elements of nature, rocks, stones, water, air, mist, wind.

$$
\text { -- Caroline }
$$

A place I make art with my friends. I would have chairs, tables and art supplies.

-- Malinda
A place I can paint. -- Andre

Drawings on the wall.

$$
\text { -- Jessica }
$$

The moon and butterflies,

I like painting jellyfish,

I am happy to see animals.

At school, the trees outside.

-- Sarah 


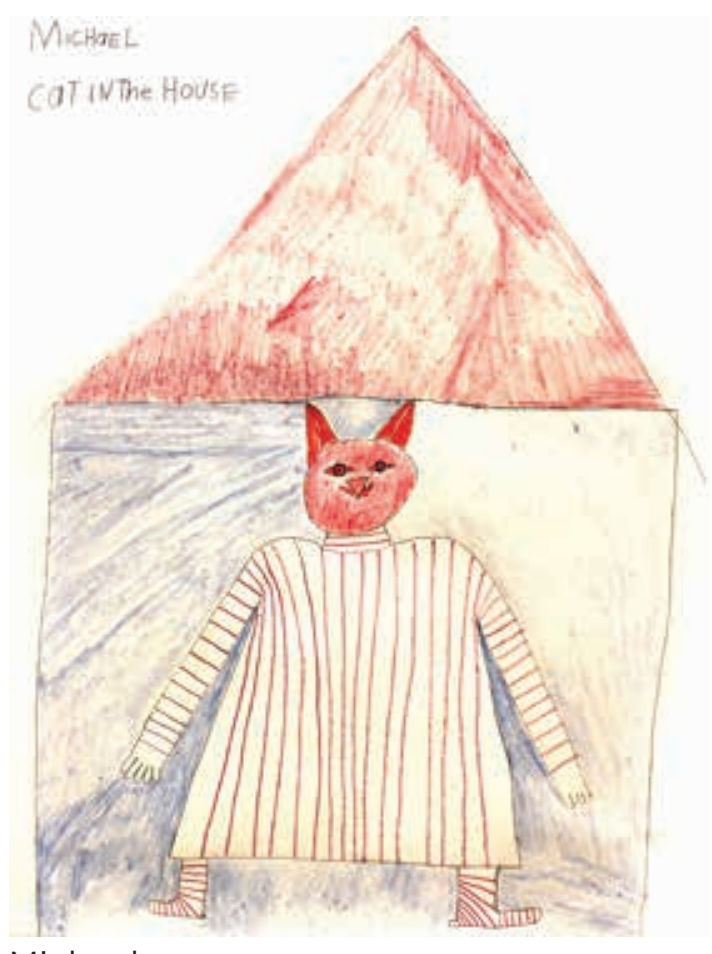

Michael

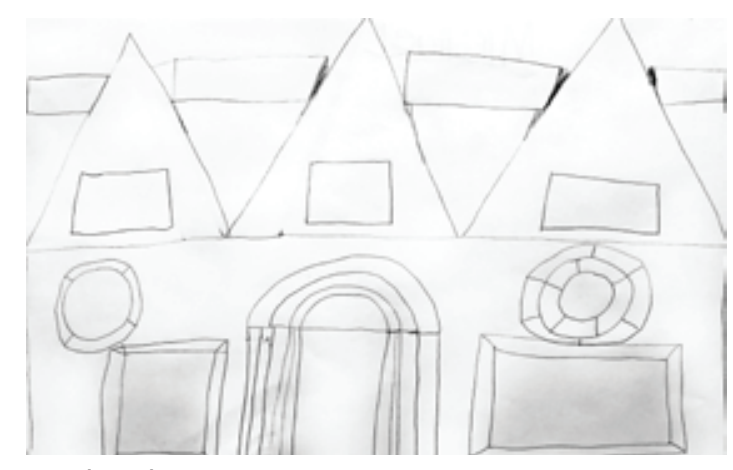

Michael QUILT 6

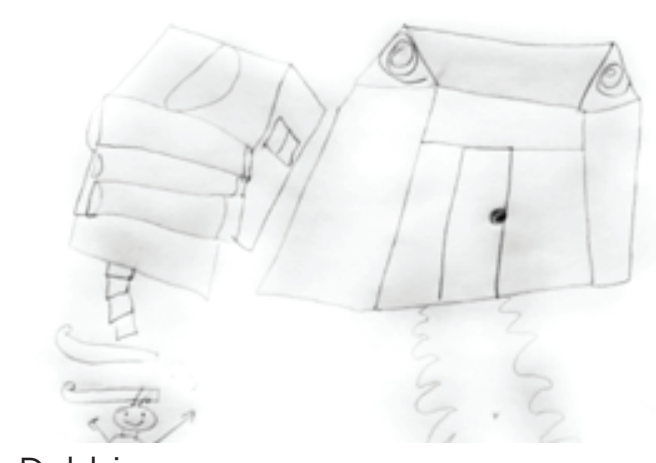

Debbie

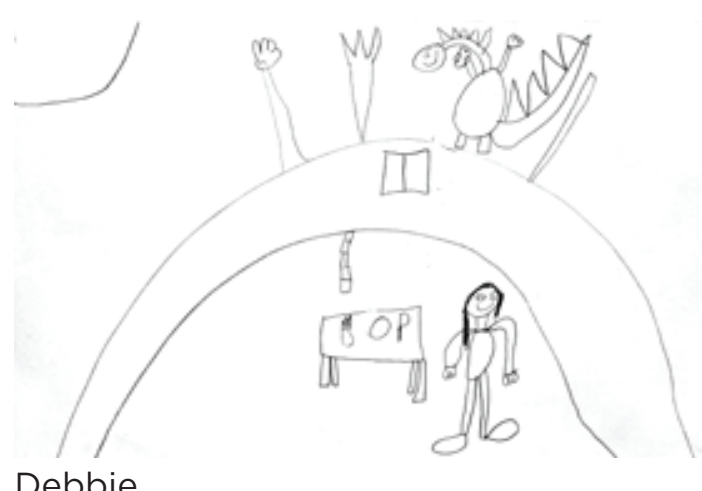

Debbie
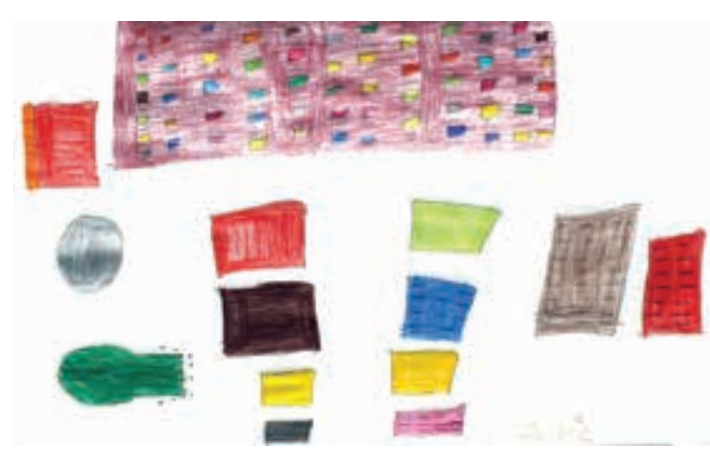

Julie

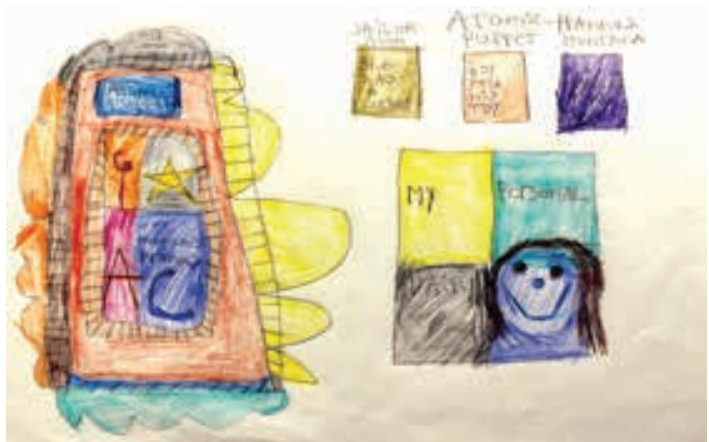

Jenny

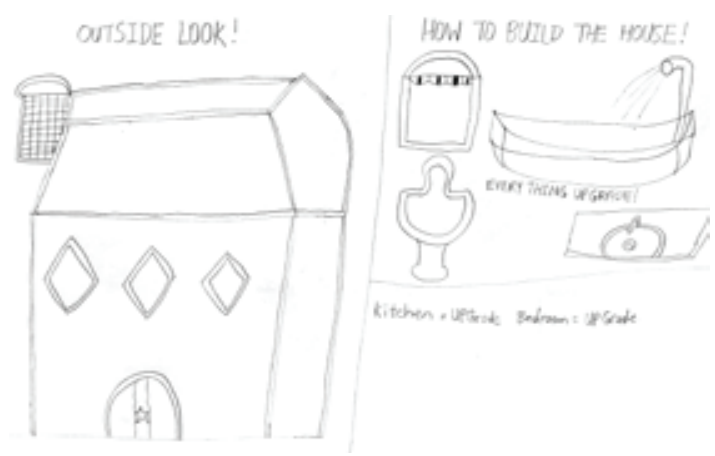

Ada

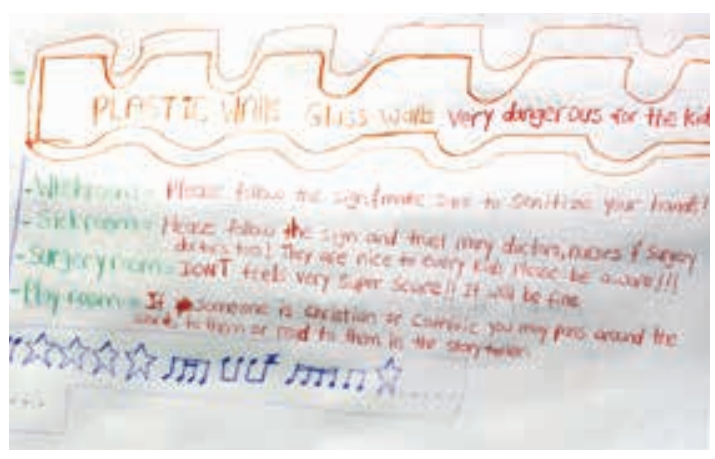

Ada 
I feel happy when I am with cats, I like being at H'Art, I love painting flowers, cakes, birds, gardens, forests, I like line painting. I like architecture paintings, all animals and birds.

I like seeing trees, nature, the garden at night,

butterflies, a family of elephants, rhinoceros, human life.

The walls are orange.

$$
\text { -- Michael }
$$

My cave, just me, out in the open, to feel free.

To be human during the day and a dragon at night. I paint my cave rainbow colours.

$$
\text { -- Debbie }
$$

I love music and art, I stutter so the language I was born with is not easy for me.

$$
\text { -- Julie }
$$

I like my drawings/ colouring book because i'm relaxed. I am watching TV Atomic Puppet at 4:30, my favourite super hero. I like reading a book called Sailormoon. I was working in my own personal diary. Where I can do my drawings, colouring book.

$$
\text { -- Jenny }
$$

\section{My own room to keep to myself} nice and personal.

Secret things, confidence, freedom, independent, exciting things.

$$
\text { -- Ada }
$$




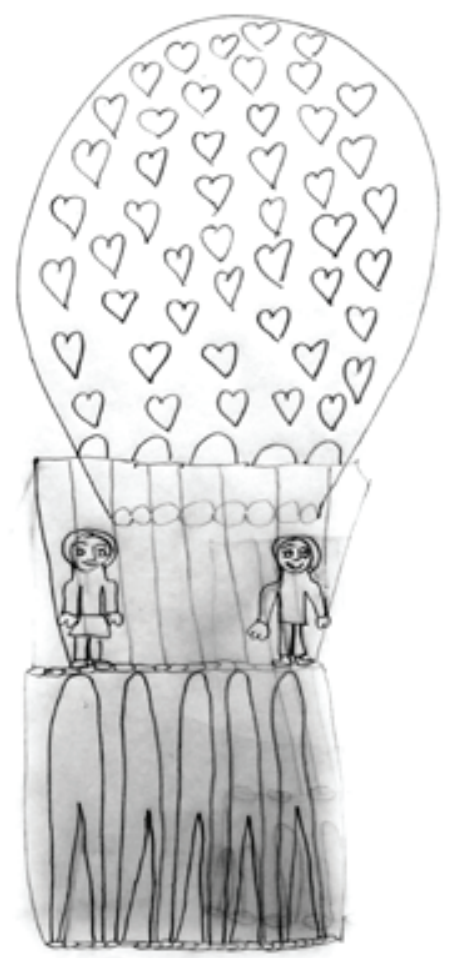

Analisa

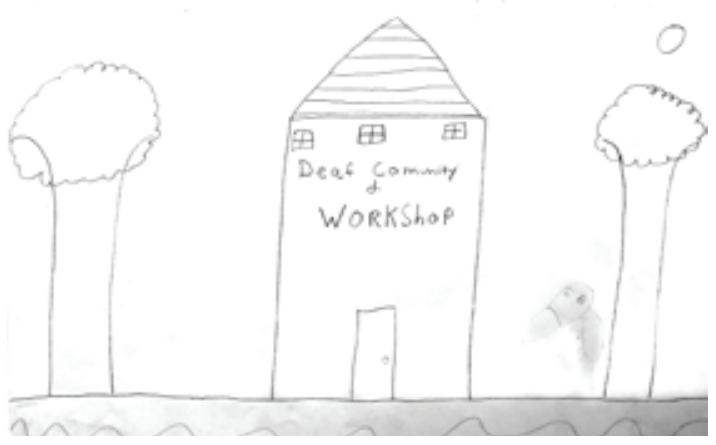

Analisa

QUILT 7

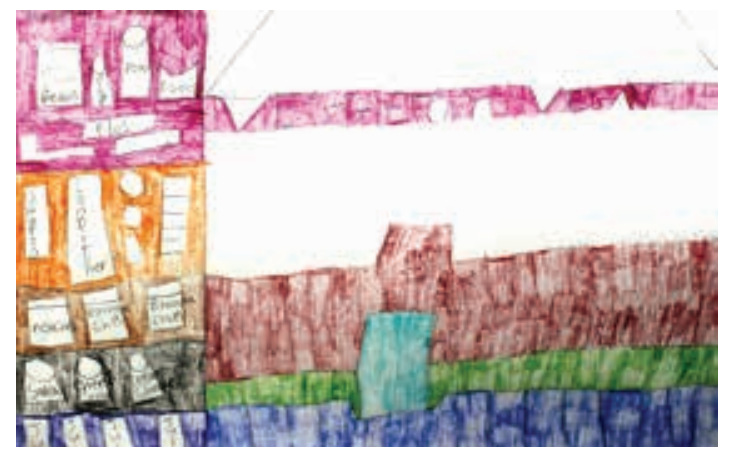
Kelly
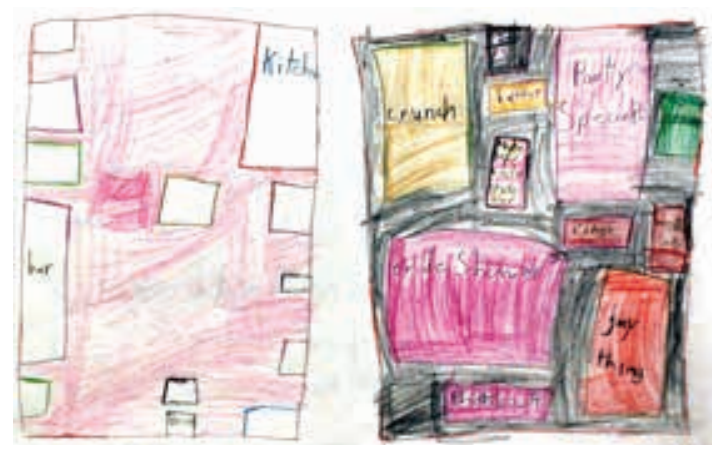

Suzan
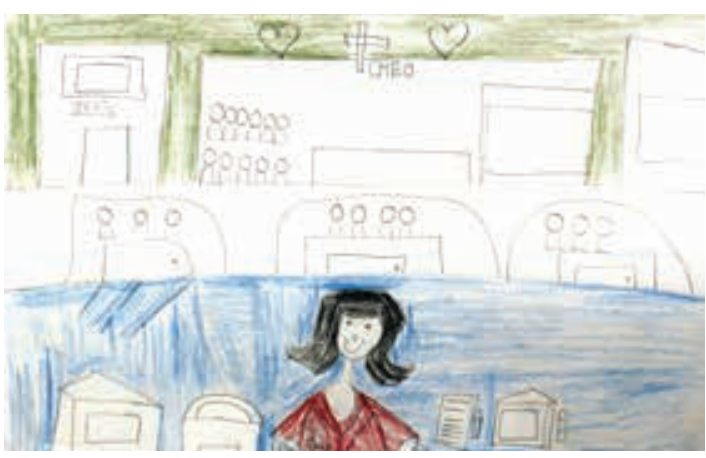

Marika
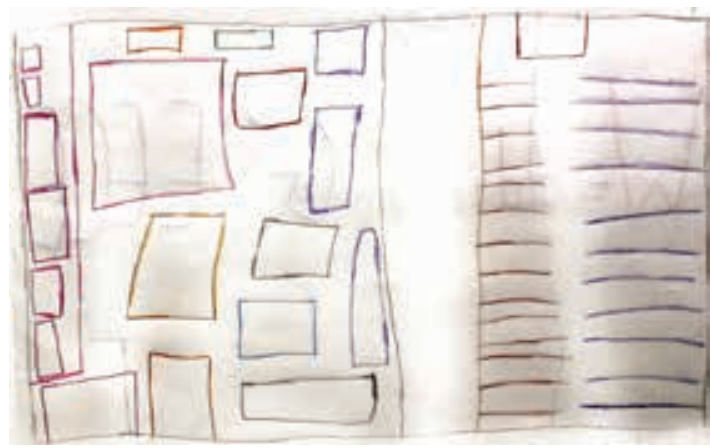

Suzan

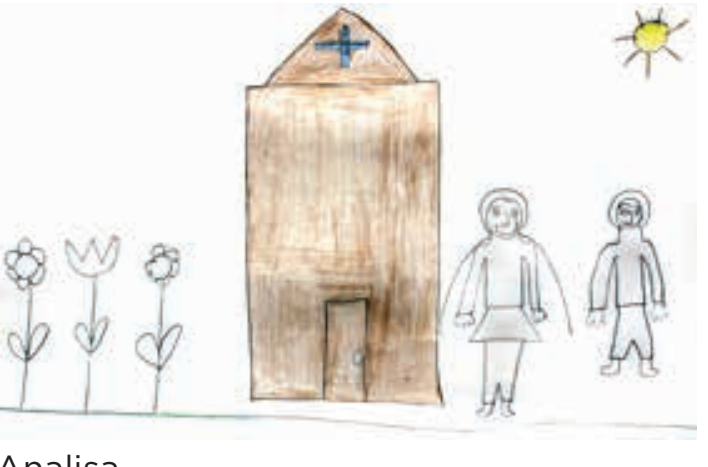

Analisa

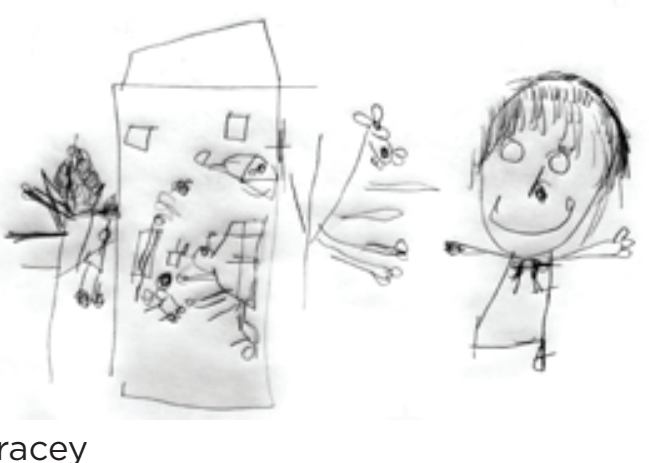


Organized,

I feel like I am at home at work,

freedom.

-- Kelly

Office, arts and crafts, to teach how to express emotions; Deaf School.

When they paint they have a smile on their face.

-- Analisa
At CHEO the nurses treated me

like a princess. I am happy I am

here at H'Art with down syndrome people.

My perfect wedding. Photobook of moments.

-- Suzan

At home.

-- Tracey 


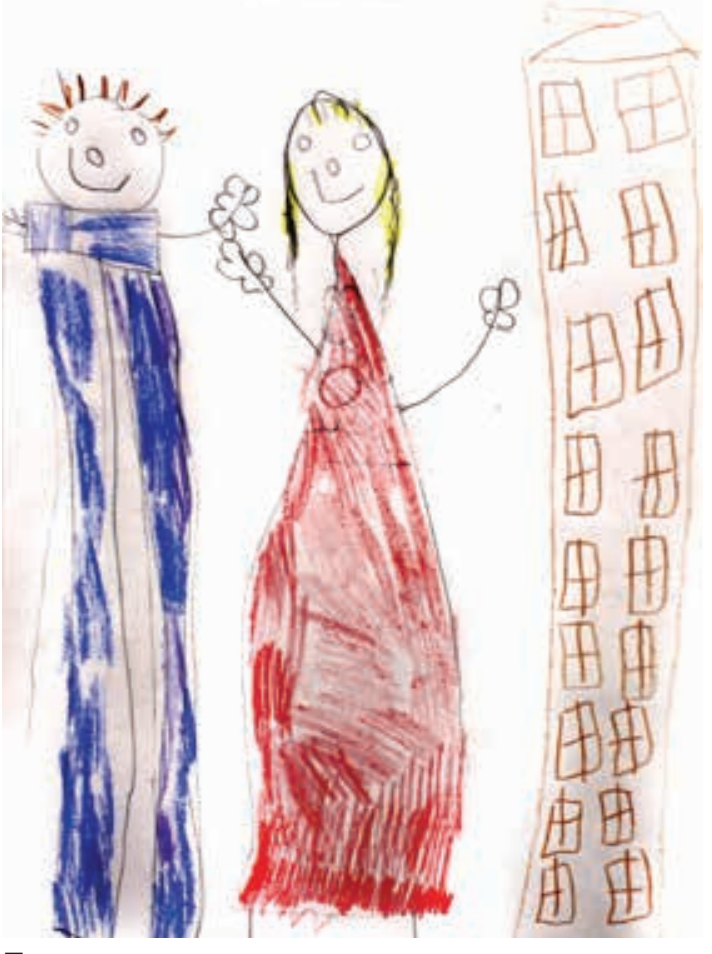

Frances

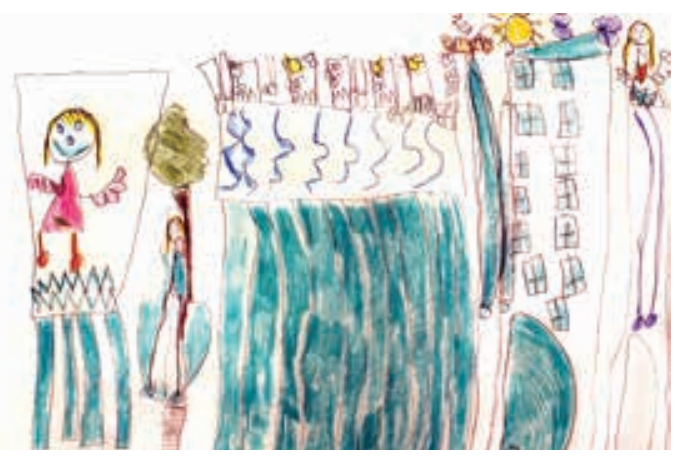

Frances QUILT 8

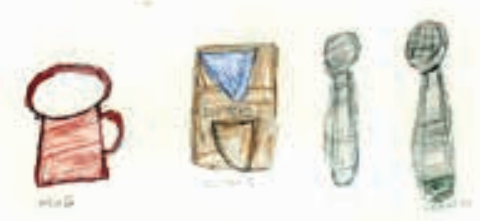

\section{0 \\ 2000000}

Jessica
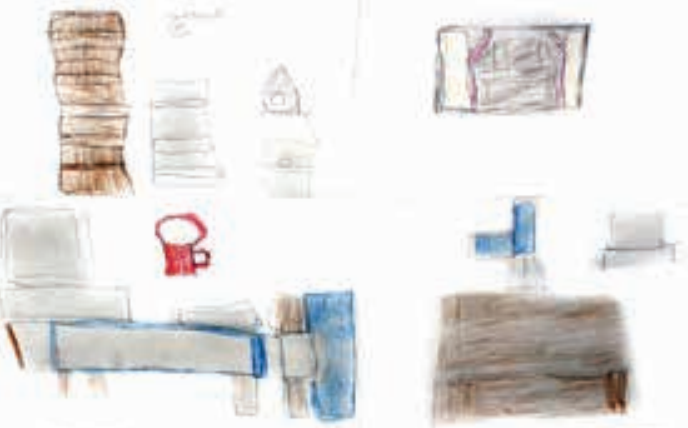

Jessica

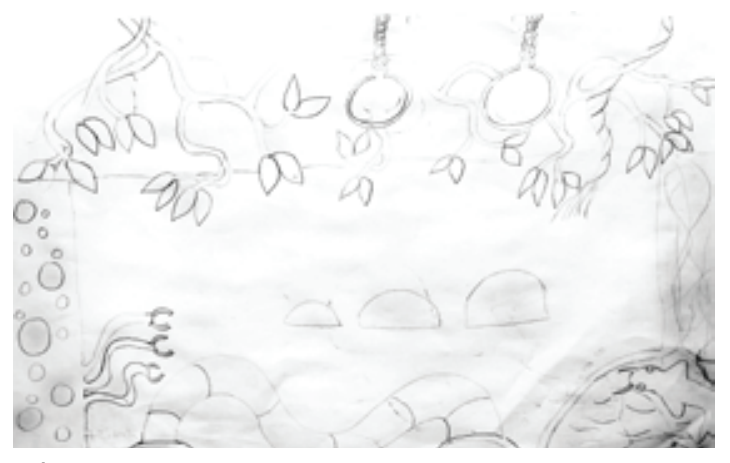

Christine

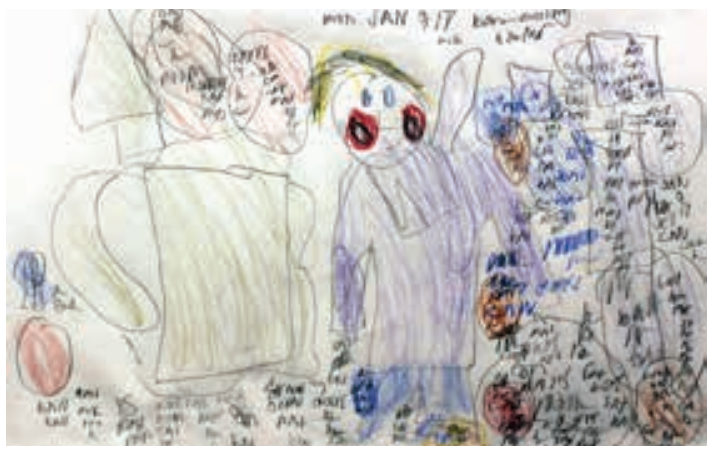

Alanna

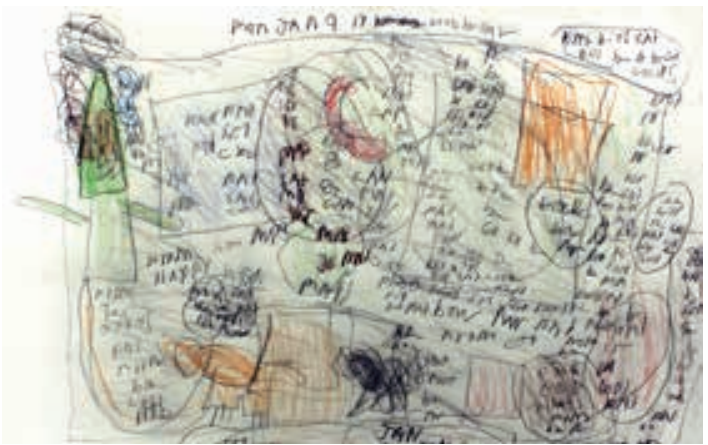

Alanna

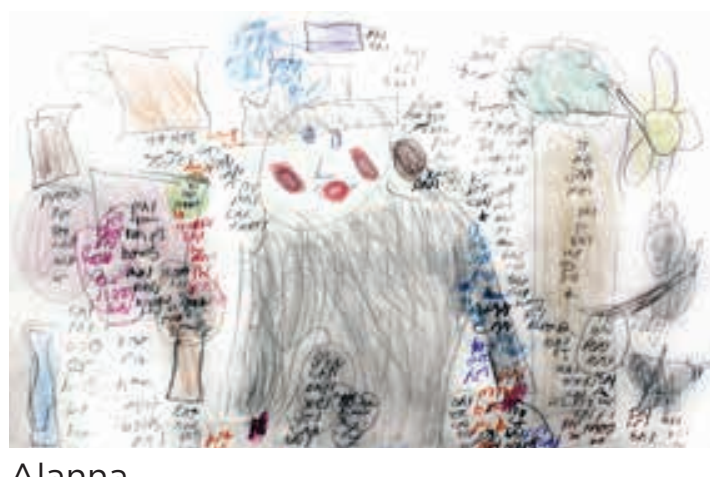

Alanna 
I feel happy when I'm at home, painting my pictures at home for all of my friends. I also have a happy place when I'm at the beach in the summertime. I love swimming in the water and having lunch on a blanket. I also like colouring in colouring books at the cottage in the summertime.

All the colours of the sea.

-- Frances

To be in a home, I paint at home.

My tea makes me happy.

$$
\text { -- Jessica }
$$

Vines hanging from the ceiling, water, a world to escape into the jungle.

-- Christine
A space where I feel happy is in my room reading books, colouring in my new colouring book, when I make coffee and tea. I like to relax in my purple coat. Hide behind a tree to relax in space, to read books in small cozy places. Christmas tree. --Alanna 

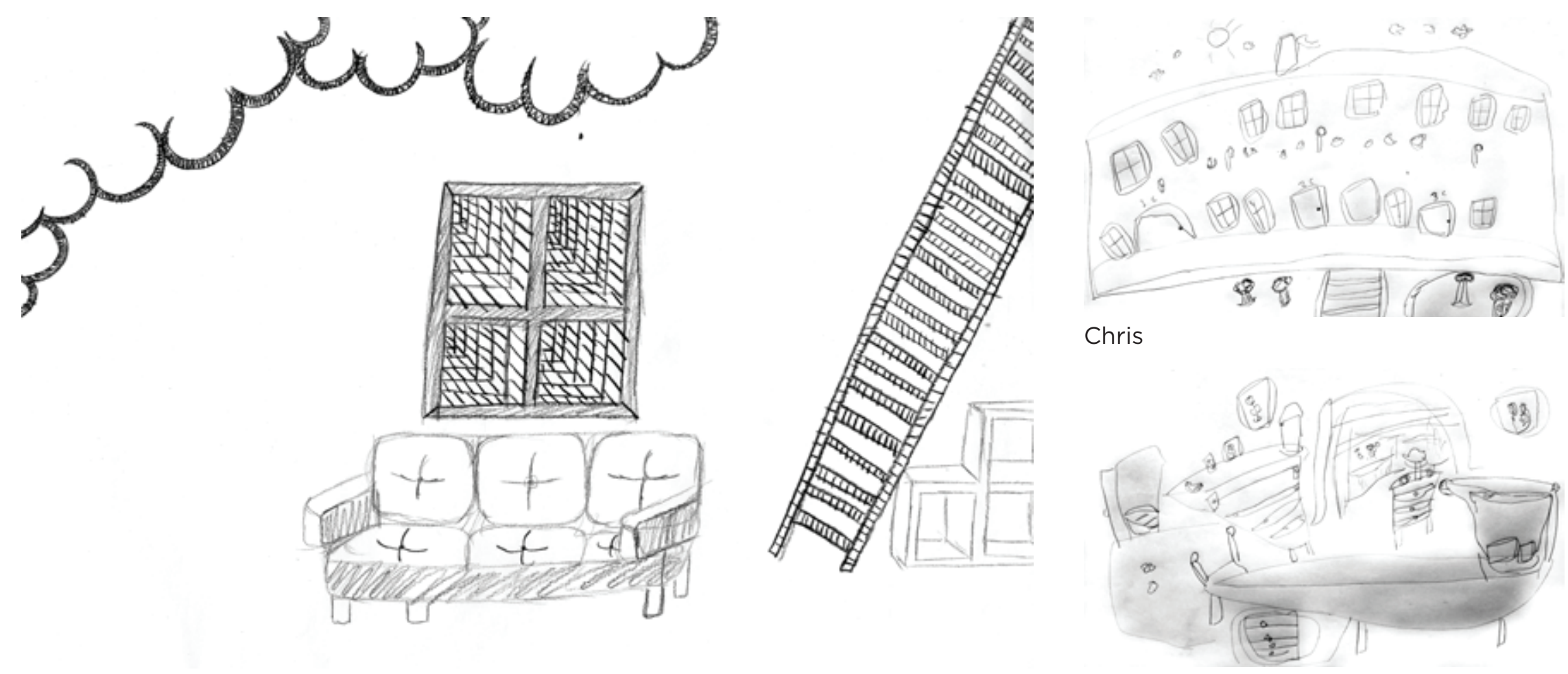

Achilla

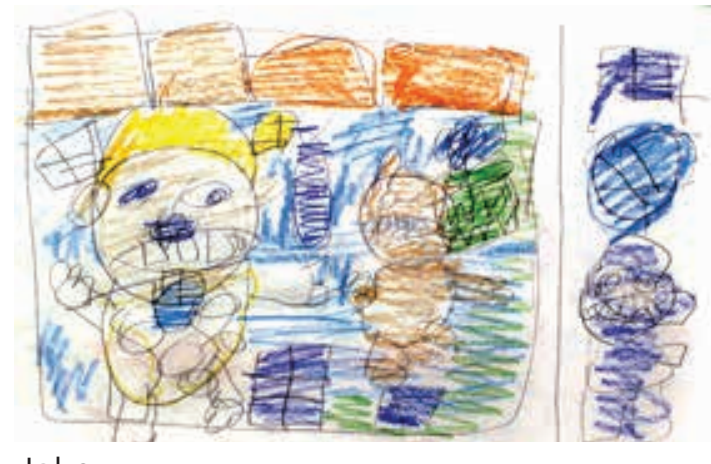
Jake

Chris

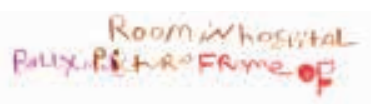

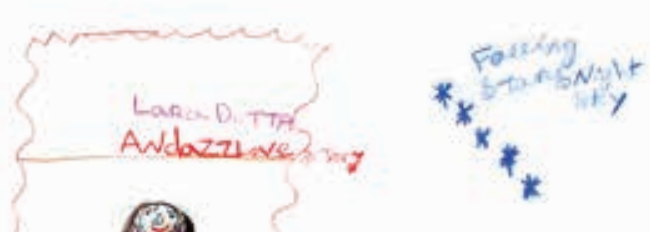

1. 
A place to daydream; the infinite window. -- Achilla

-- Chris

In my room where I can read, with a nice big window. -- Millan
When I think about it, I don't know what it looks like, when I draw it I see it.

-- Jake
Falling stars,

night sky.

-- Nadia 


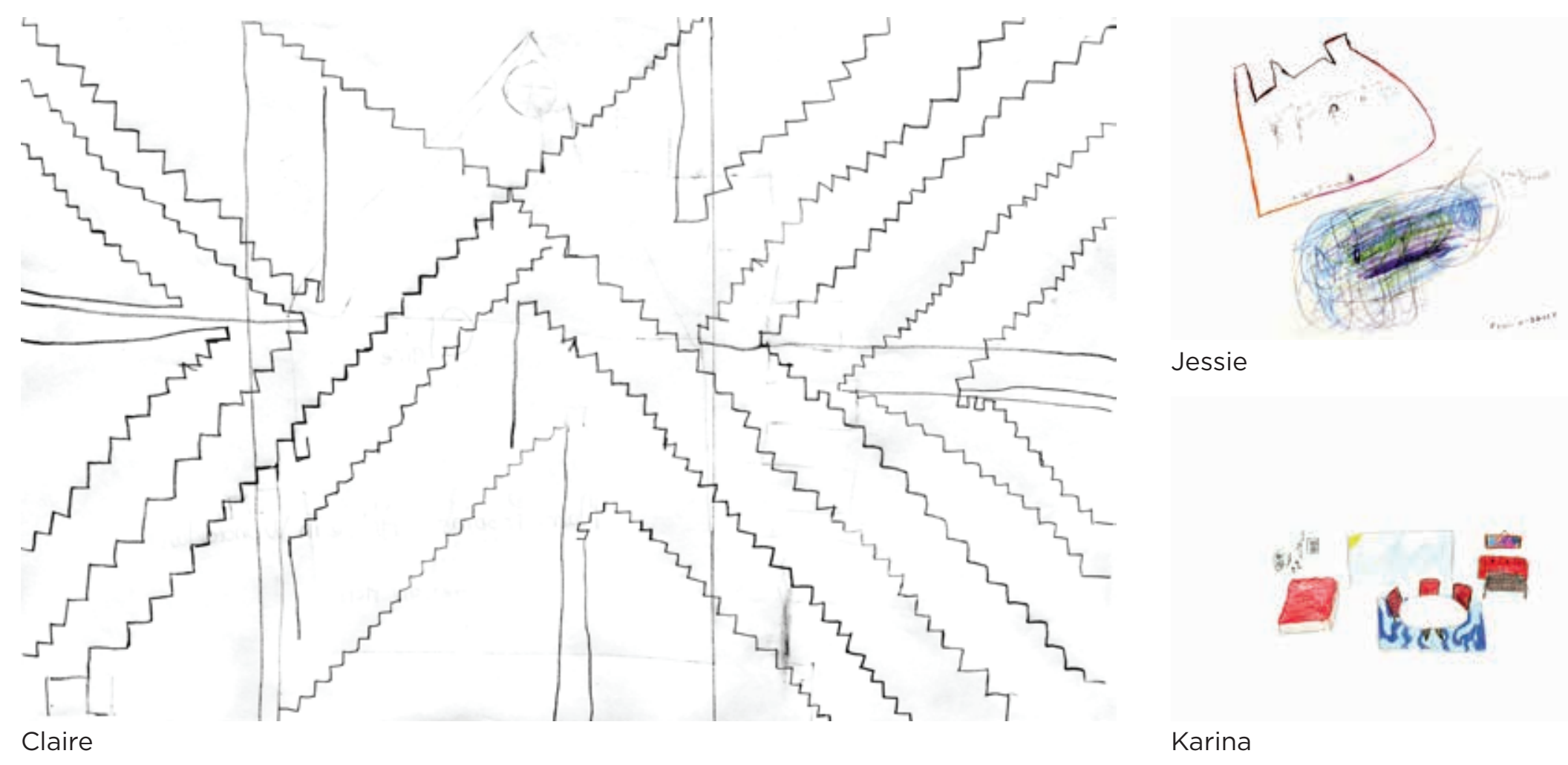

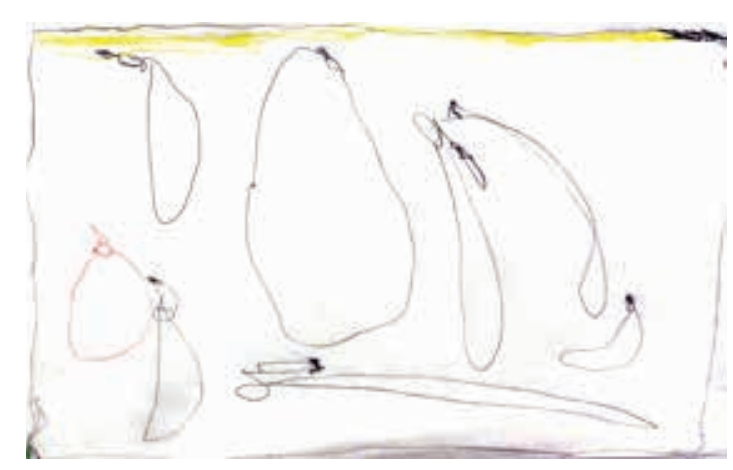

Elaine

QUILT 10

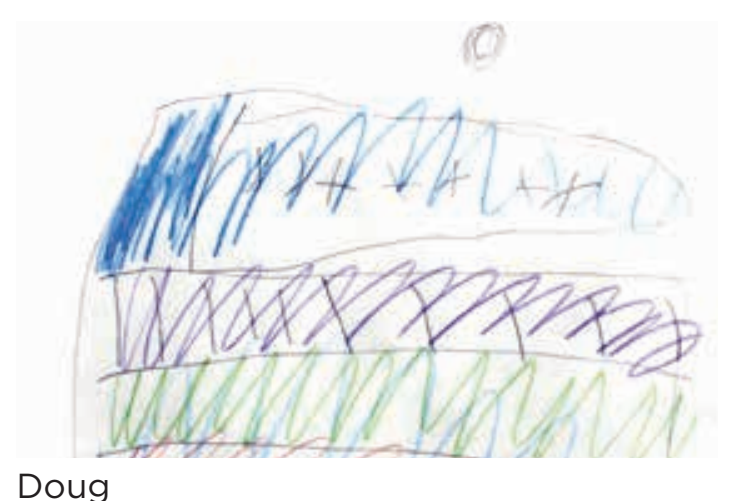

Doug

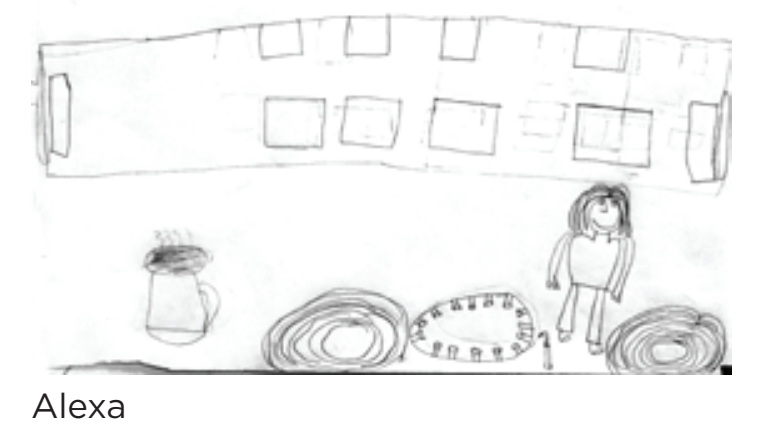



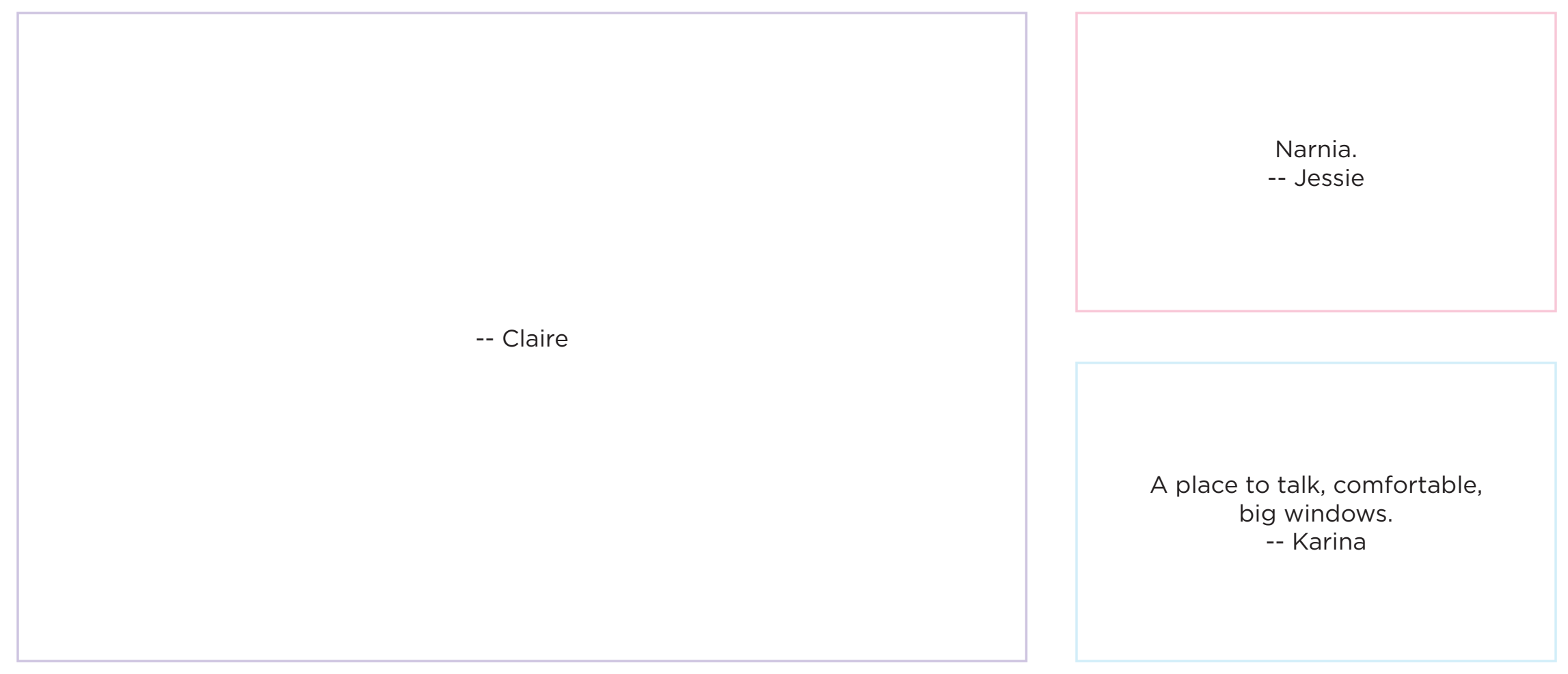

l'd like a little TV in my happy space because watching it makes me feel calm, I want the window to be open sometimes to let the fresh air in. I would like red and yellow colours on the walls. I would like to be around things that remind me of when my family was together.

$$
\text { -- Elaine }
$$

$$
\text { -- Doug }
$$

My happy space is at home in my bedroom where my art studio is, where I do my artwork. I have a happy space on the couch with a hot chocolate doing my knitting. 


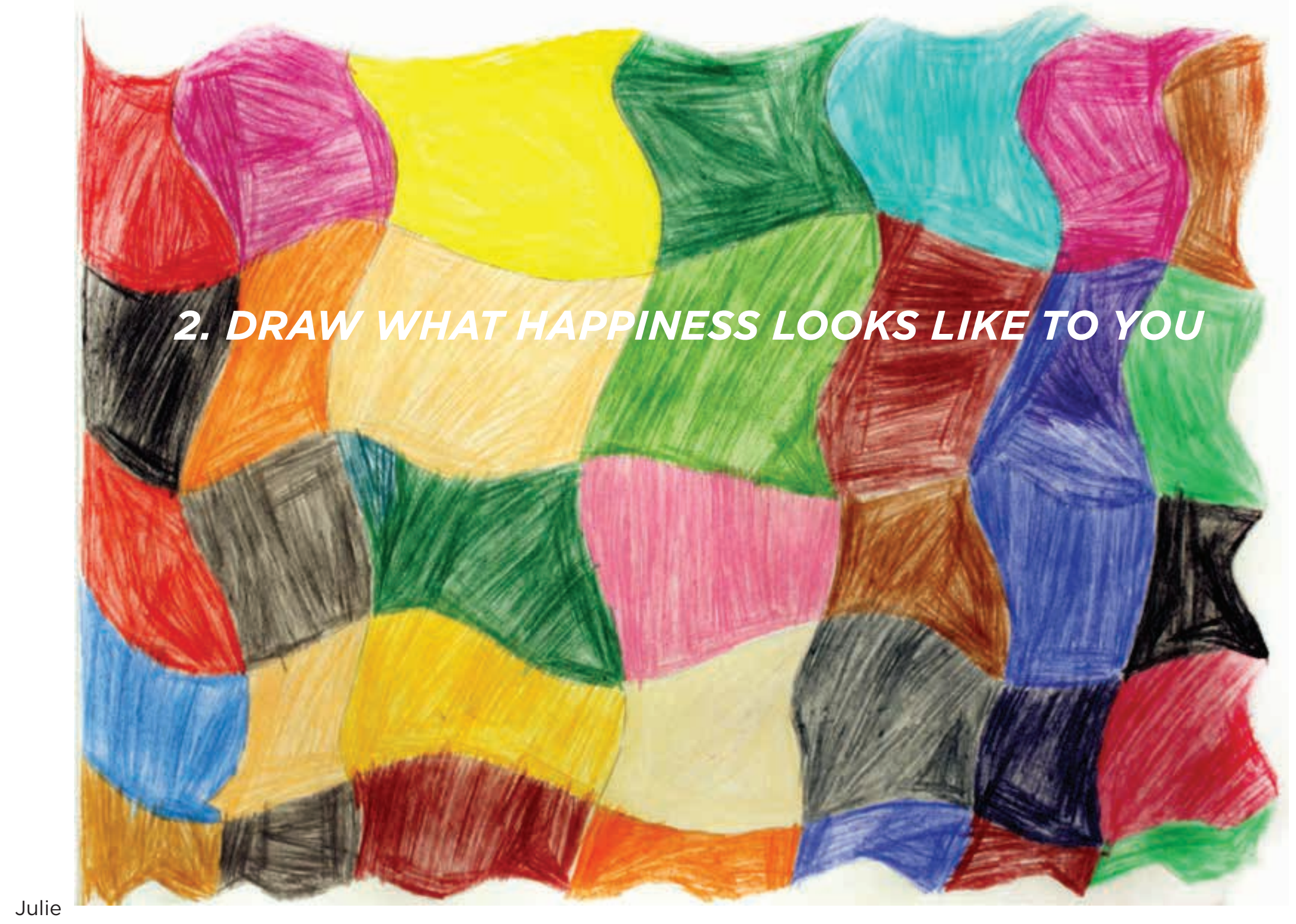




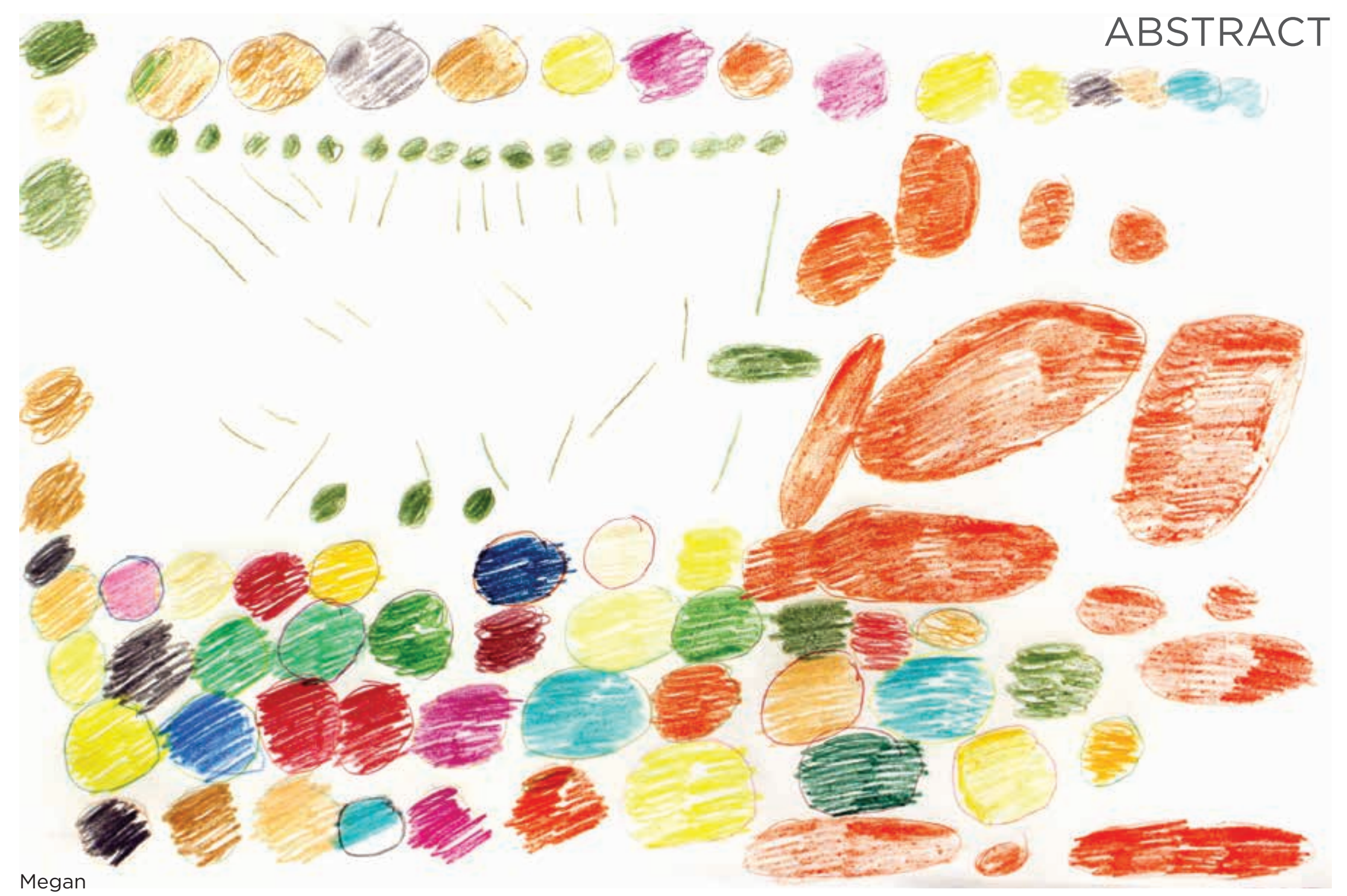




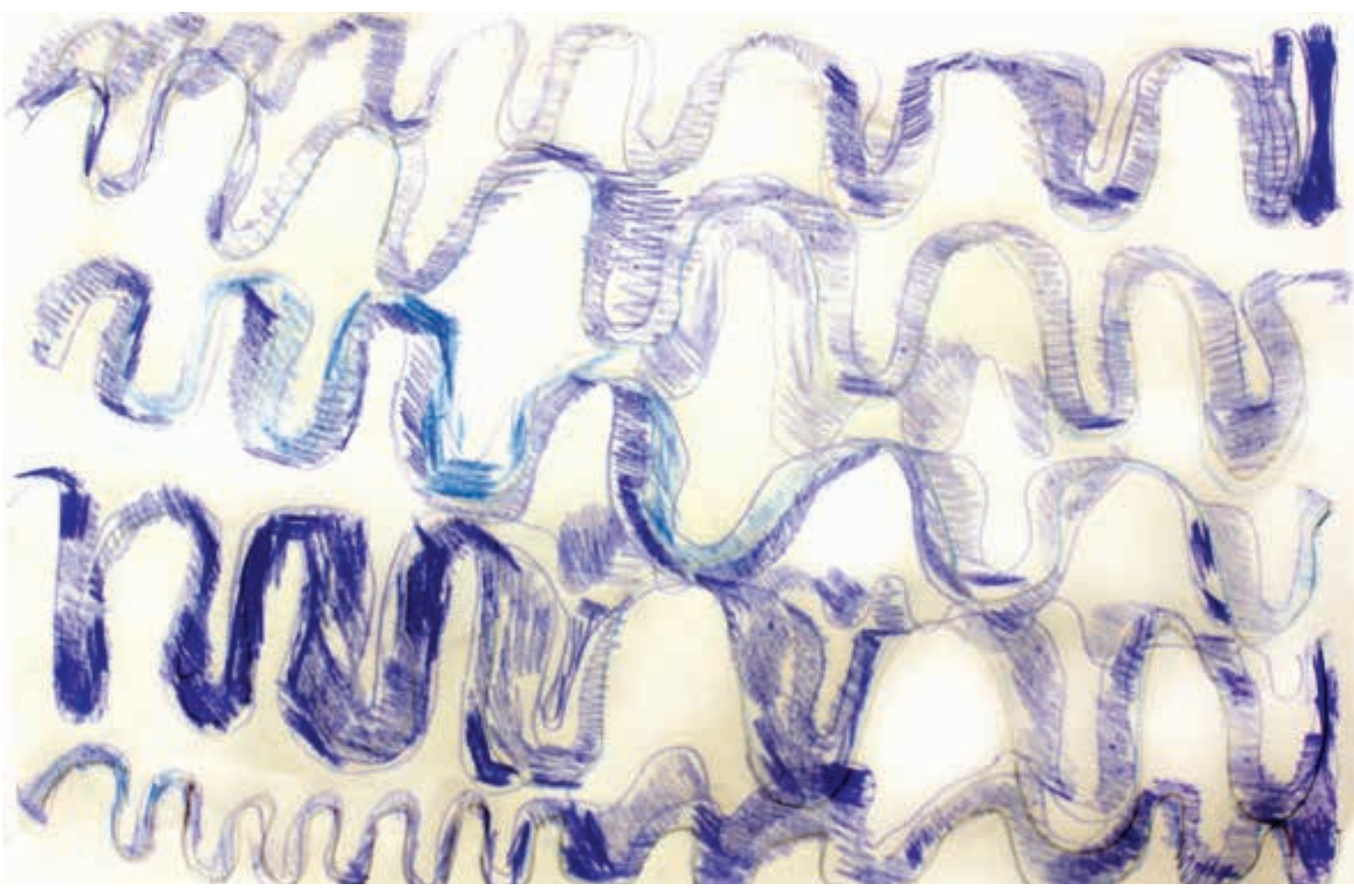

Frances

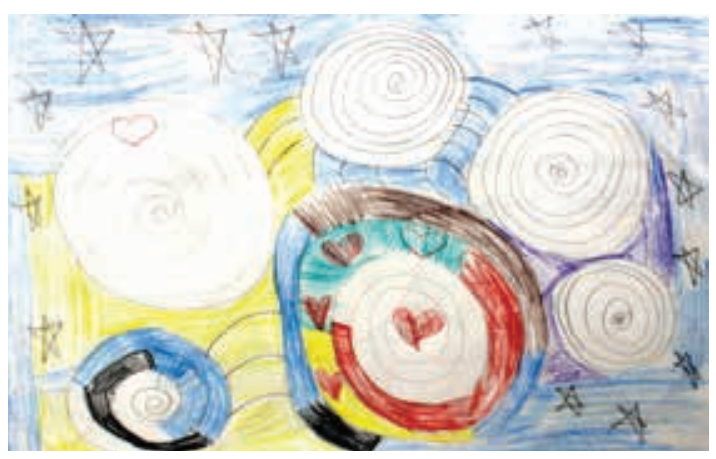

Marika

QUILT 11

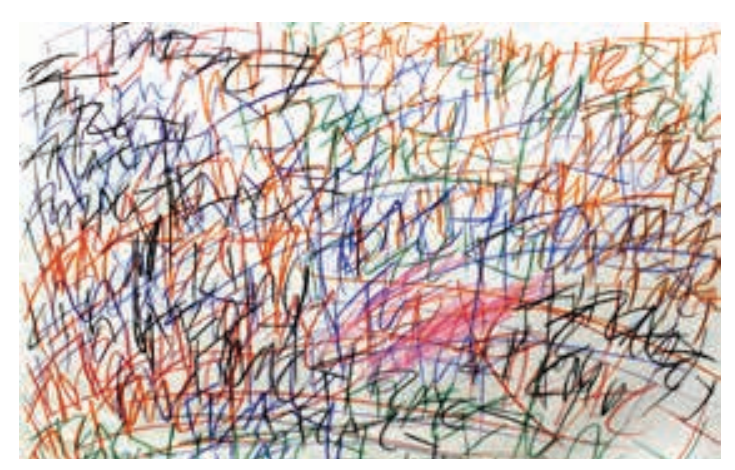

Alixe

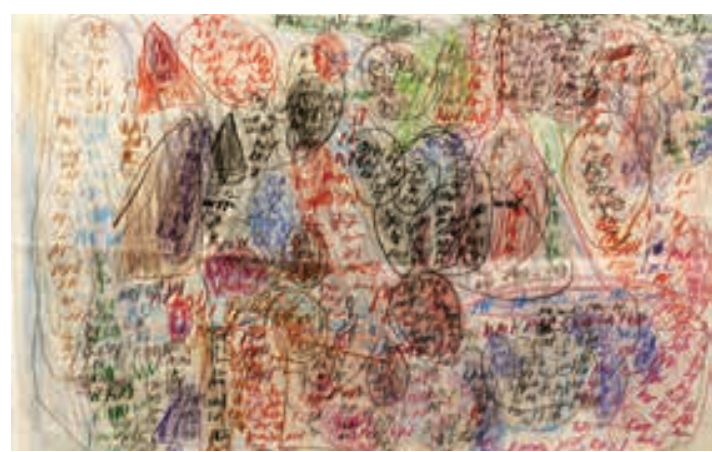

Alanna

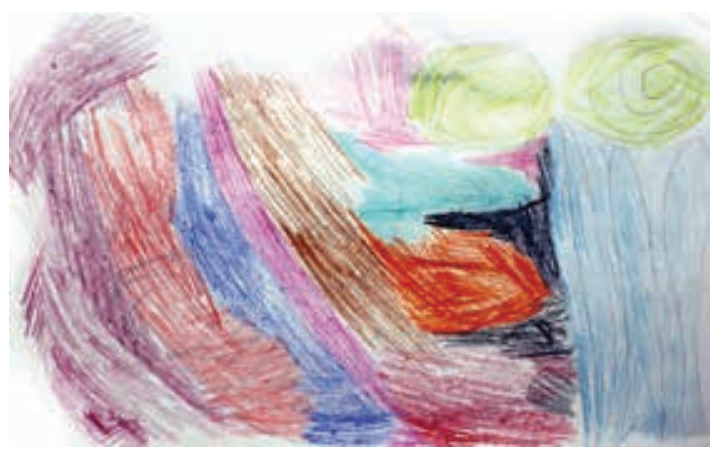

Sarah

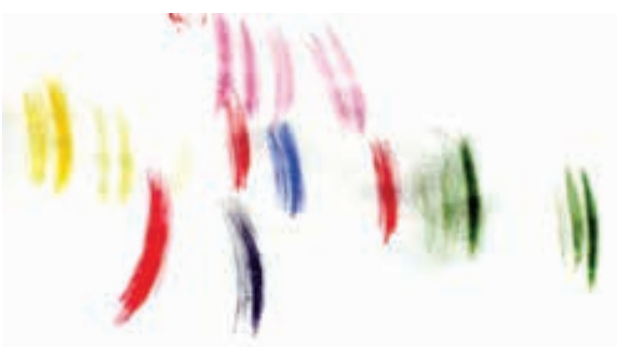

Amanda 


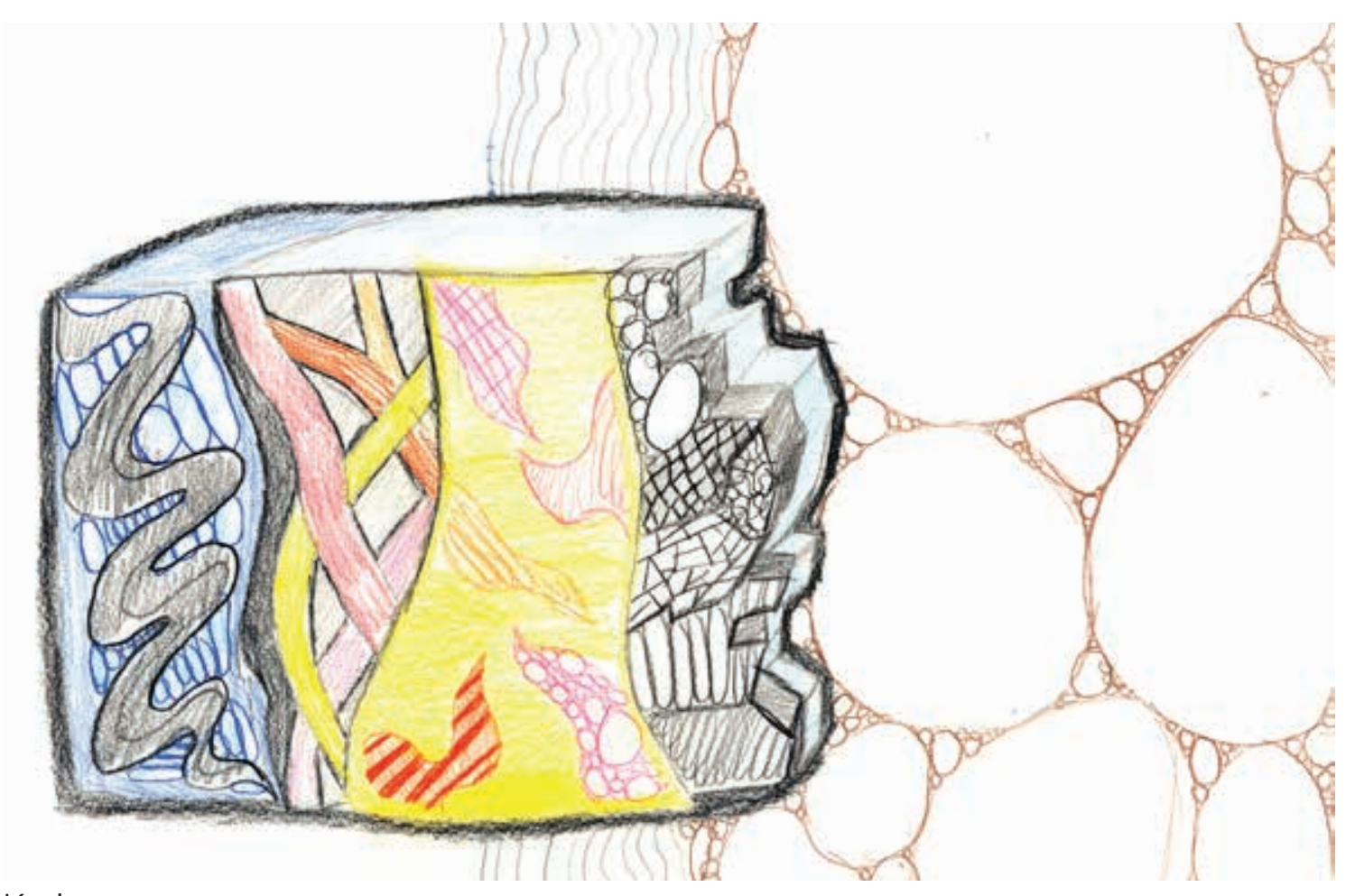

Karina

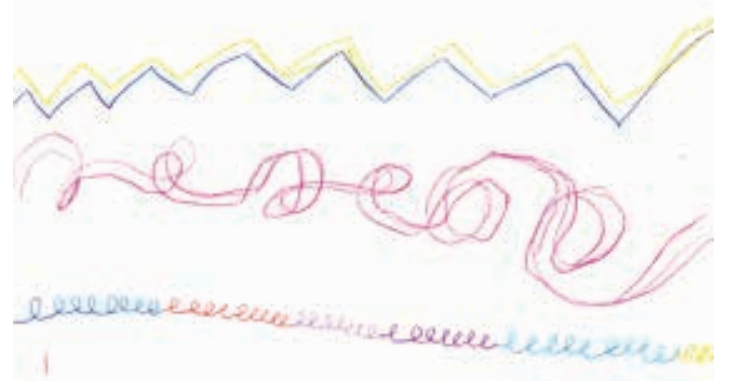

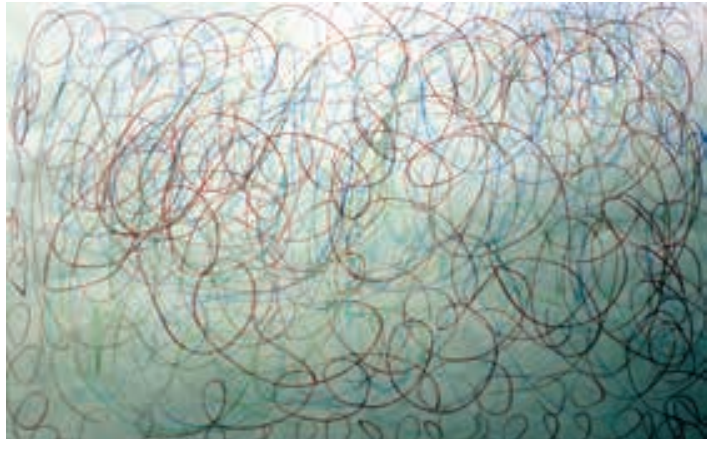

Debbie

QUILT 12

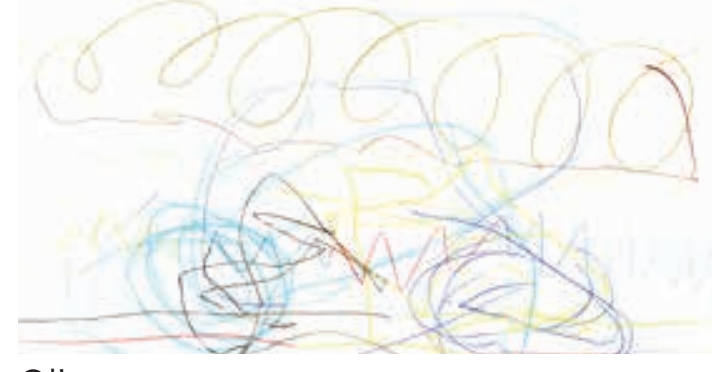

Oliver
Millan

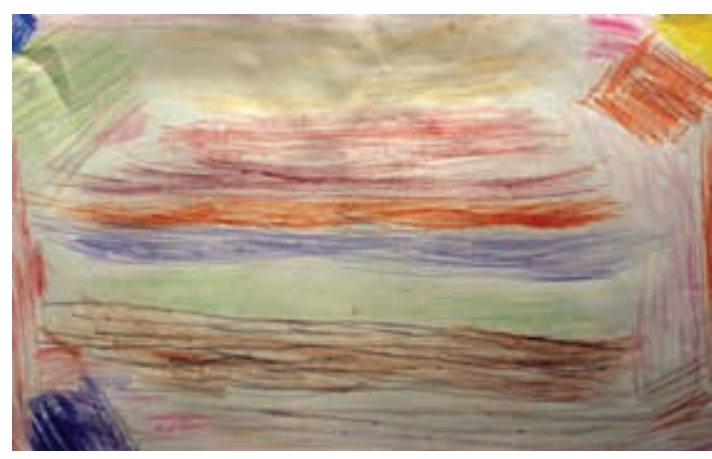

Alexa 


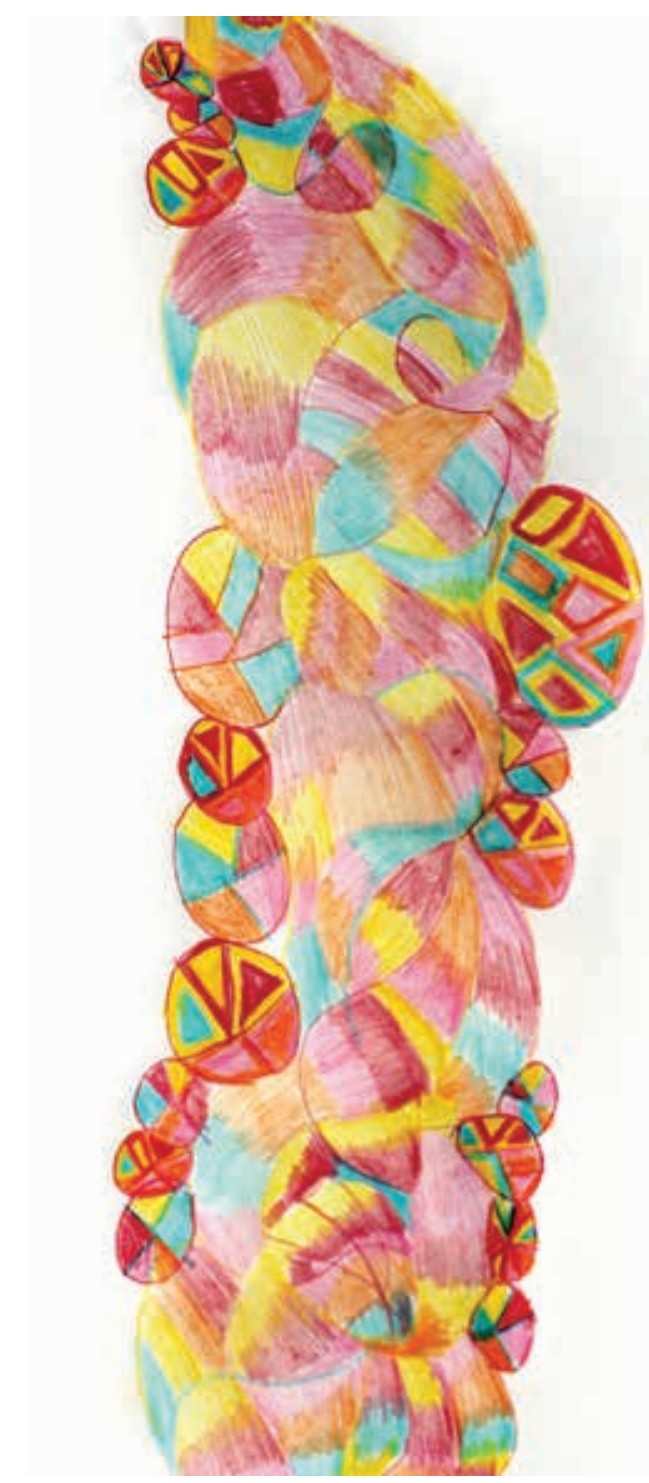

Christine QUILT 13

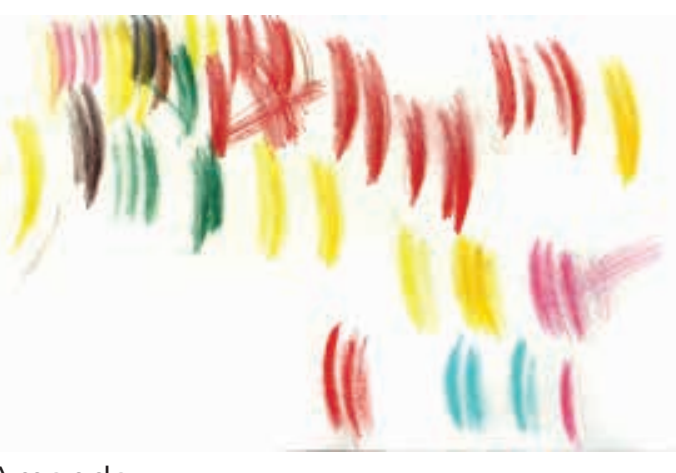

Amanda

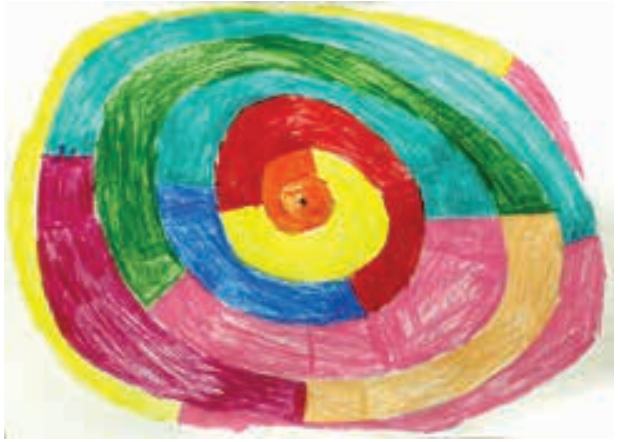

Claire

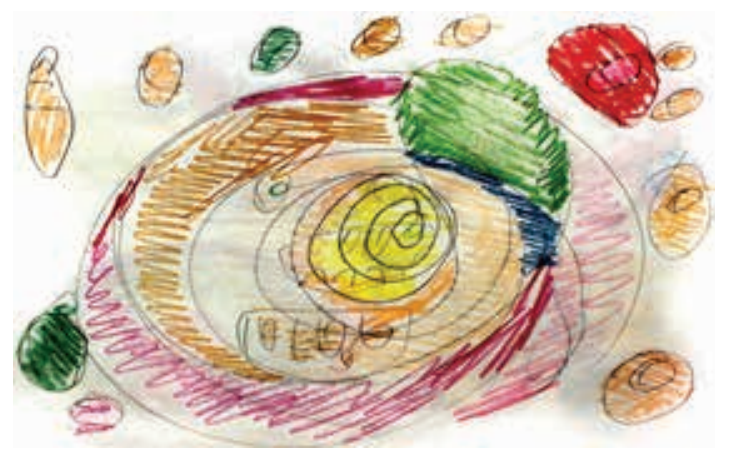

Jake

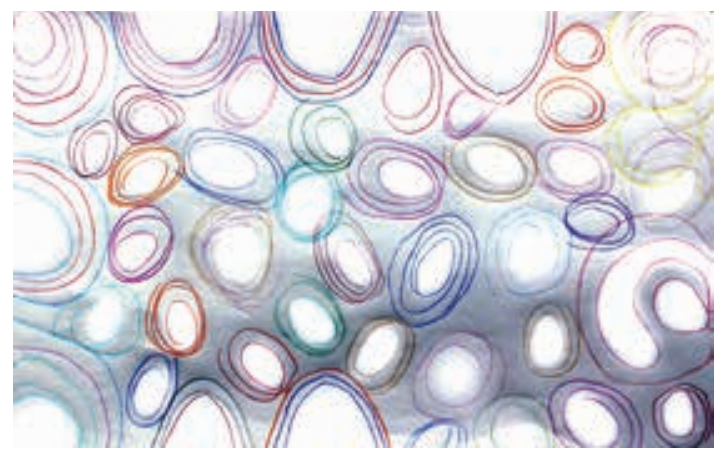

Kesley

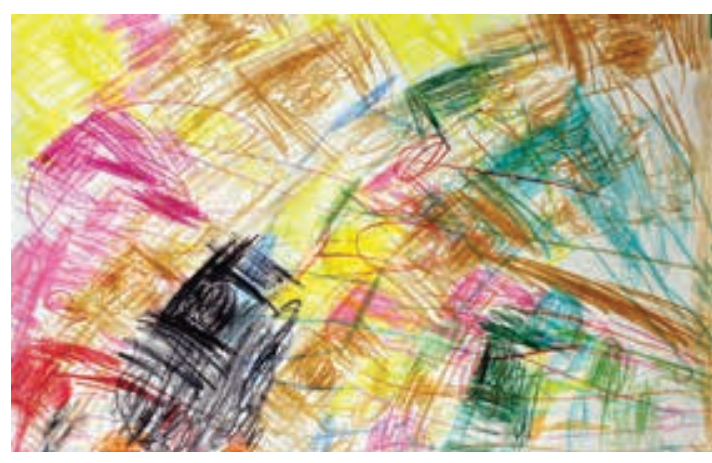

Bella

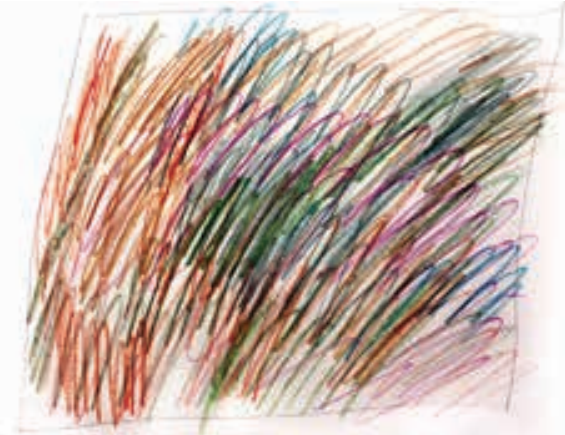

Doug 


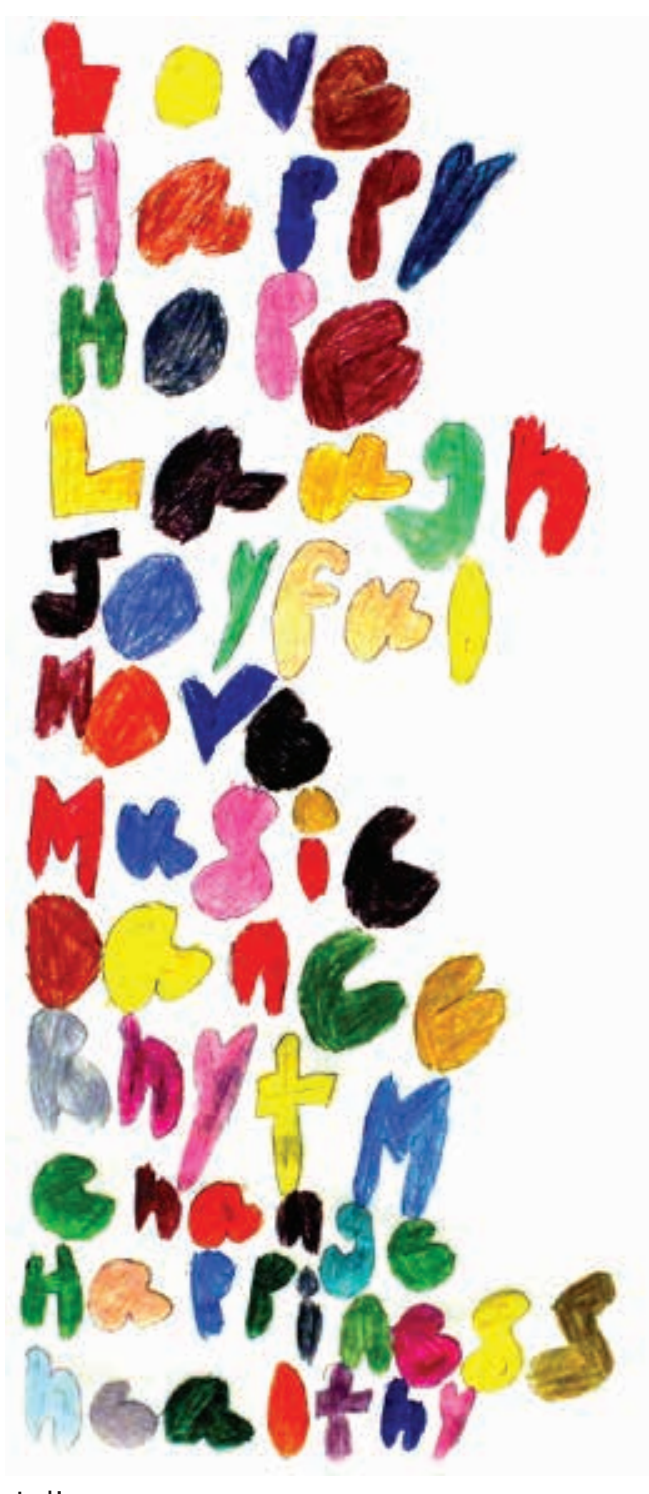

Julie

QUILT 14

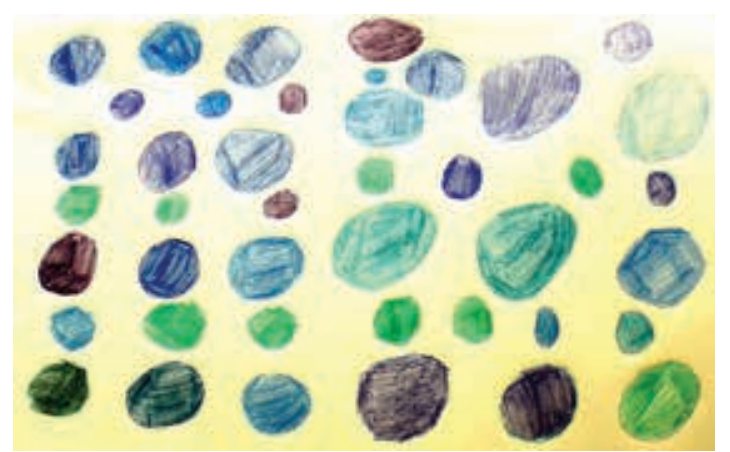

Malinda

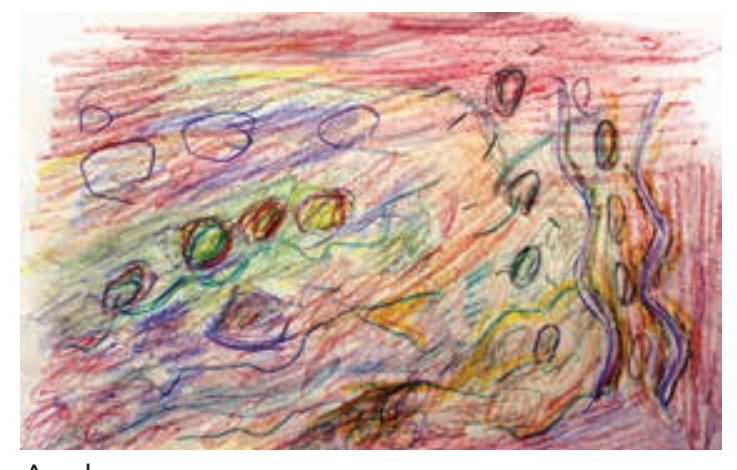

Andre

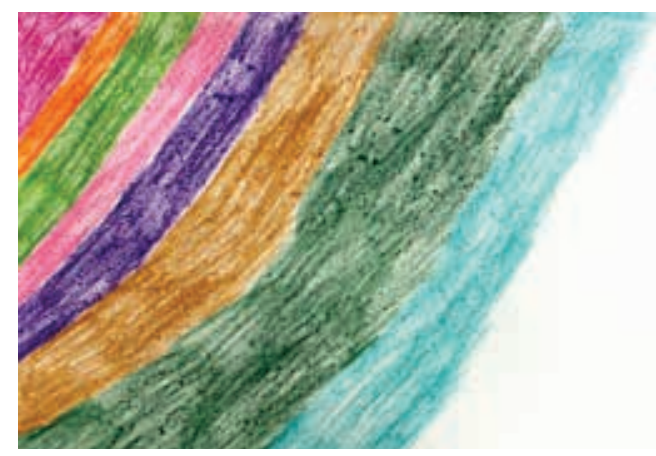

Anna

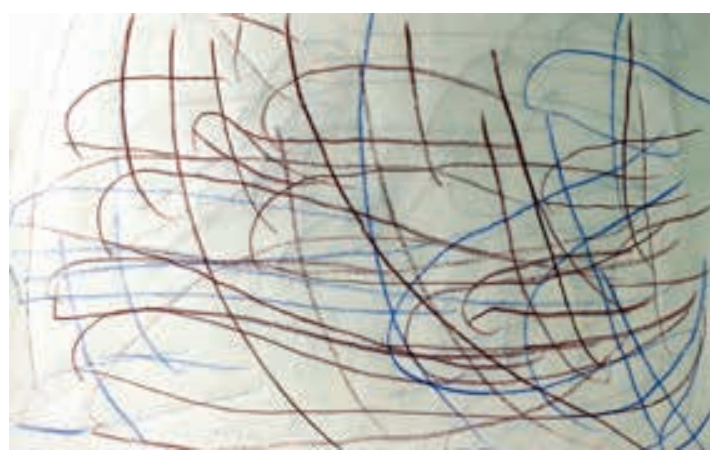

Christopher

fyy X)

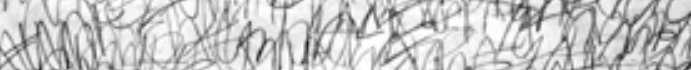
(1) - a

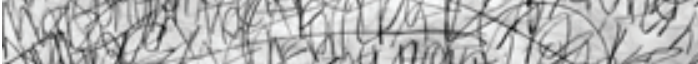

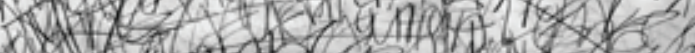

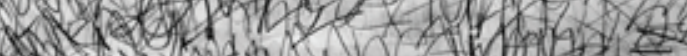

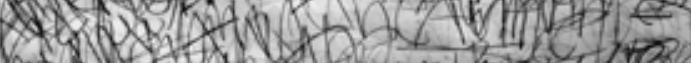
M. Alixe
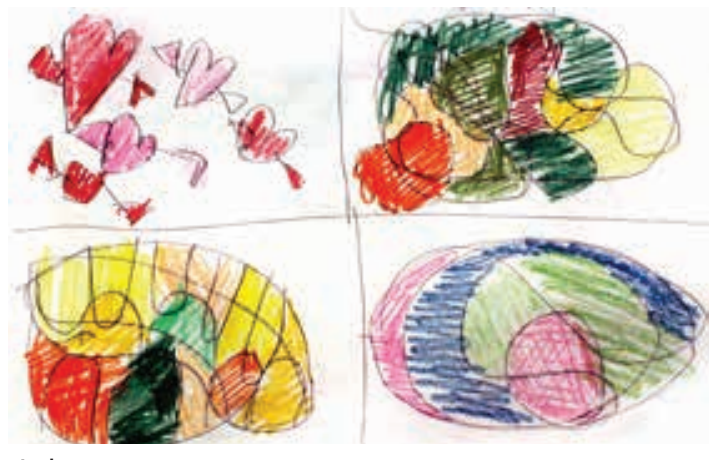


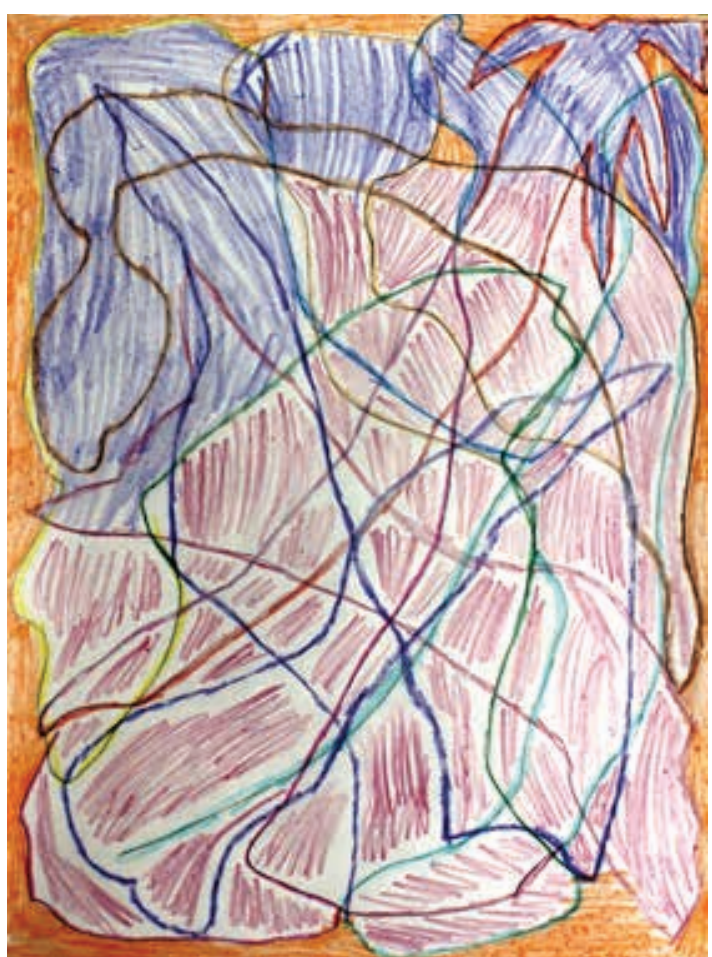

Caroline

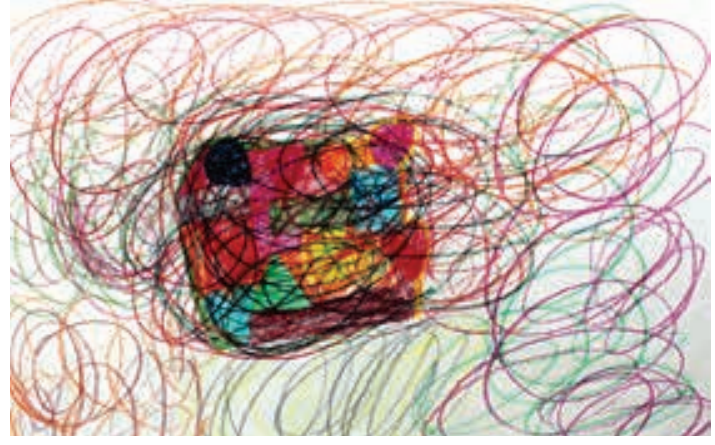

Tanya

QUILT 15
Fonting

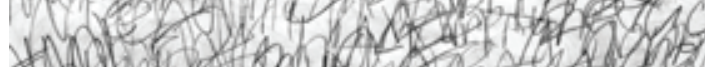
* Hab

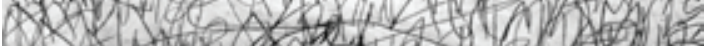

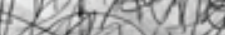
In 10 X 7 on

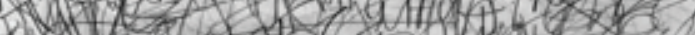

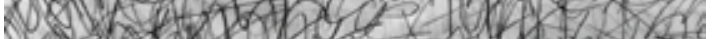

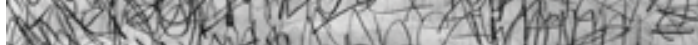

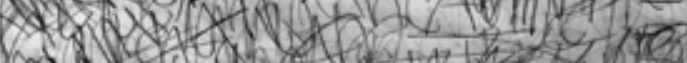

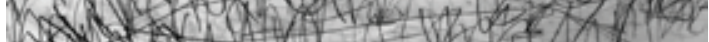
Alixe

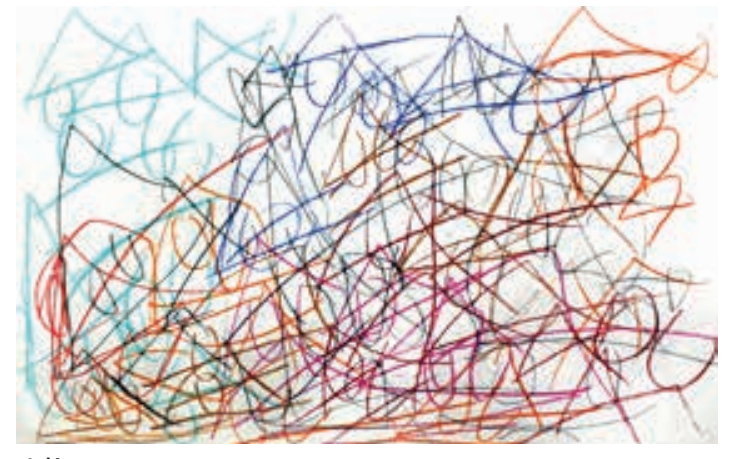
Alixe

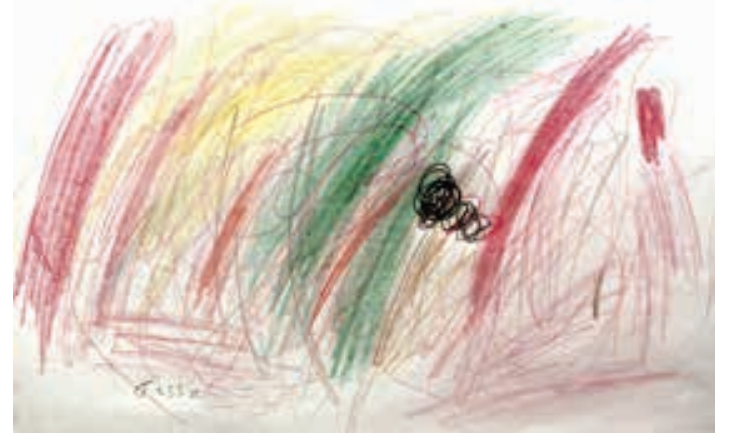
Jessie

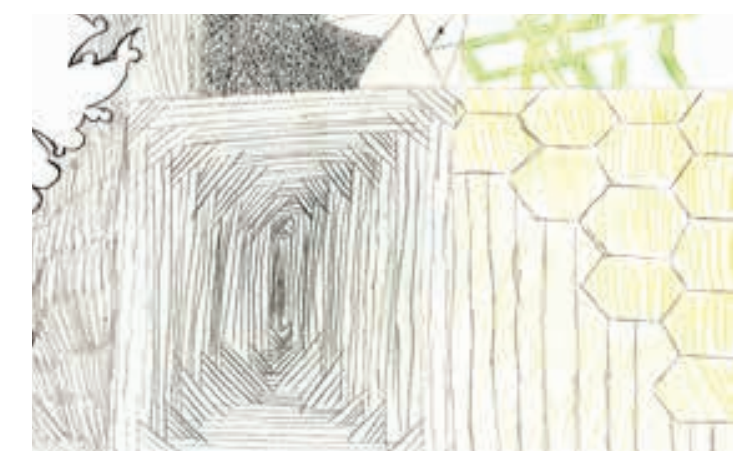

Achilla

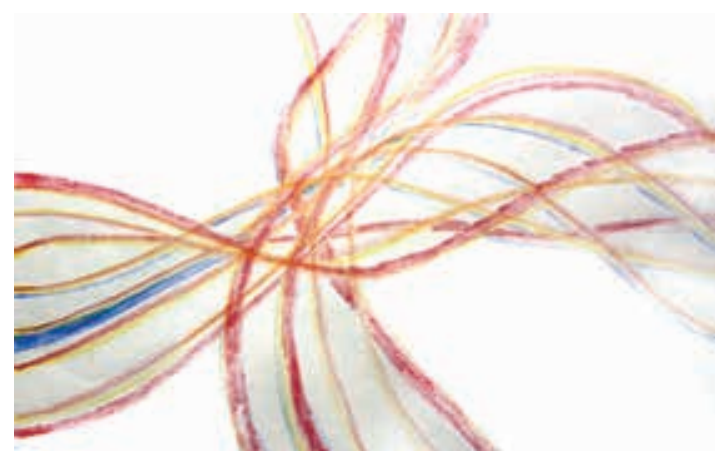

Richard

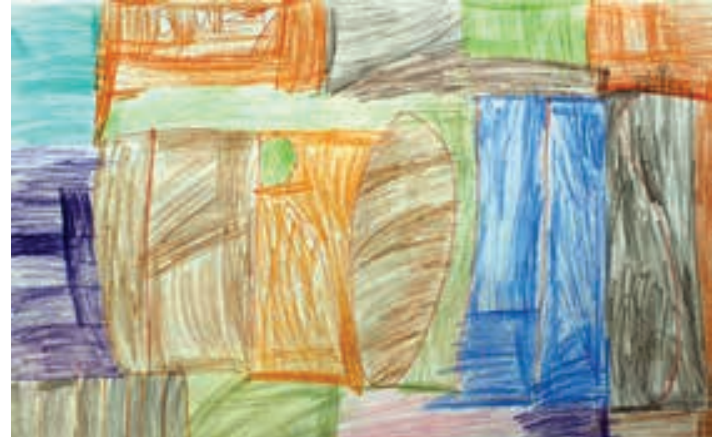

Suzan 


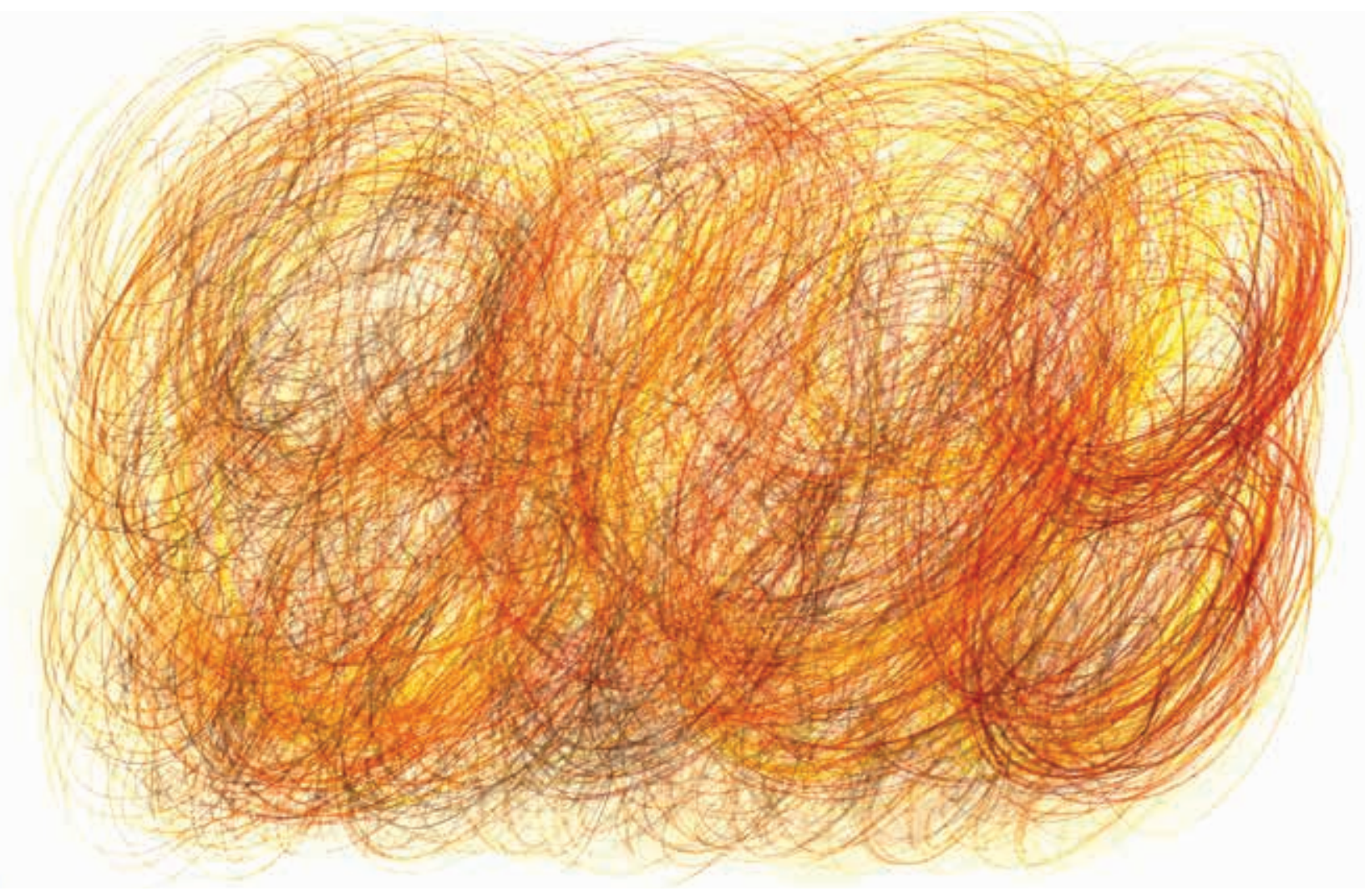

Henry

FIGURE 10 


\section{ENTERING THE DRAWING OF ANOTHER}

Designing a wondrous architecture is not merely an intuitive operation, or an unreflective action, but rather the continuation of drawings, a kind of rational wisdom capable of considering actions that can deliver desired effects. This is not done by simply a skill or a technique, however, since it involves not only the ability to decide how to achieve a certain end, but also the ability to reflect upon and determine good ends, consistent with the aim of entering the drawing of another.

The drawings in this research activate the reading for this thesis, which have brought about three strong themes. Many of the drawings draw upon the notion of nature, architecture, and abstraction. Subcategories within nature are trees, flowers, leaves, sunshine, rainbows, water, waterfalls, fresh air, animals. As well, subcategories within architecture are homes, bedrooms, villages, tree house pods, stairs, galleries, playgrounds, art studios. The abstract drawings are mostly curvilinear shapes and colourful. To see beyond the image, to spatialize the drawing, I collaged and drew on top of the drawings. Figure 11 and 12 shows two ways to enter the nature drawings. The trees surround you, the sail becomes a protective and sculptural wall; it is a peaceful space within nature and the drawing. 


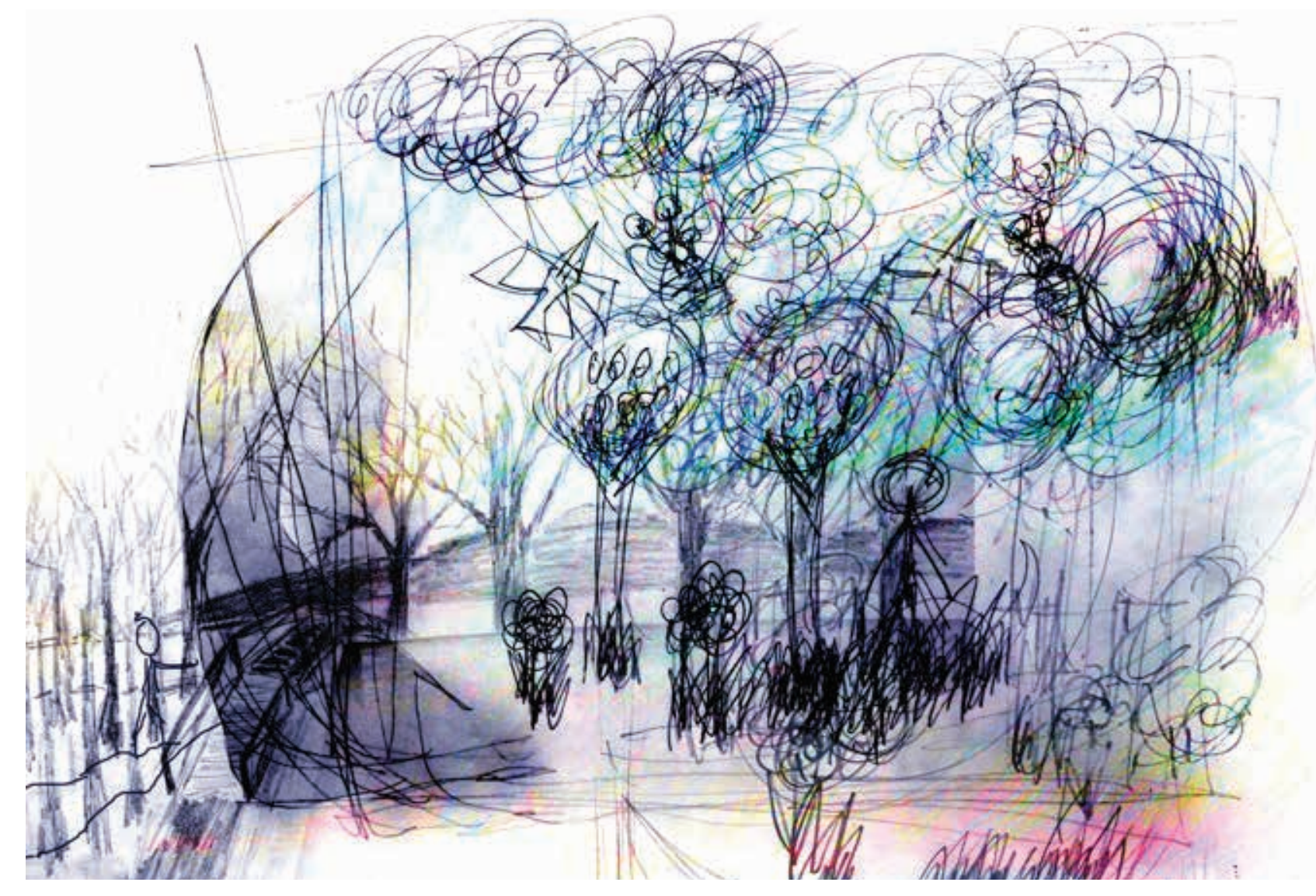

FIGURE 11 
Figure 13 displays the architecture collage: a realm of tree house pods, hills, circles to sit and to paint in, enigmatic stairs parallel to the roof-line of the village. Figure 14 and 15 are in the abstract realm; how do we start to inhabit the shapes: the shapes become floors, walls, ceilings, rooms, windows, thresholds.

Drawing is the primary mode of imagining. Here lies within a strong idea of interpreting drawings. On a literal level, how do we read drawings in the form of a dream and how do we interpret them. Drawing is a form of dreaming. ${ }^{9}$ Marco Frascari offers a theory of drawings and dreams -- a reading of drawings. Drawings reveal what is in the imagination. There is magic in the drawings, with its ability to move the imagination of the gazer. Drawings carry signs of the manifestation of dreams which become a way to imagine in architecture. ${ }^{10}$ In order to read drawings one must read between the lines in order to understand a reading of the lines." Meandering lines of thought are discovered in the workings of architectural imagination and threads of ideas. ${ }^{12}$ Dreams are visual in structure, they are a way of thinking by using images. Architectural drawings come to life and understanding through daydreaming. ${ }^{13}$ Dreams are our identifying and making sense of the imagination as they draw a connection between the visible and the invisible. ${ }^{14}$ There is a capacity of waking up to dreams through drawing and through entering the drawings of another. ${ }^{15}$ 

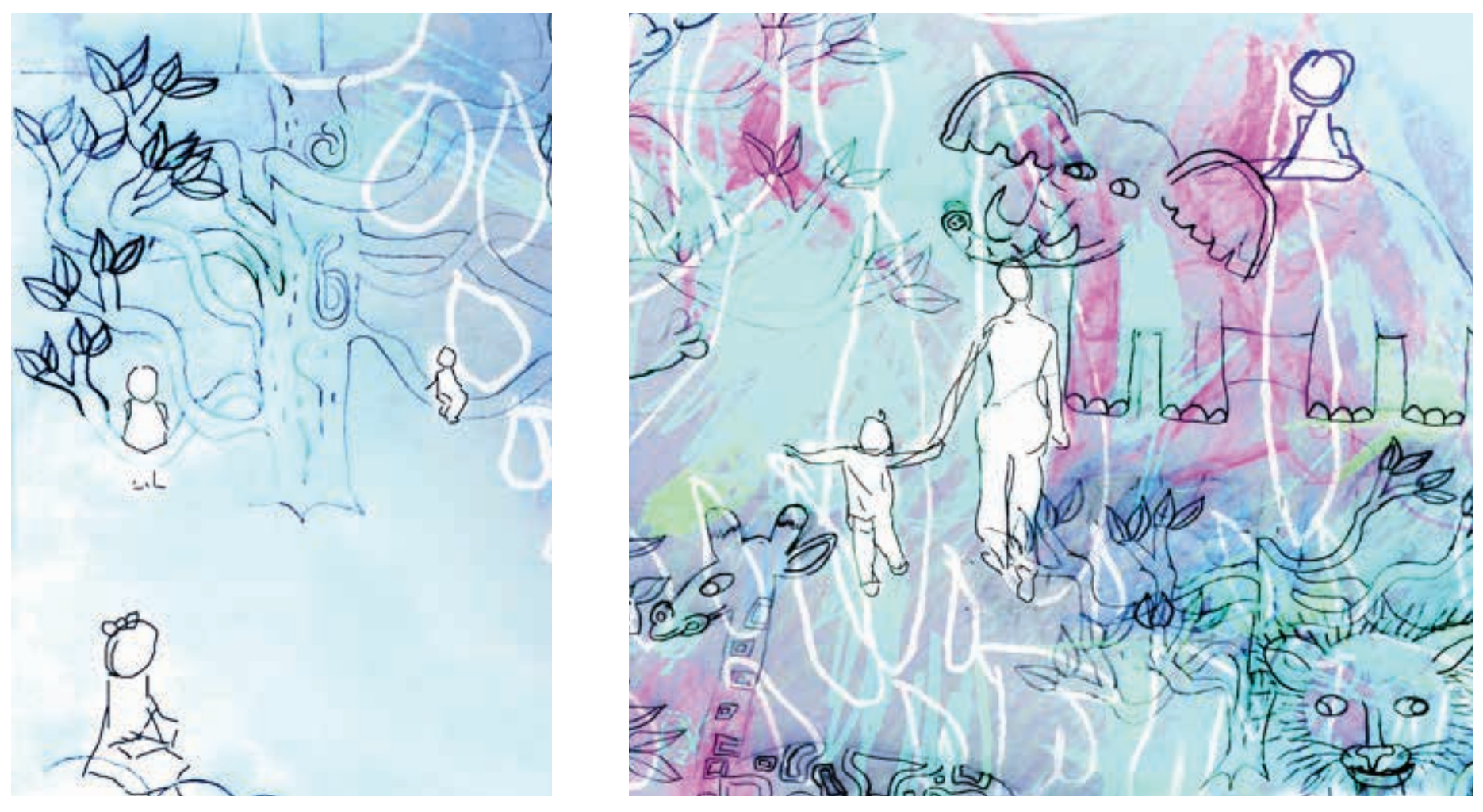
Ambiguity in art activates the imagination, as an unfinished image calls upon our creative resources to complete its story, to collude in its plot-to round out its body. ${ }^{16}$ The harmony that resides in the delicate proportions of lines and masses in the abstract drawings becomes mirrored in the mind; the repetitions of pattern give us rest. The drawings in this thesis take the role of a communicative tool, becoming an instrumental design language that creates an exchange of ideas. These drawings mediate ideas on the cognitive mapping of happiness, amounting to a series of architectural spaces obtained through digital and hand drawing -- represented moments of a suspended experience within each drawing. 


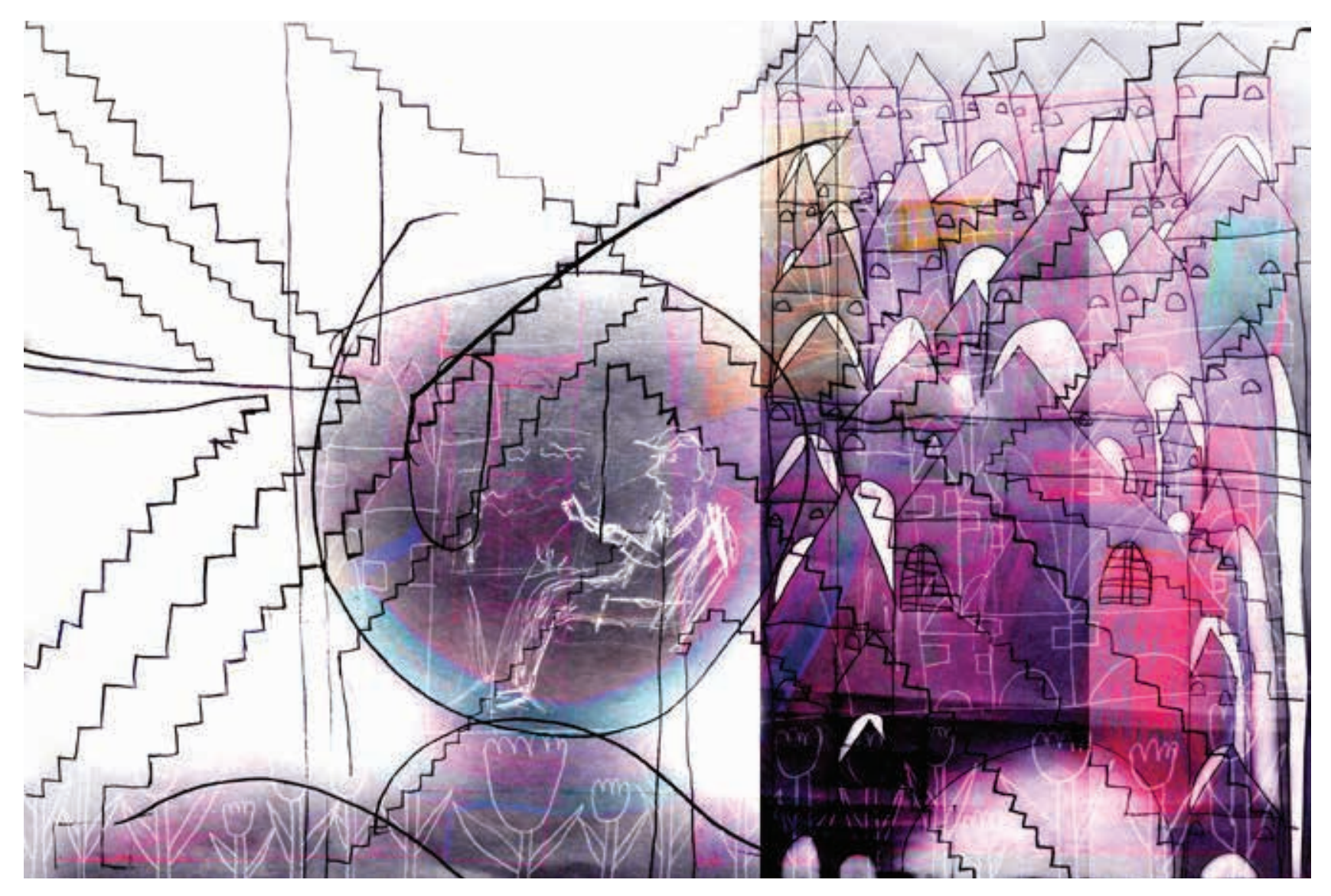

FIGURE 13 


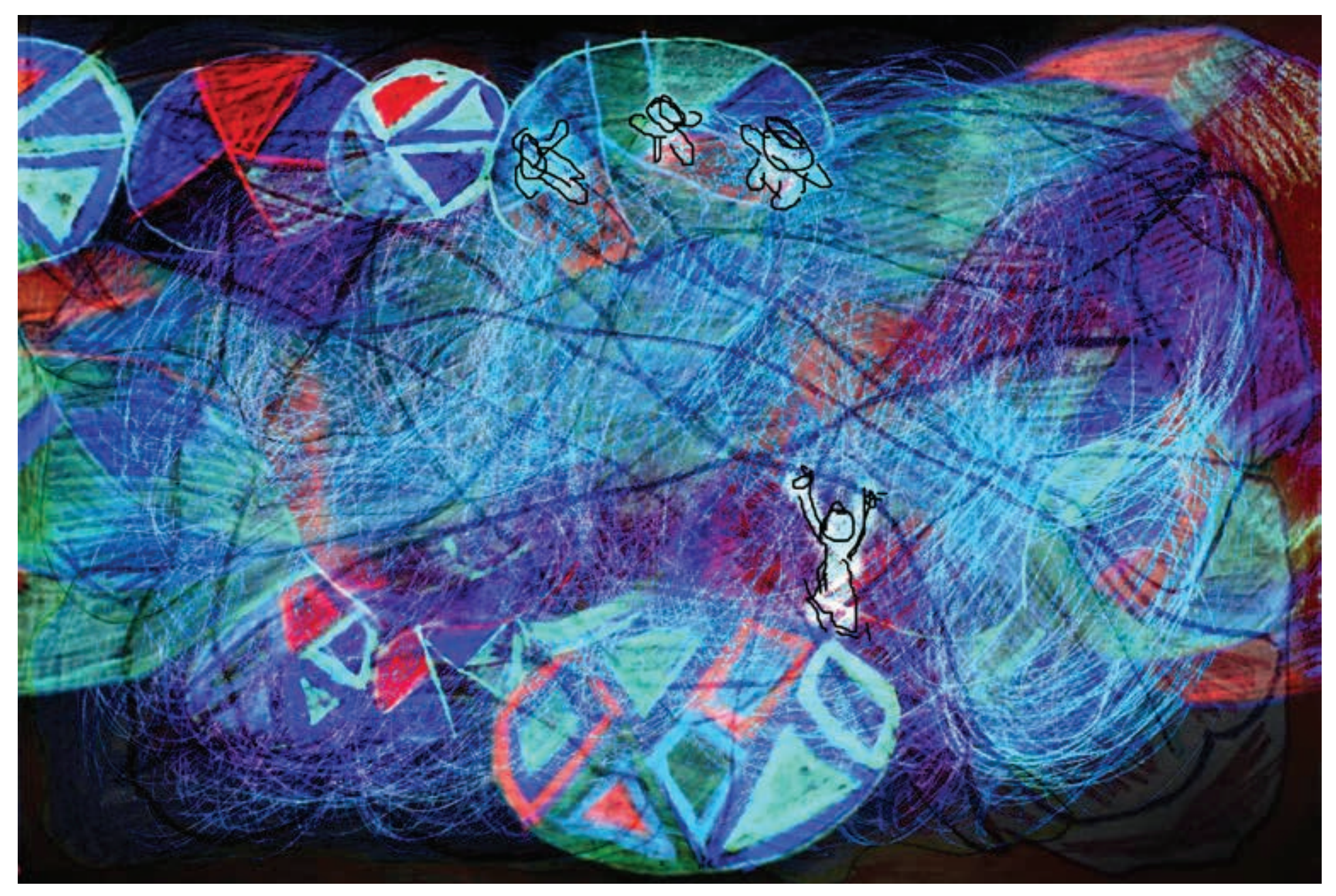




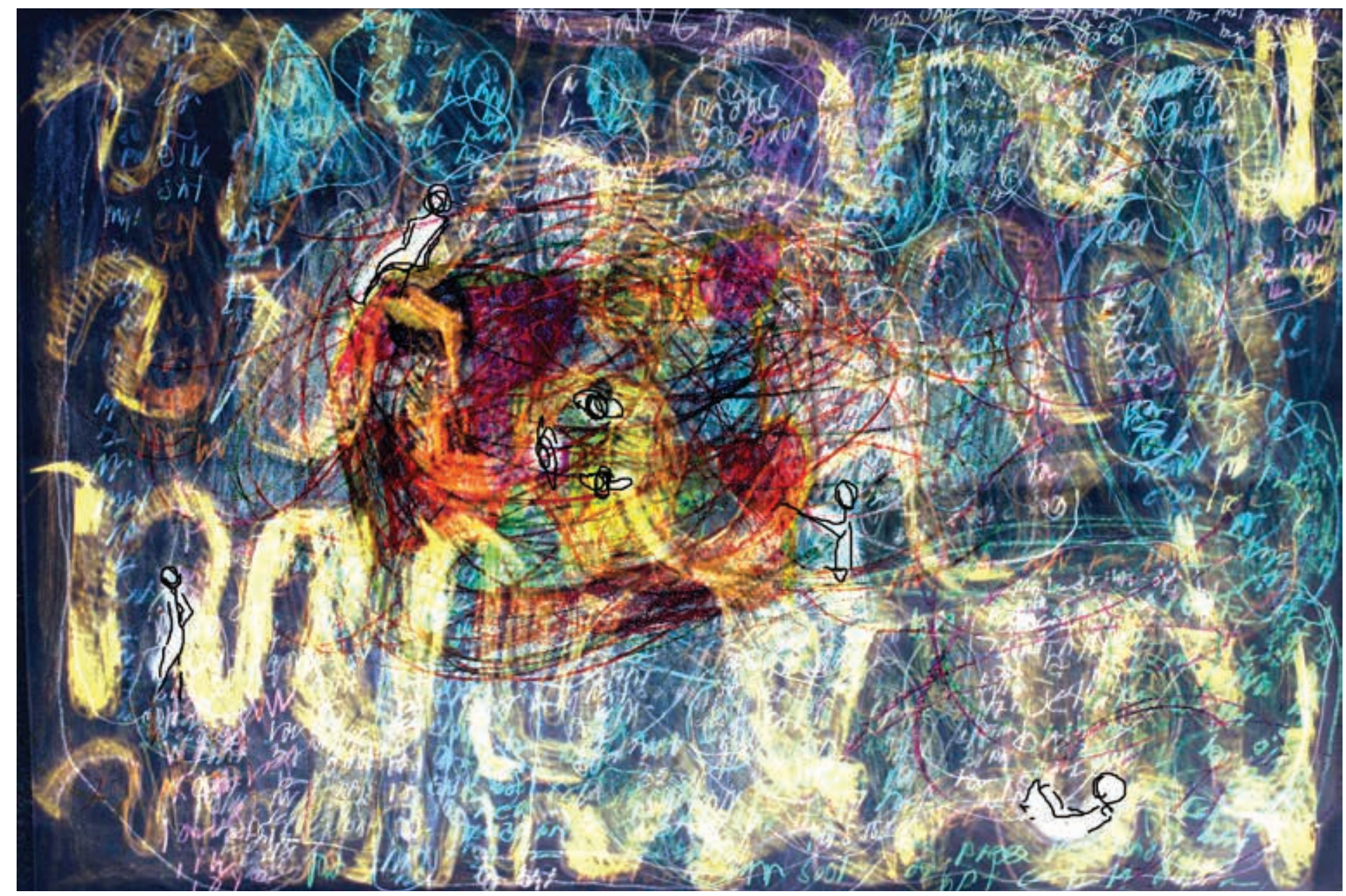

FIGURE 15 


\section{DRAWING OUT EVIDENCE}

\section{THE LANGUAGE OF DRAWING}

When words lack intelligibility or when they cannot describe something, drawing can define both the real and unreal in visual terms. ${ }^{17}$ Drawing through its expression of the conscious and subconscious mind, provides interconnected ways of orienting knowledge that contributes to a multidimensional understanding of the lived experience. ${ }^{18}$ Drawing is a universal language of knowledge and experience; it is a way of coming to know the world that is explicated through the act of drawing. ${ }^{19}$ Art brings to light self-knowledge, and acts as a communication tool. ${ }^{20}$ Art has the ability to help us understand ourselves and our surroundings. The picture captures and conveys the non-verbal part of one's mind. ${ }^{21}$ After all, a picture is worth a thousand words.

It is difficult to describe certain phenomena with words. When a patient says that they have a sharp pain, what does sharp mean to us? What would happen if we asked patients to explain their pain through drawing? If these drawings of pain became inhabitable spaces would they also cause negative emotions? How would drawings of certain emotions give insight on how to design therapeutic architecture? If we asked children to draw happiness, could we thus create architecture of happiness? Drawing affords insightful glimpses into experiences and emotions. The process of looking, seeing and viewing enables us to interpret drawings visually, emotionally and aesthetically. ${ }^{22}$ 
The brain mediates a conversation between vision and the hand. The hand in drawing invokes our embodied experience. ${ }^{23}$ Based on philosophy, and the writings of Maurice Merleau-Ponty, drawing is experienced through intricacies and connections of mind, object and body. It is a means through which the act of seeing is evinced in a tangible form. Illustrations can make the invisible visible; it is a way of discovering the built environment through thinking, feeling, sensing, and doing. Drawing explores the potentials of experience, ideas and memory through its ability to retain and articulate traces of the past, the present and imagining the future. ${ }^{24}$ Thinking about drawing and thinking through drawing; highlights that drawing can be a critical and reflective form of investigation. Drawing is an instantaneous process of reflecting within the realm of creativity. It is the manifestation of an incessantly mutable process, the partially realized ruminations of the mind -- the acts of thought. ${ }^{25}$

Neuroaesthetics explains how art conforms to the laws of the visual brain, it is not unusual for art to expose these laws to us, often astounding us with the visually unforeseen. Art does not embody the visual world, rather it makes things visible. ${ }^{26}$ Seeing the world through the diverse lenses of art and science and, by assimilating these perspectives, we attain a deeper understanding of reality. ${ }^{27}$ Systematically, drawings are visual and produce meanings, while at the same time construct knowledge. ${ }^{28}$ Qualifying a method of designing through drawing, while uncovering a methodology for wondrous architecture, and enhancing the experience of architecture will cultivate a more rewarding experience of wellbeing in our built environment. 


\section{THERAPY THROUGH DRAWING}

Drawing can help us with our most intimate and ordinary predicaments. Art is also a form of therapy. Art therapy has its origins in early 20th-century psychiatry and its discovery of the unconscious. The importance of creative expression for wellbeing and recovery is well recognized. Art can be a self-initiated activity providing a form of self-expression; it can be used to improve care environments; and can also provide people with a voice. ${ }^{29}$

Wondrously gazing at a drawing and the act of drawing itself allows us to remember, to instill hope, it rebalances us, gives self-understanding, growth and appreciation. ${ }^{30}$ Empirical research has shown that we experience fictional realities through neurobiological mechanisms fairly similar to those through which we experience real life. ${ }^{31}$

Our mind looses both factual and sensory memories. Considering the urge to take photographs, the impulse to pick up a camera from our fear of forgetting. Art is a way of preserving experiences that we need help containing; it helps us hold on to things when they are gone. ${ }^{32}$ At the most basic level we enjoy drawings because we like the real thing they represent; art rebalances us emotionally. ${ }^{33}$ We 
are not quite 'transparent' to ourselves, however drawing gives us self-understanding. ${ }^{34}$ Personal identity and qualities of the mind and character can be found in one's drawings; art builds up selfknowledge and acts as a communication tool. ${ }^{35} \mathrm{~A}$ cause of our unhappiness is our mastery of the art of habituation; we often yearn for the imagined places of elsewhere. Drawing can lead us to a more truthful assessment of what is valued by working against habit and allowing us to reshape what we admire. ${ }^{36}$

Art and drawing contributes in the role of promoting positive mental health and wellbeing. Drawing carries an intrinsic sense of relaxation and happiness; it instills a meditative state. ${ }^{37}$ Drawing with others can improve self-esteem and empowerment, which in turn enables positive social behaviour. ${ }^{38}$ Drawing is a tool which can extend our capacities; it allows intricate associations between parts to be realized. ${ }^{39}$ It addresses us in the fullness of our being while concurrently talking to our mind, emotions, imagination, memory, and physical senses. ${ }^{40}$ 


\section{DRAWING FROM NEUROLOGY IN ARCHITECTURE}

Cognitive neuroscience can reframe how art functions and how architecture is experienced, revitalizing and empirically validating longstanding instincts about the relationship between body and aesthetic experience. Architectural design changes our brain and our behaviour. ${ }^{41}$ The human brain alone has over one hundred billion neurons, and each has an average of 7,000 synaptic connections, which means we each have around 500 trillion synapses. ${ }^{42}$ Neurology in Architecture is conceptually concerned with understanding architecture's role in shaping the mind; it assumes a fixed and measurable reality. ${ }^{43}$ It is in the coalescing of the quickly advancing neurological knowledge and drawings conducted in this thesis that the phenomenology of architectural spaces becomes richer. Neuroscience elucidates communication of architecture and the human mind, and exposes unseen intricacies that have thus far escaped measurement and rational analyses. ${ }^{44}$

There are many mirror systems dispersed across different brain regions. More recently, mirror systems have been concerned in artistic measures. In a study scientists were recording the 
activity of mirror systems involved with touch, such as watching a person touching someone else. Moreover, scientists also found evidence of mirror activity when people observed two inanimate objects touching one another. Space around us is full of objects touching each other. ${ }^{45}$ The experience of art and architecture is worked through the precognitive activation of embodied mirror mechanisms involved with the simulation of action, emotions, and corporeal sensations. ${ }^{46}$ All our perceptions, feelings, emotions, thoughts, assessments, and actions are consequent on our embodied transactions with our physical surroundings. ${ }^{47}$

Ecological logic lies at the heart of our experience of architecture. Consequently, we come to desire shelters of a certain size, height, and configuration. We want access to light and air, and doors and windows which open us to exchanges with our surroundings. ${ }^{48}$ Low light levels cause depression, and views towards greenery evoke our innate biophilia. ${ }^{49}$ There is already quite a bit of research to prove that natural daylight and views of nature improve cognitive function. ${ }^{50}$ Architecture is a multifaceted source of information. The sensory appearance tells us how space is organized, 
and this its utility and navigability. ${ }^{51}$ Good connection and free access to the outside space, and views out are very important. As well, the primitive mind connects with the built environment in picking up vistas in refuge, safe spaces. ${ }^{52}$ When there are feelings of containment within a space, there are negative emotions that often go with it. Architectural design elicits certain outcomes that have clinical value: anxiety and aggression are reduced in settings with limited numbers of common spaces that each have a distinctive identity; agitation is reduced in settings that are more residential than institutional in character. ${ }^{53}$ Non-institutional, light, airy buildings; places to rest, sit, places to watch the world go by, places to stop, places to shelter, all have tangible clinical benefits. $^{54}$

Human psychophysical experiments have shown that patterns of line segments stand out perceptually more from arbitrary shapes. A manifestation of a sense of order is deeply rooted in the mind. The visual cortex has organizational properties which facilitate such perceptual sensitivities to these kinds of patterns. These patterns have a statistical regularity between adjacent contour orientations such as repeating lines in collinear, curvilinear, parallel and radial patterns which are ubiquitous in the natural world. Architecture that adopts this principle benefits in some way. ${ }^{55}$ 
A study at the Harvard medical school found out that emotionally neutral objects with predominantly pointed features and sharp angles are liked significantly less than matching objects with curved features. ${ }^{56}$ Sharp transitions in a contour may bear a feeling of threat and this activates a negative bias. Old research on person perception suggest that sharp pointed human scale figure drawings are perceived as being associated with aggressive traits. ${ }^{57}$ There are other physical features that can influence a high level of judgment such as the colour black is shown to be perceived as more aggressive. ${ }^{58}$ Colours influence emotional states. ${ }^{59}$

Acts of perceiving and imagining take place in the same areas of the brain; every act of perception is an act of creation. Reality is therefore a product of most majestic imagination. ${ }^{60}$ Architecture is beyond its mere aesthetics, it is a mental and existential sphere of life which besides providing physical shelter for our fragile bodies, it must also house our minds. ${ }^{61}$ Echoing Merleau-Ponty's phenomenological notion of the chiasmatic bind, architecture is constructed mental space and mental space is constructed and affected by architecture. This is a dialectic relationship; a continuum of space and mind. ${ }^{62}$ 


\section{ARCHITECTURAL PROPOSITION}

\section{DRAWING THE LINE}

It was the determination of physicians, elected officials, parents and the community whom joined forces to establish a hospital for children and youth. CHEO formally opened its doors May 17, 1974. Just this past year there were 6720 admissions to CHEO, 70586 emergency department visits, 7816 visits to Surgical Day Care, 169621 ambulatory visits, and 11009 visits to the Medical Day Unit. ${ }^{63}$ There will be 70, 000 more children and youth in the Ottawa region in 20 years and 1.3 million more children in Canada in 20 years. CHEO is a frontrunner in pediatric care and with its ever-expanding programs, it continually requires more space as an opportunity to improve efficiency and care for the increasing volume of patients.

Hospitals have come a long way, however, the many transformations and advances in the hospital has led to the barrenness and stressfulness of today's hospitals. ${ }^{64}$ Crammed and isolated places can cause people to be stressed. Research has shown that stress is destructive to our health; stress affects the immune system and its capacity to heal. It slows healing and, prompts the body to more severe and more persistent infections, and compounds the effect of illness. ${ }^{65}$ This is especially important to consider in a hospital environment as illness is a catalyst for fear and stress. Hospitals tend to devote more attention to the space designed to house machines rather than to the architecture for people's wellbeing. It is time to start designing for our wellbeing; place influences one's wellbeing. The hospital should be a bridge to health which aids in recovery. It is the children whom spend weeks, months or even years of their lives at CHEO which require the hospital to be more than just a machine. Many of the children are isolated to their designated floor. At $\mathrm{CHEO}$ the 


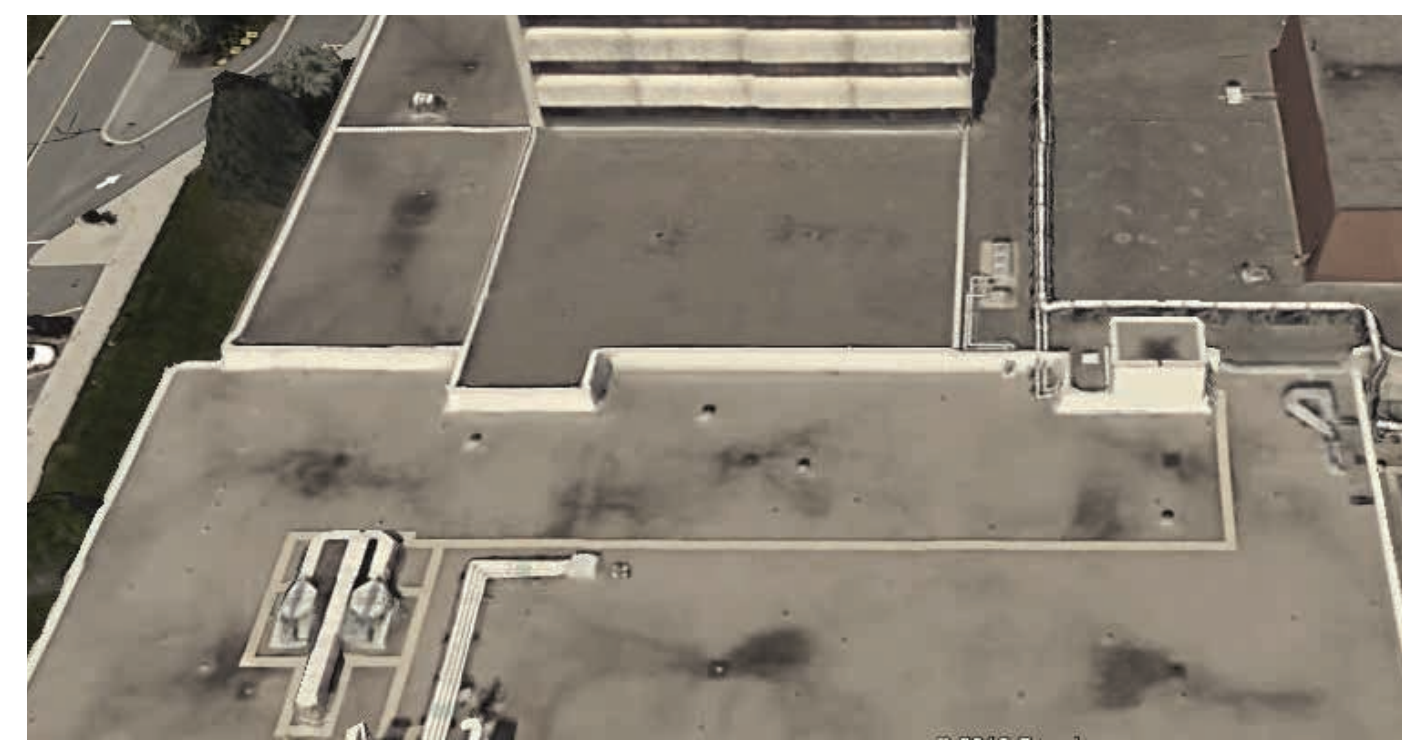

FIGURE 16 most populated inpatient floor is the fourth floor, which happens to be eye level with a daunting view of a vast industrialized hospital roof (Figure 16, 17, 18). The fifth floor is a mix of inpatient, medical and surgical spaces and the sixth floor is mental health, which is in complete lockdown. Level four to six is in the 'tower' of CHEO, all of which only have a view down on to the intimidating hospital roof (Figure 19).

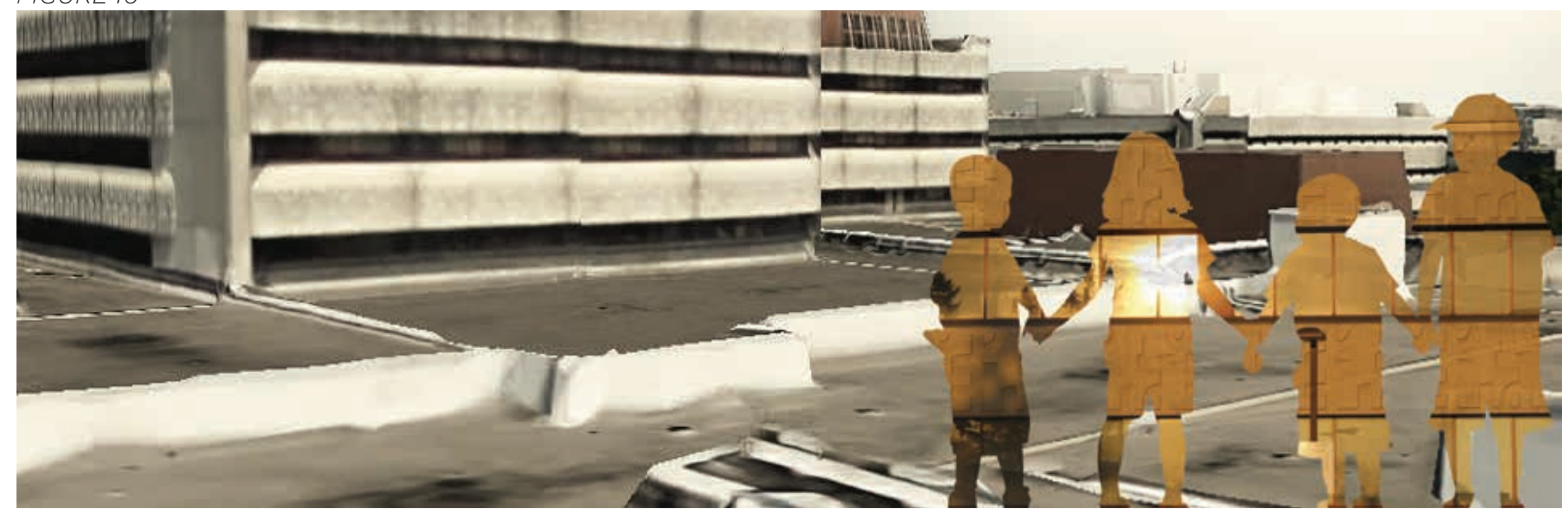


Aesthetic design is not just a matter of artistic expression-- together with other factors, it can improve, or damage the health and wellbeing of people.

CHEO, is a place for improving the human condition and it is important that the architecture also reflects this. CHEO indeed has virtuous intentions and is always looking for ways to improve the human condition, as seen in their Zen Garden project. However, if a patient wants to go there, if they can even leave their floor in the first place, they must face the challenge of navigating through the anxiety provoking hallways. I myself was lost in the hallways of CHEO not even knowing which floor I was on, trying to get back to the front door; a very intimidating experience. Imagine what a child whose senses and emotions are even more affected by their surroundings, trying to gather up their bravery to roam through the hospital. If they make it past the first challenge, they must then walk past two large parking lots, then cross the street of the emergency lane where all the ambulances come and go, then they go past the 'danger helicopter zone', to then only be situated at the back of the hospital where the helicopters and ambulances come and go (Figure 20).
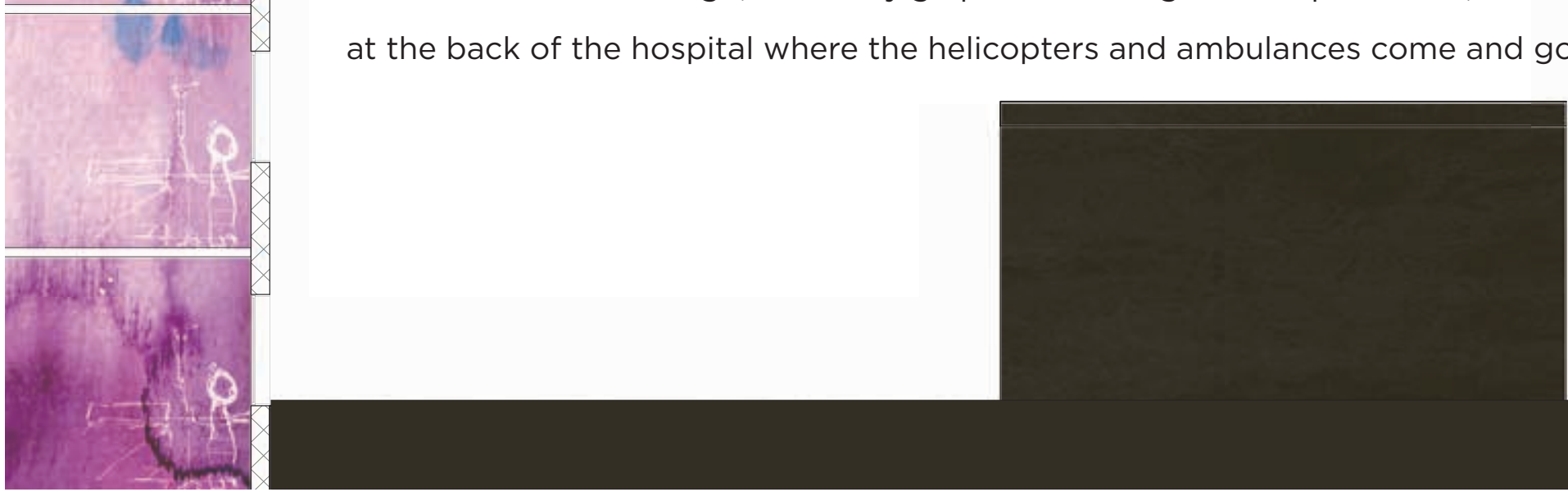

FIGURE 18 


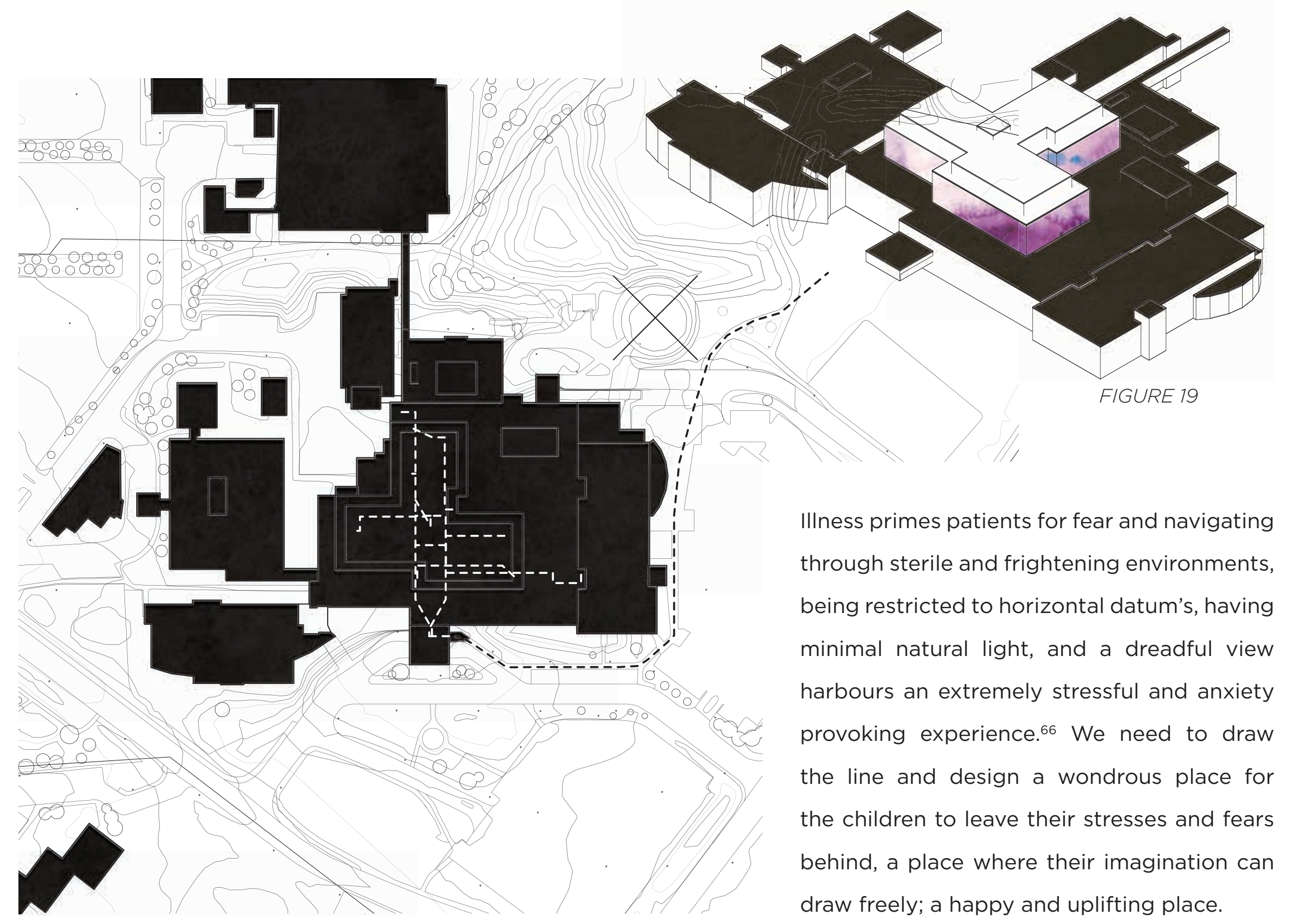

FIGURE 20

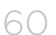


CHEO's external exterior façade contains the notion of drawing on and around its building envelope (Figure 21-24). The building has an intuition which is not yet achieved as it is presenting a static image. The design of CHEO has optimistic intentions, as the architects described their concept as a building designed to respond not only to the physical but to the mental and emotional needs of children. ${ }^{67}$ We design and build architecture that ends up shaping us. ${ }^{68}$ This thesis carries that notion throughout its design. The design is concerned with wellbeing and human understanding of the lived experience through drawing - to allow the children at CHEO to find a voice through art.

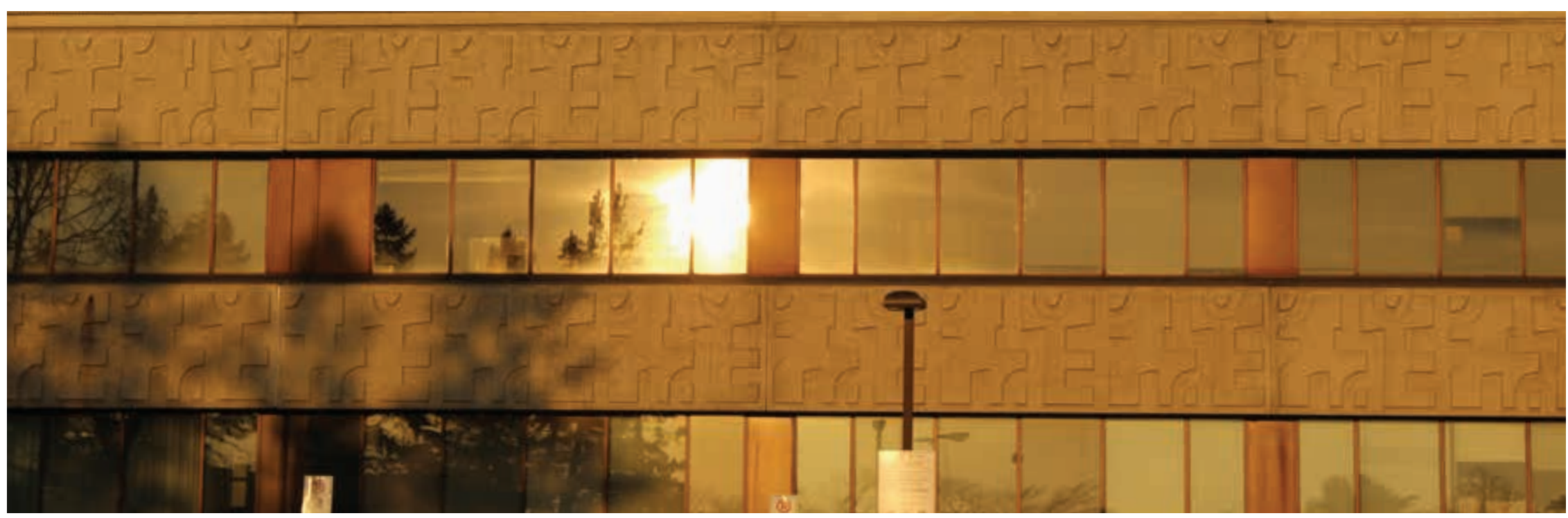



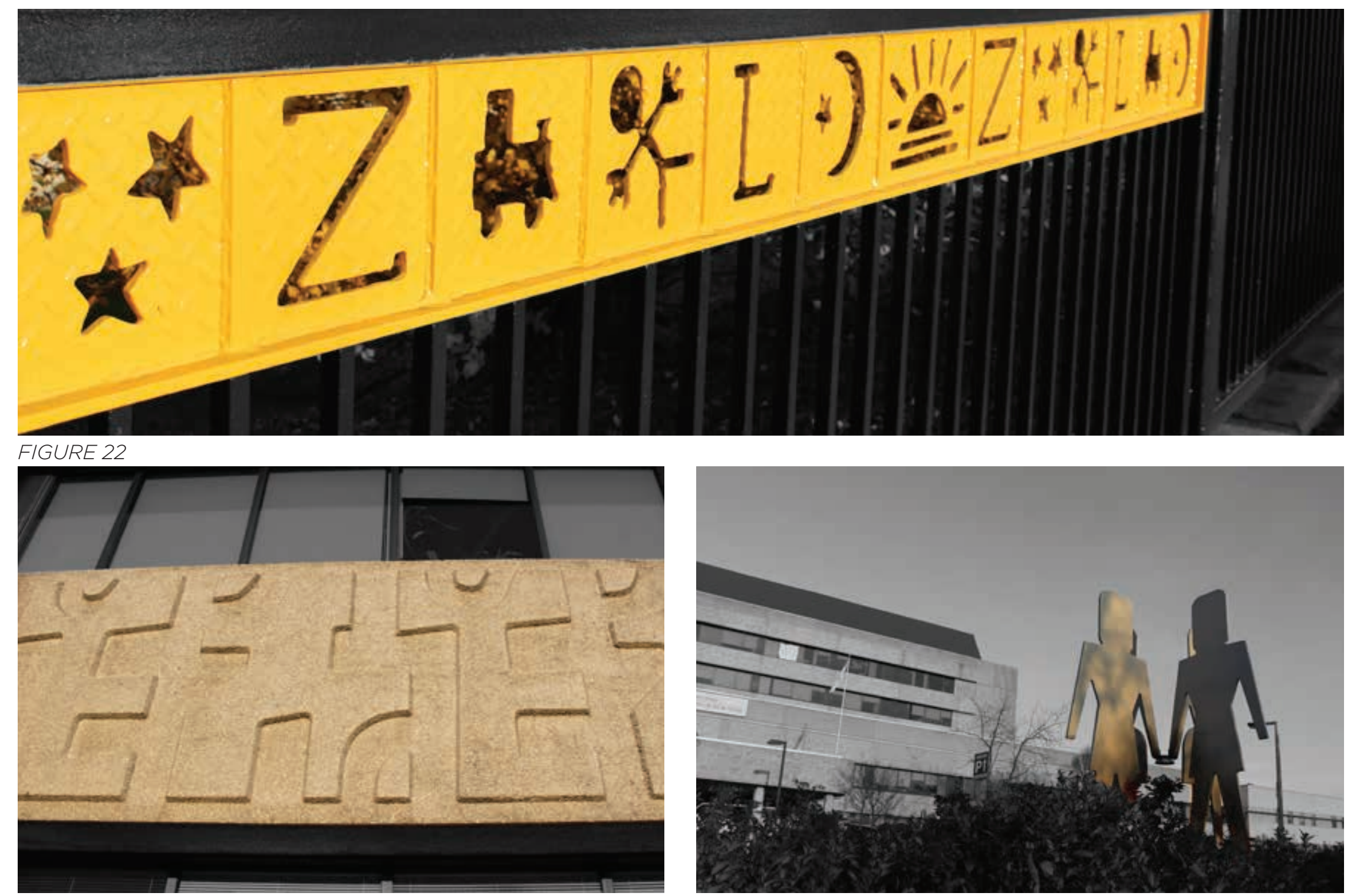

FIGURE 24 


\section{EMOTIONAL DRAWINGS IN CHEO}

The foundational phase of the project is a minor interior renovation to the existing hospital which will allocate spaces for the children in the hospital to draw, to be creative, to be free. The design of the interior renovation was primarily based on existing research in the field of Neuroaesthetics; before the interaction with the children and intellectually disabled artists was conducted. This allows the storyline of the proposal to be more realistic in terms of how it would unfold. This phase allows more drawings to be conducted in addition and parallel to the research drawings in this thesis to guide the design of the addition. This also allows the project to have presence at CHEO almost immediately.

Atmosphere is determined by experience and to make people feel like they are going somewhere, this phase will be laying out the canvas for things to happen. The children will be given the role and the control of helping design the addition to come; their drawings are concerned with the articulation of space. By imagining things, they are inhabiting the addition already. They are 
constructing their dreams through drawing. Every drawing produced will also be subject to being analyzed by researchers of interdisciplinary fields, coming from all around the world. All the drawings will be electronically archived, capturing a moment in time-time is art. Every drawing captured will be involved in the design of the addition and will be projected onto the skin of the new building, creating a digital quilt of all their drawings. Each drawing projected translates into moments and fragments of the mind. Drawings can reveal what is yet to be exposed. Having the power of what kind of spaces the children will inhabit allocates purpose to the them and will allow them to put their human handprint into the architecture. Recovery is what people experience as they become empowered in a manner that allows them to achieve a meaningful and positive sense of belonging. ${ }^{69}$

In the interior renovation, the corridors and unfilled spaces will transform into places for drawing. The hallways become an interactive whiteboard surface to draw on the wall, as well as a place for the children to connect with drawings. With the capacity of the interactive whiteboard, children 
can draw using touch, making it more intimate while at the same time saving the hospital funds in crayons, paper and waste. Over 28000 packs of crayons were used last year to help kids pass the time during their stay at CHEO. ${ }^{70}$ Having the existing hallways in $\mathrm{CHEO}$ turn into a drawing surface will allow the interior space to become more creative and wondrous; a place to express one's emotions. There is harmony which resides in the delicate proportions of the repetitive pattern in the corridors (Figure 25).

Existing spaces in CHEO will be transformed to allow the children to be creative: drawing with shadows, with light, with drawing tools and their hands (Figure 26). It is a place where the sunlight draws shadows for the children to play with, a place where they are free to draw on the walls and floors (Figure 27). The drawings will inhabit the walls in a state of transition, as progress drawings just before they enter the drawing archive and thus the addition of the project-entering the drawing of another. 


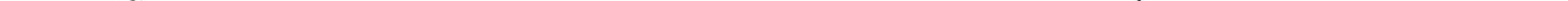




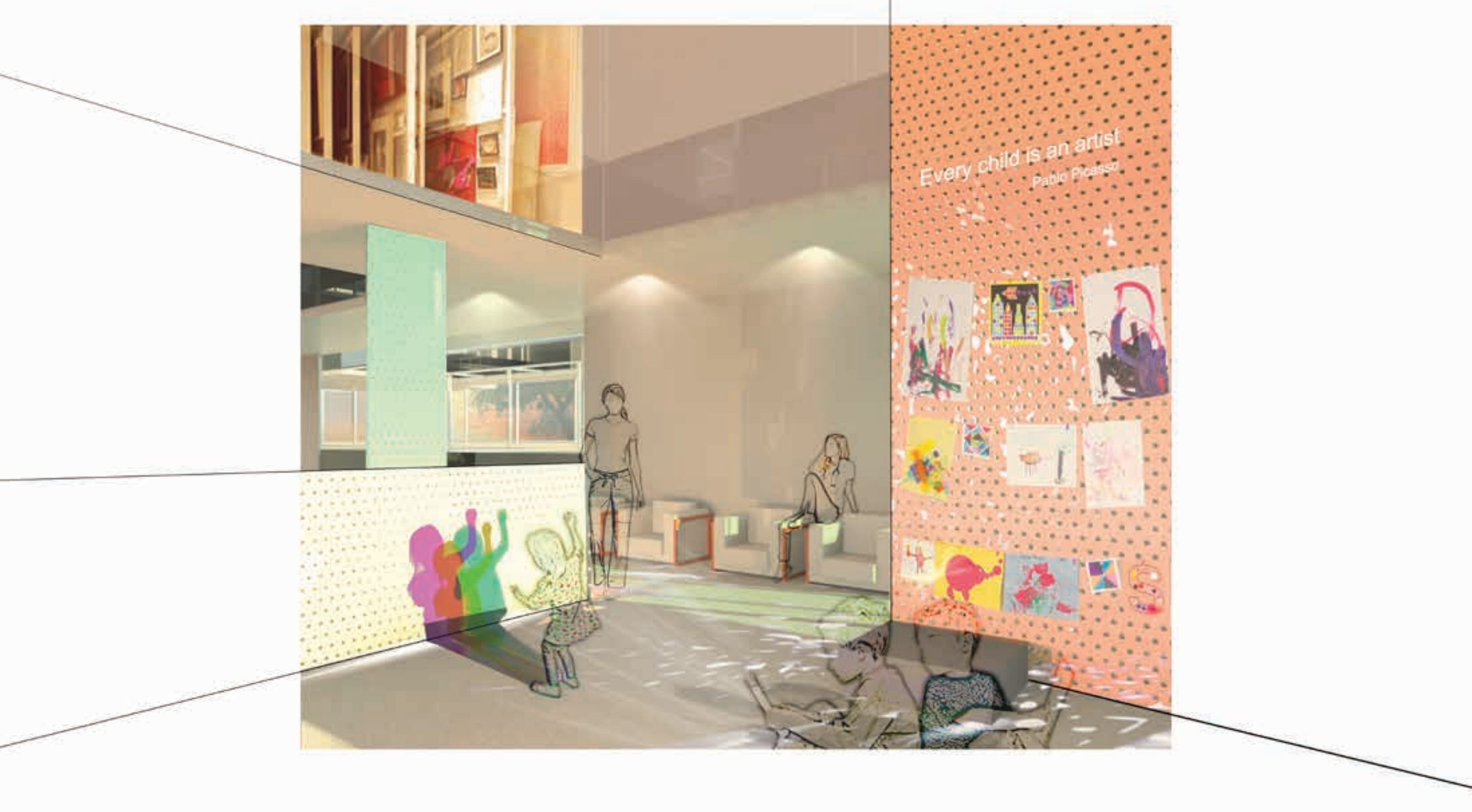

FIGURE 26 


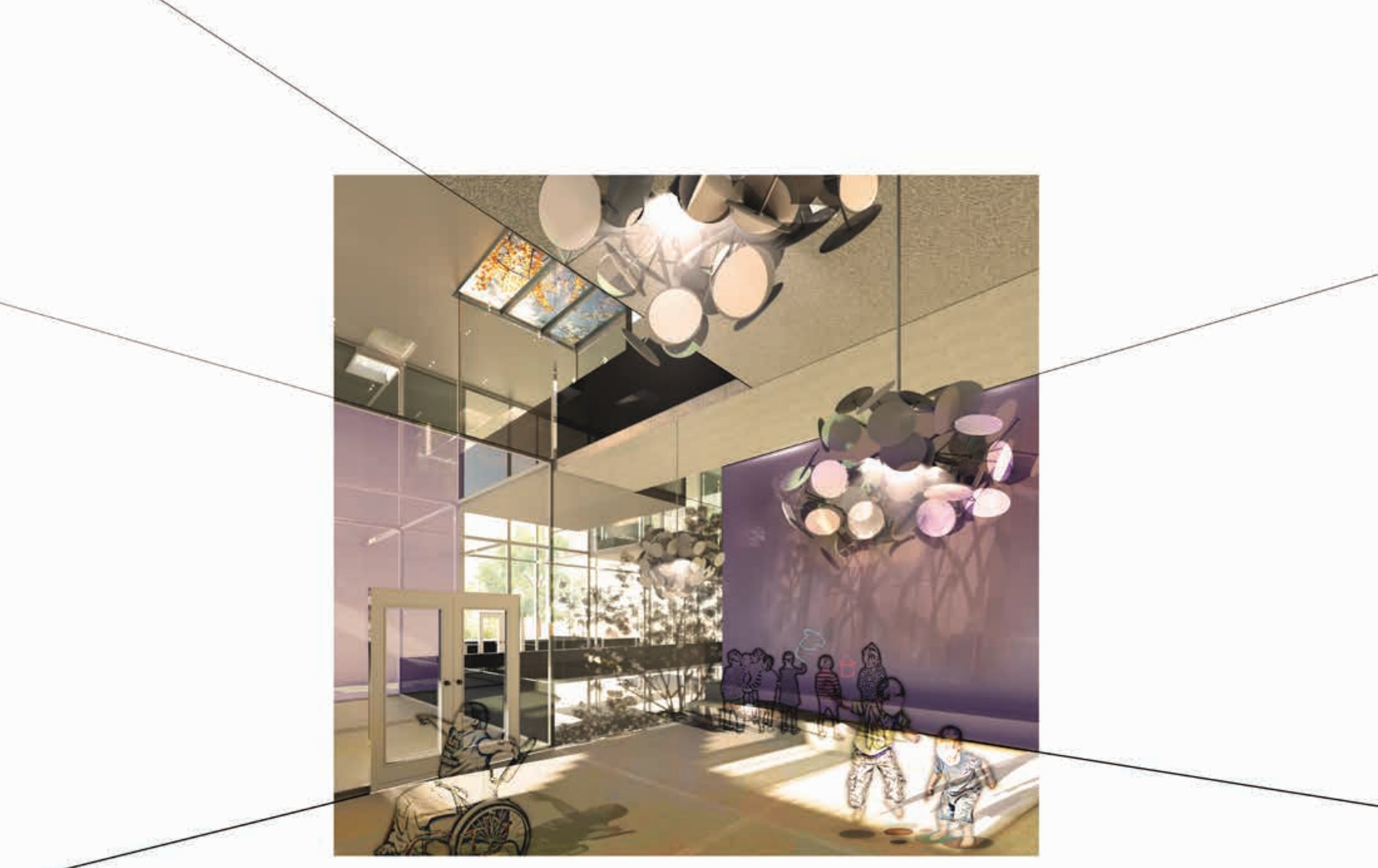

FIGURE 27 
Thereafter, the current Zen Garden at CHEO will evolve onto the barren rooftop (Figure 28). Having the garden accessible to patients whom are trapped on their floor will bring reams of benefit and it will also give the children a calming view out of their windows. This enhances their connection of nature, it is a way to connect inside space with the world outside, in normalization. Also, a study published in Science Magazine showed that healing would occur more rapidly if patients in hospital rooms had windows looking out on nature. ${ }^{71}$ Comparable in importance is access to natural daylight, which was considered in the process of locating the volume of the new addition. Looking at the site plan, CHEO is partially surrounded by other large buildings of the hospital precinct, as well as a residential neighbourhood. Nevertheless, the most unobstructed view is towards south east, which faces many green parks (Figure 29). As well it is the sunniest location (Figure 30). The utmost ideal place for capitalizing on the sun while considering structural integrity is just on top of CHEO's former addition (Figure 37). The approach to massing was inspired by the existing geometry of the CHEO 'tower'. This existing geometry consists of three pods, and the massing of the addition proportionately replicates the south-east pod. 


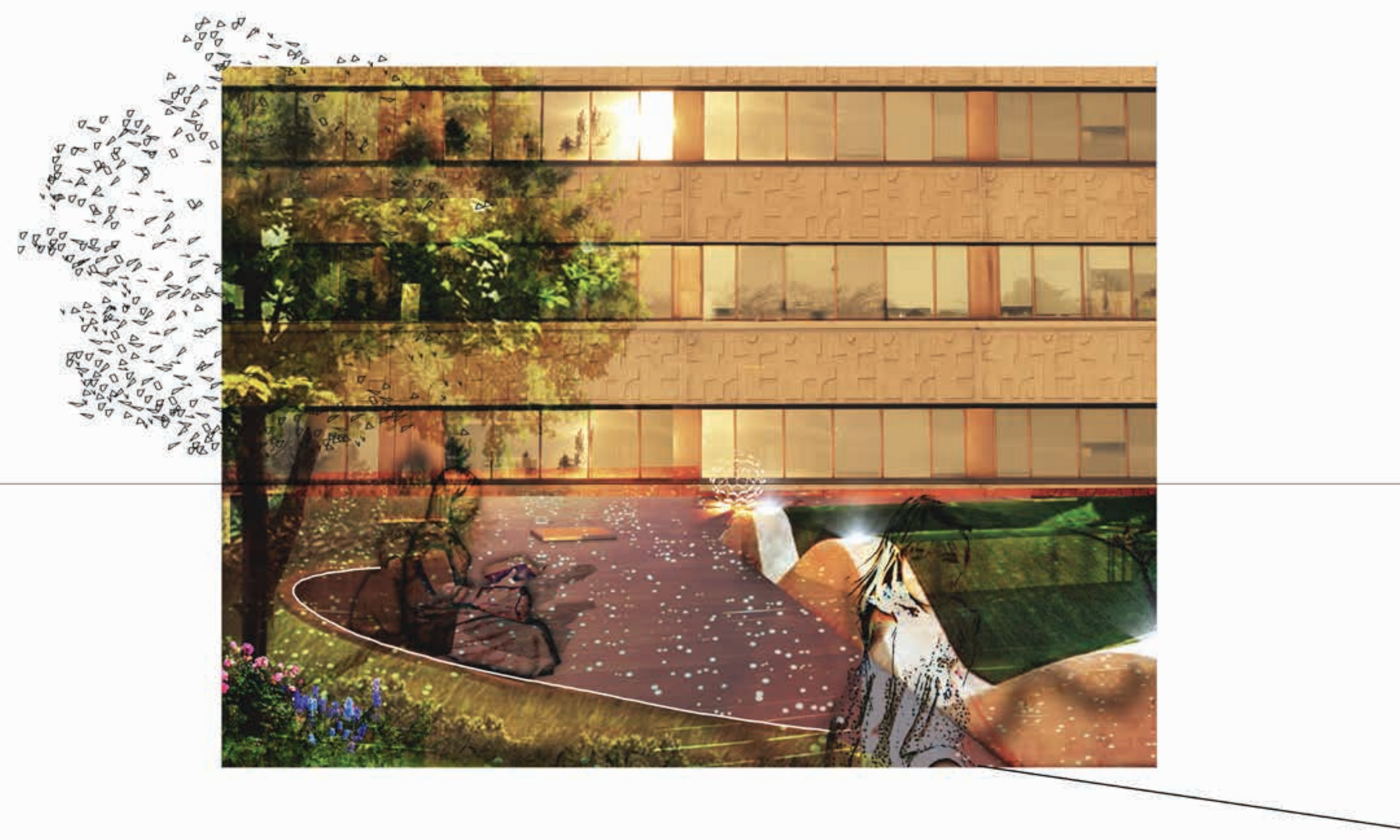

FIGURE 28 


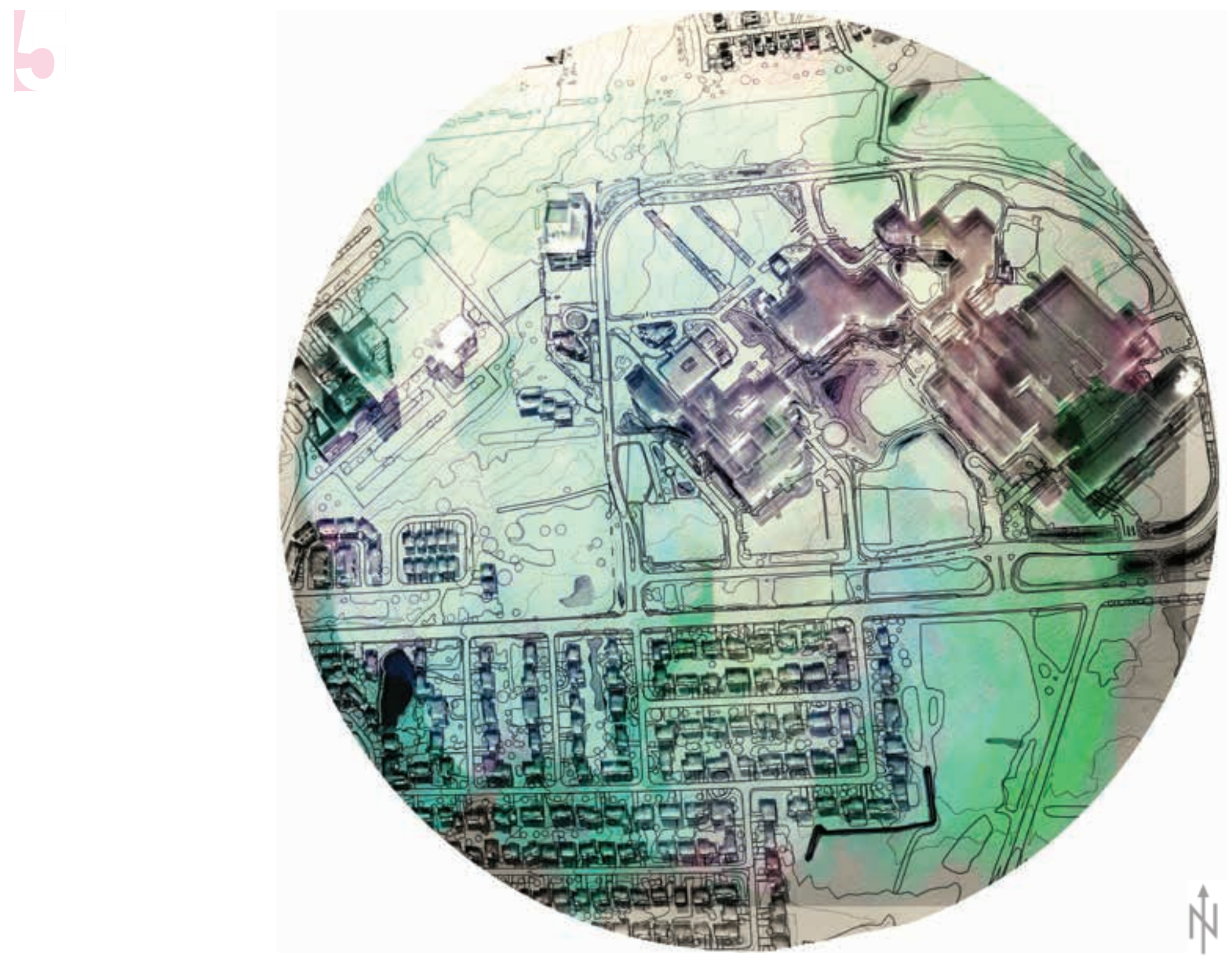

FIGURE 29 Site Plan Model 
Morning
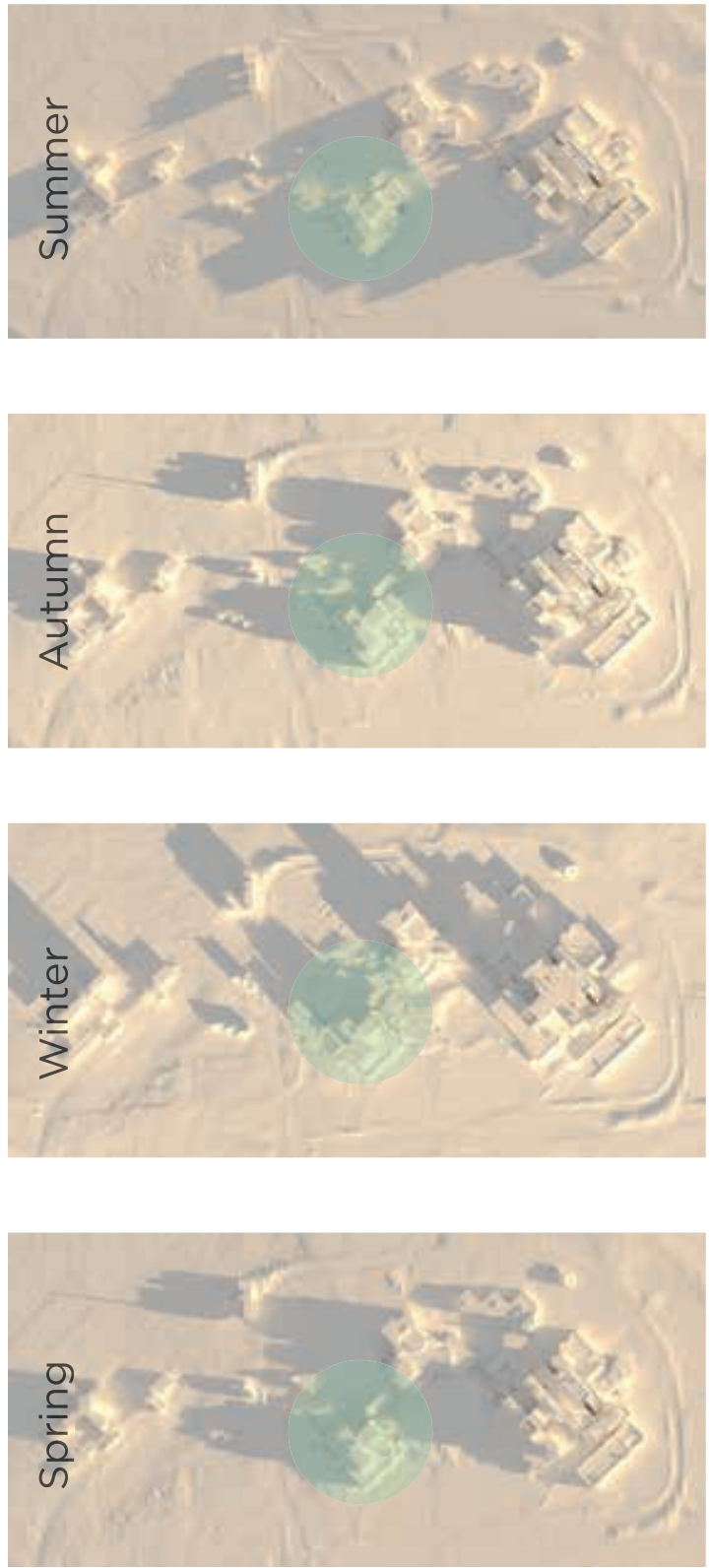

FIGURE 30 Sun Study
Afternoon

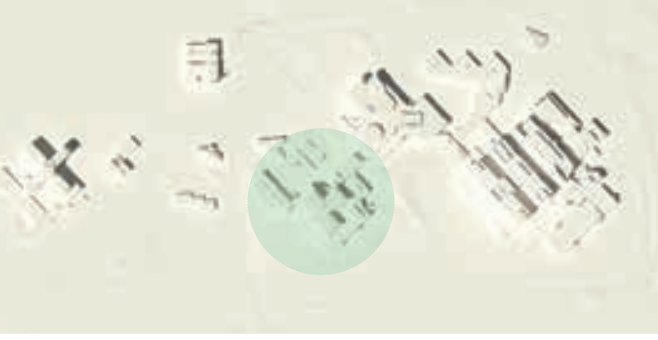
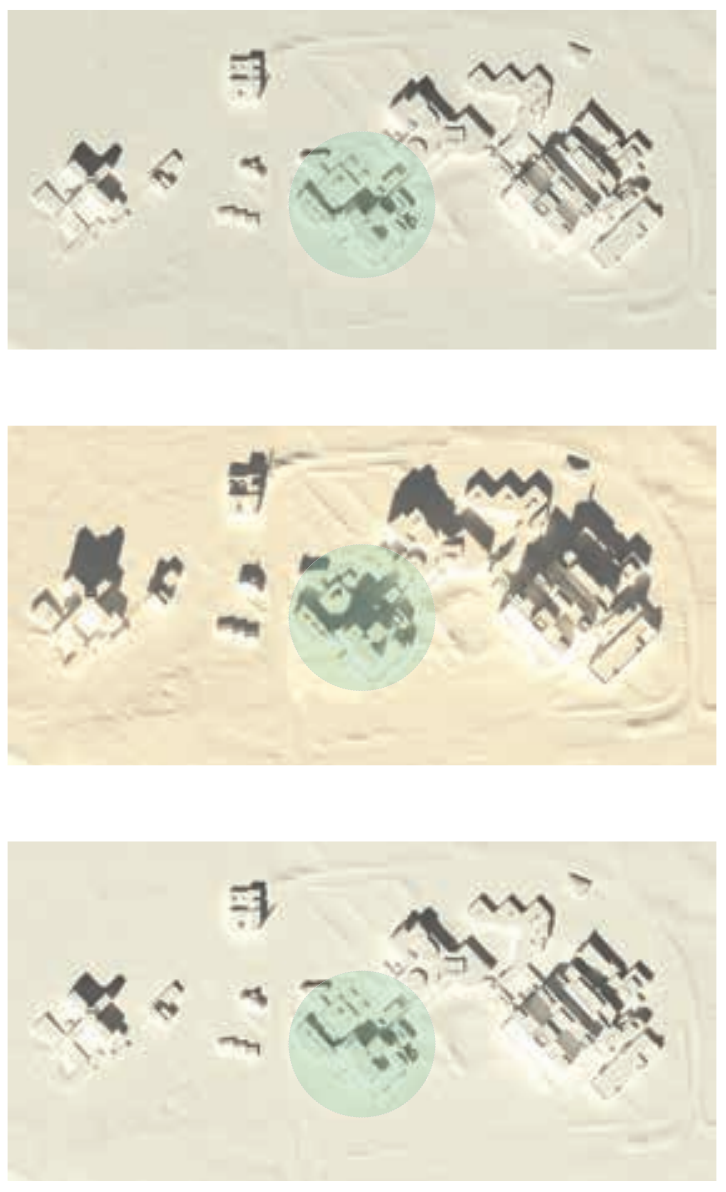

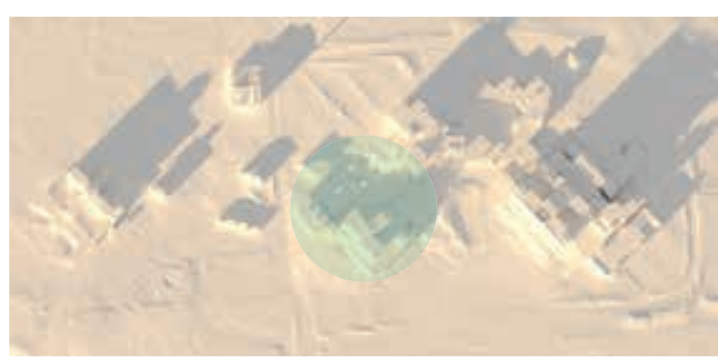

\section{Evening}
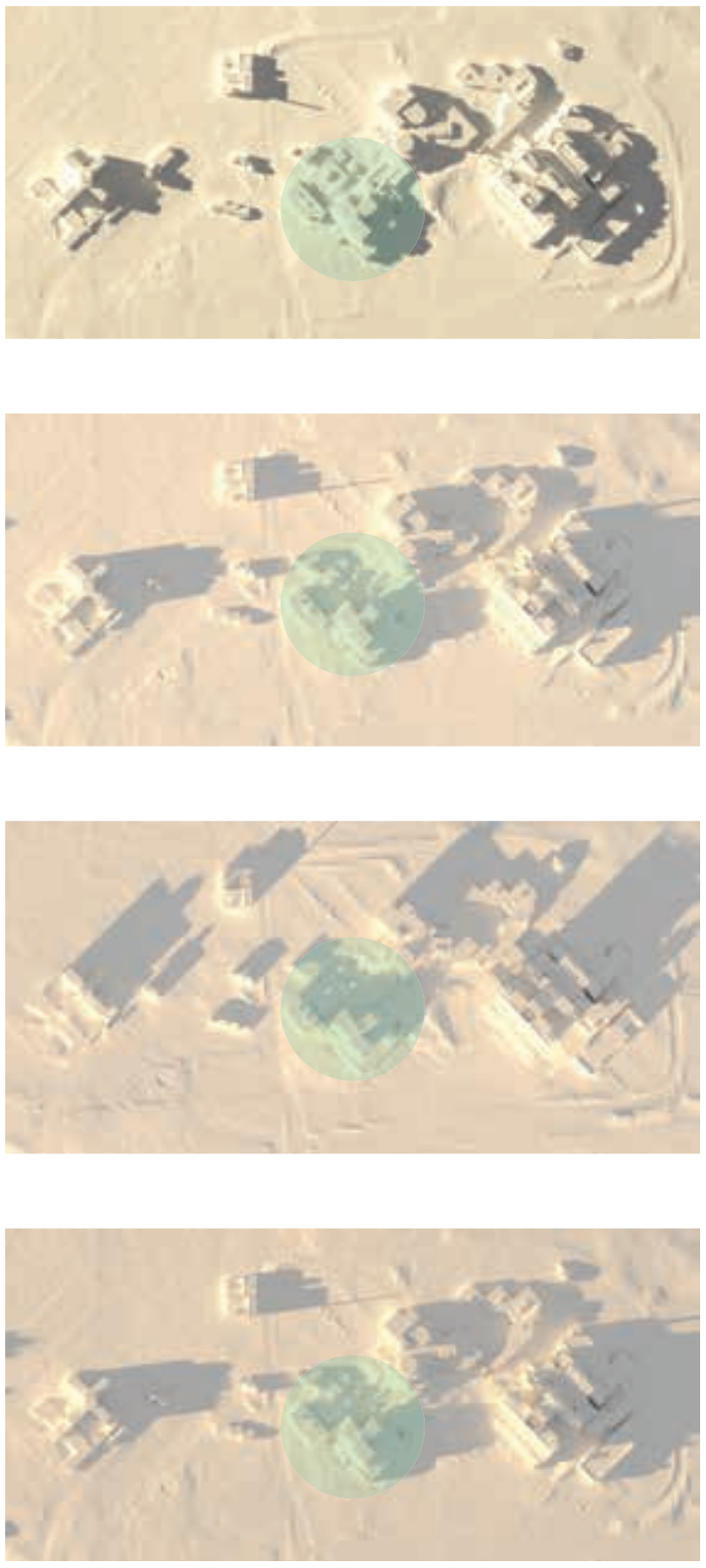


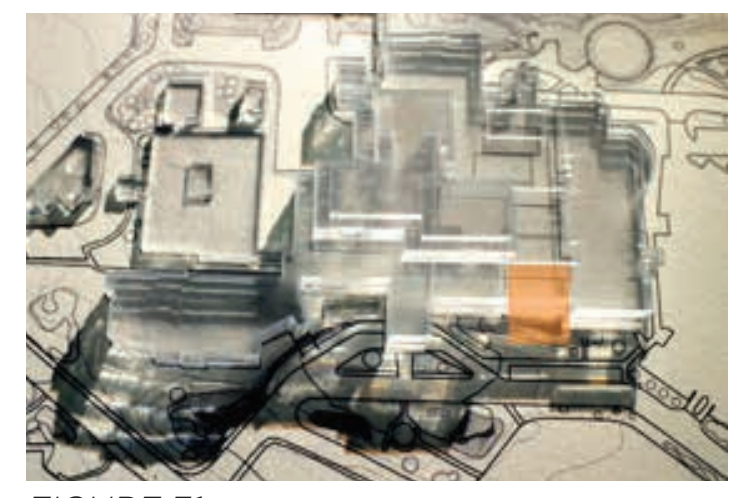

FIGURE 31

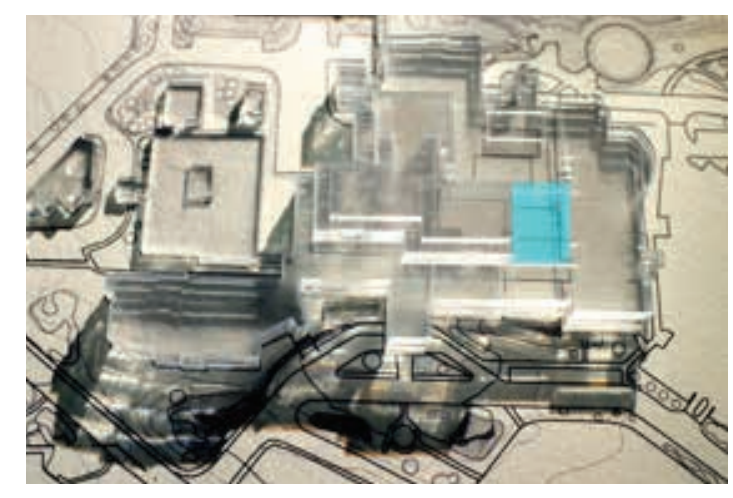

FIGURE 34

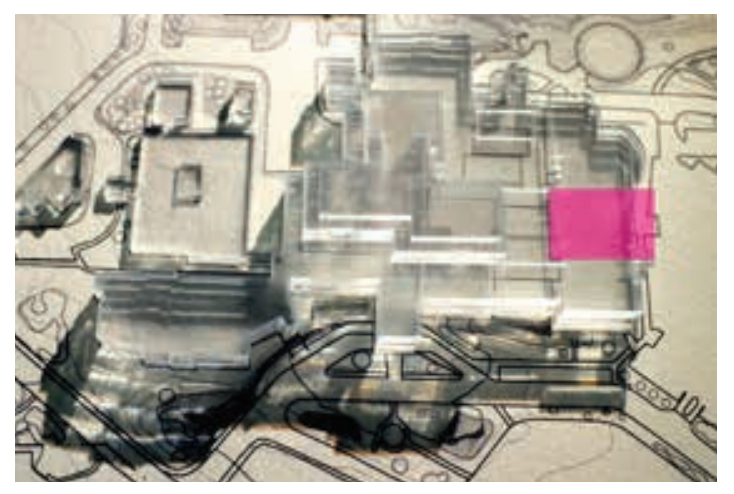

FIGURE 32

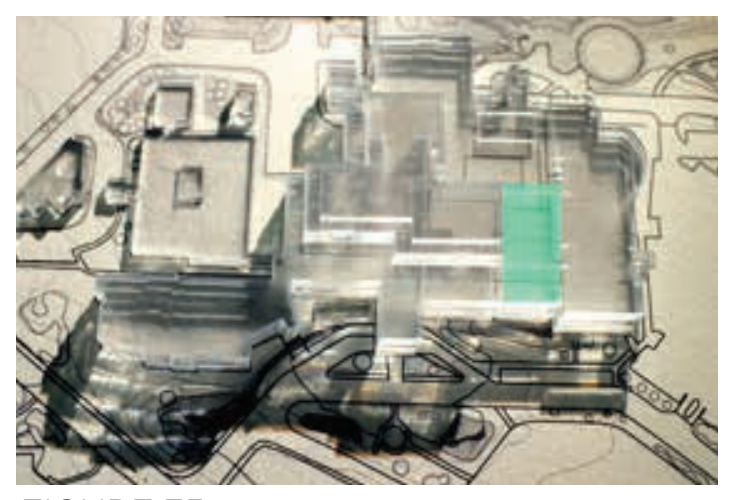

FIGURE 35

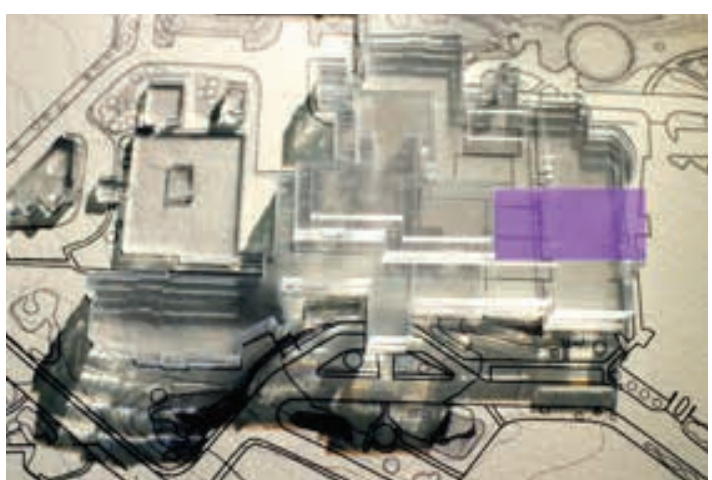

FIGURE 33

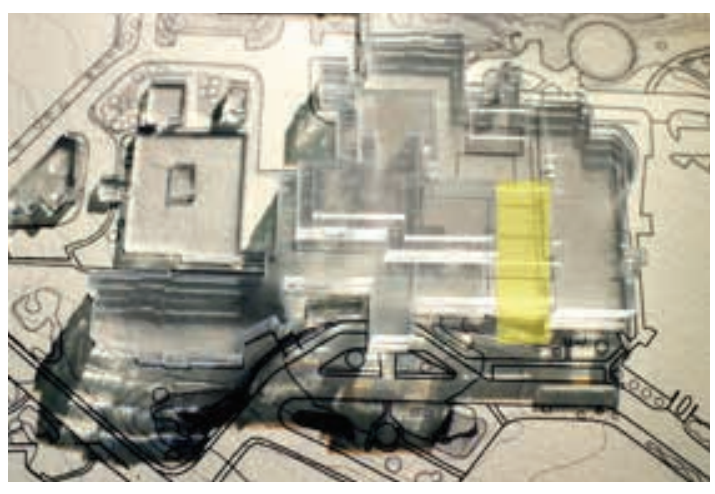

FIGURE 36 
A

D
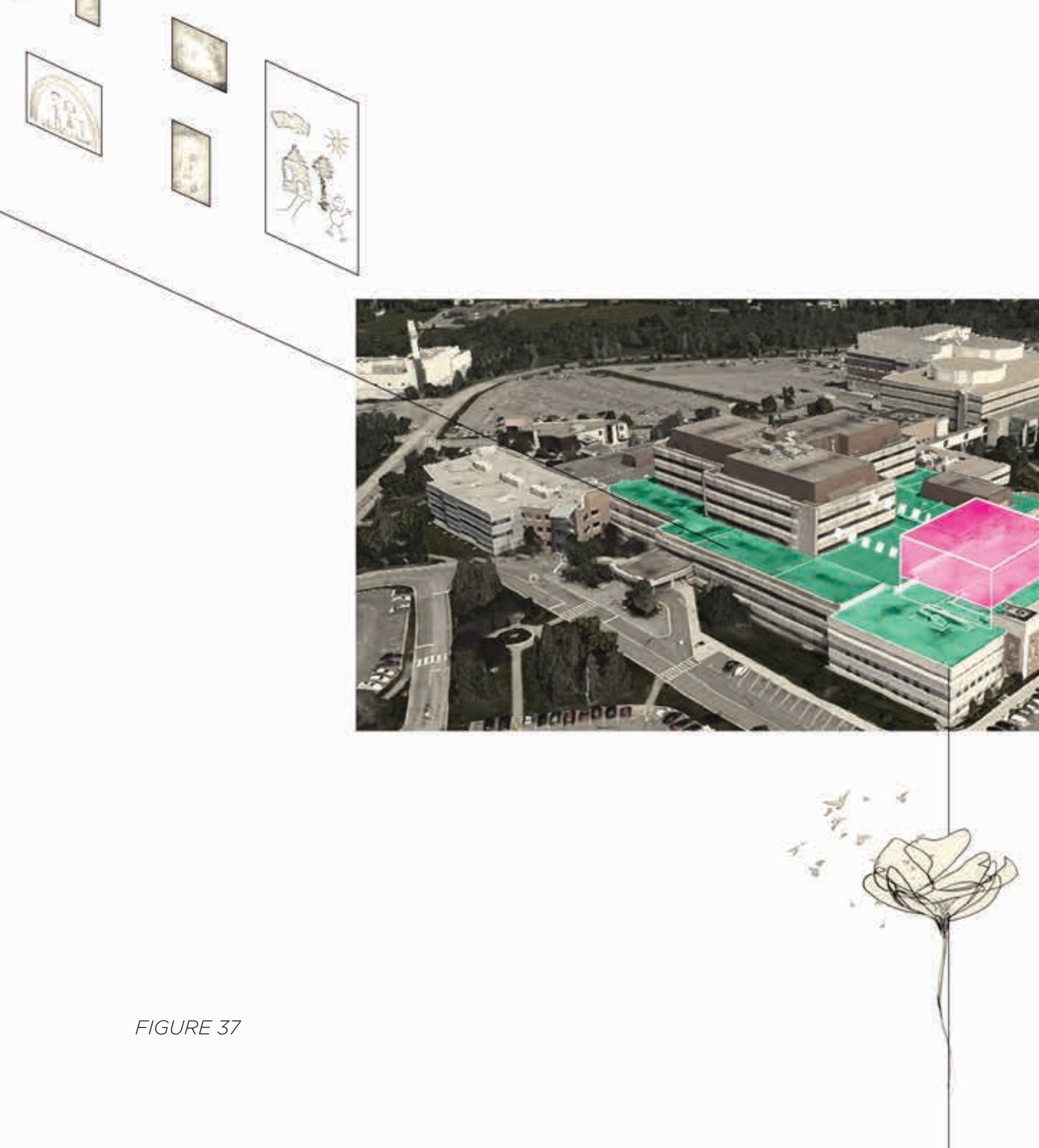
DRAWING ON TOP OF CHEO

Overlaying the drawings of happiness with architecture inspired the design and the program in the addition. Figures 38-43 show the preliminary proposal and the inception of the concepts of the addition. Henry's drawing of his happy place in nature inspired a central atrium, bringing the outside elements of nature into the architectural spaces (Figure 38). There are several house shaped drawings and particularly Anna's drawing of the houses inspired the tree house pods on the bridges which create a homey feeling (Figure 39,40). Many of the abstract drawings of what happiness looks like, are curved or round which inspired the design, ranging from the walls, windows, all the way to the design of the furniture. As well, all the colours in the design are from the emotional drawings of happiness. Moreover, the many children whom are at CHEO for a long time will also find learning centers at the new addition to continue their schooling, which was inspired by Alanna's drawing (Figure 41, 42). As further programming, which also has been inspired from the drawings is a place of reading (Figure 43), a place of quietness, drawing spaces, places to sit, places to shelter, places to be with animals, to be free. A place of happiness and wellbeing; a progressive healing of the hospital. It becomes a place where the imagination can permeate, to inspire wellbeing. 


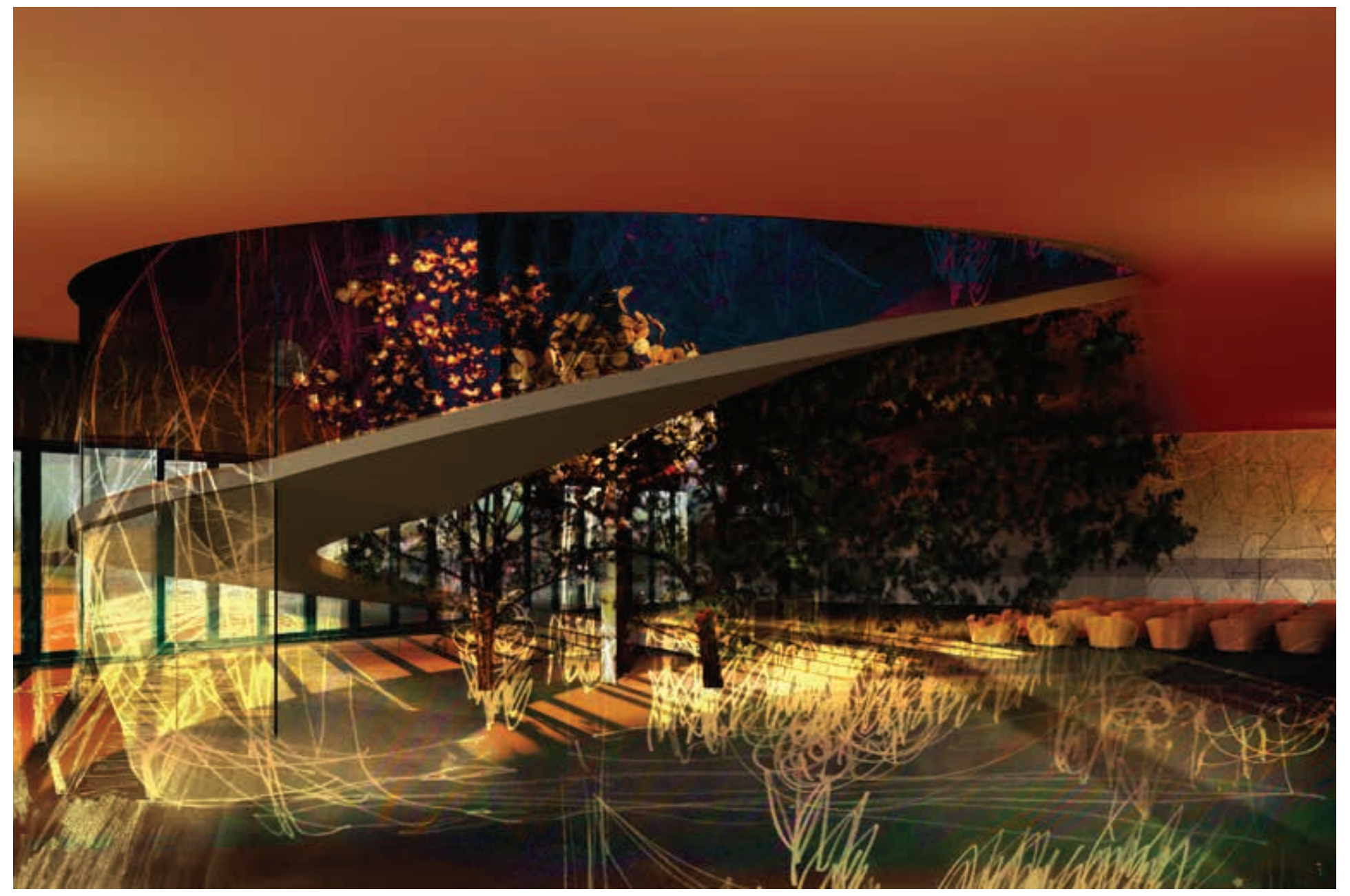

FIGURE 38 


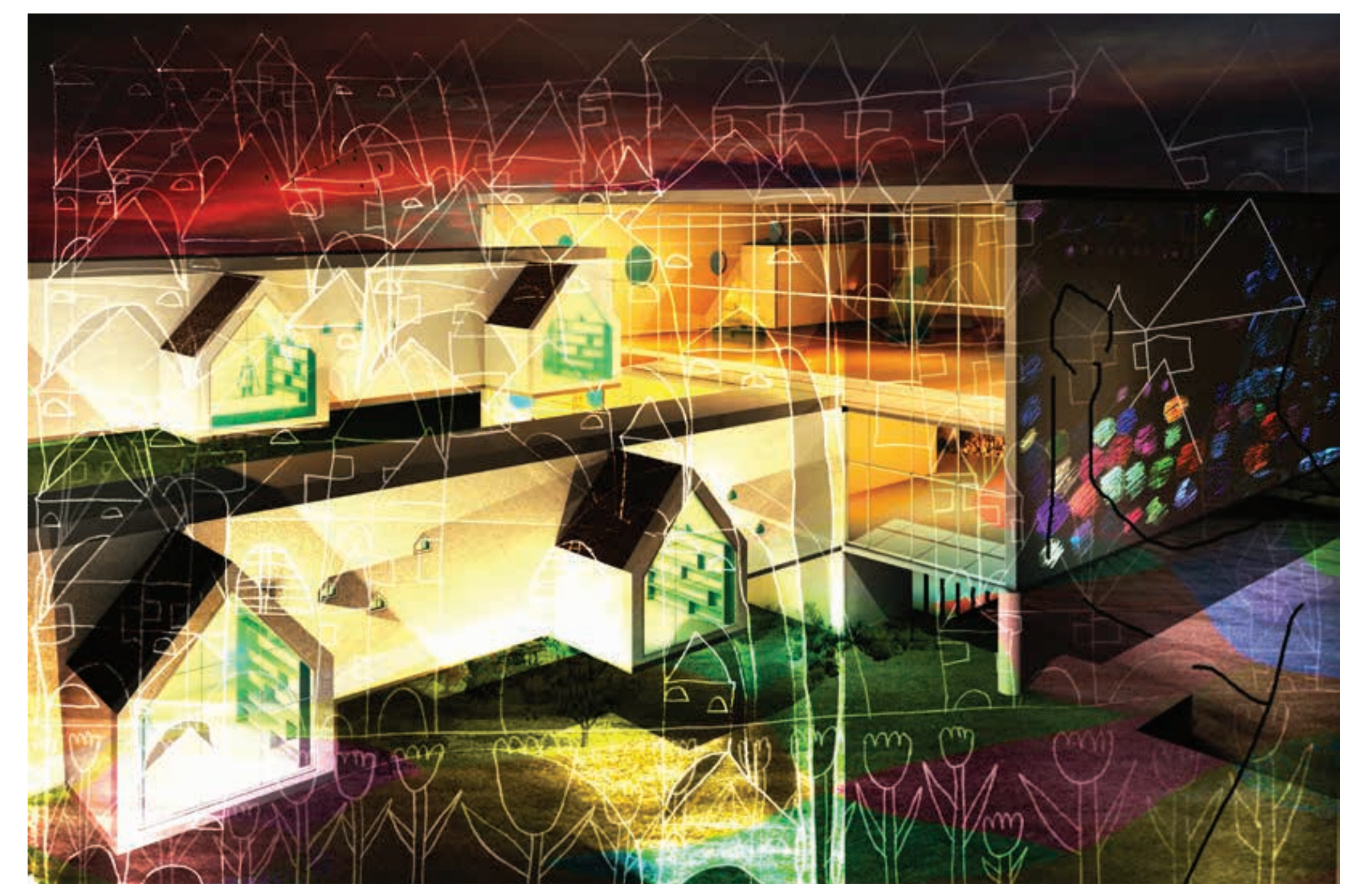

FIGURE 39 


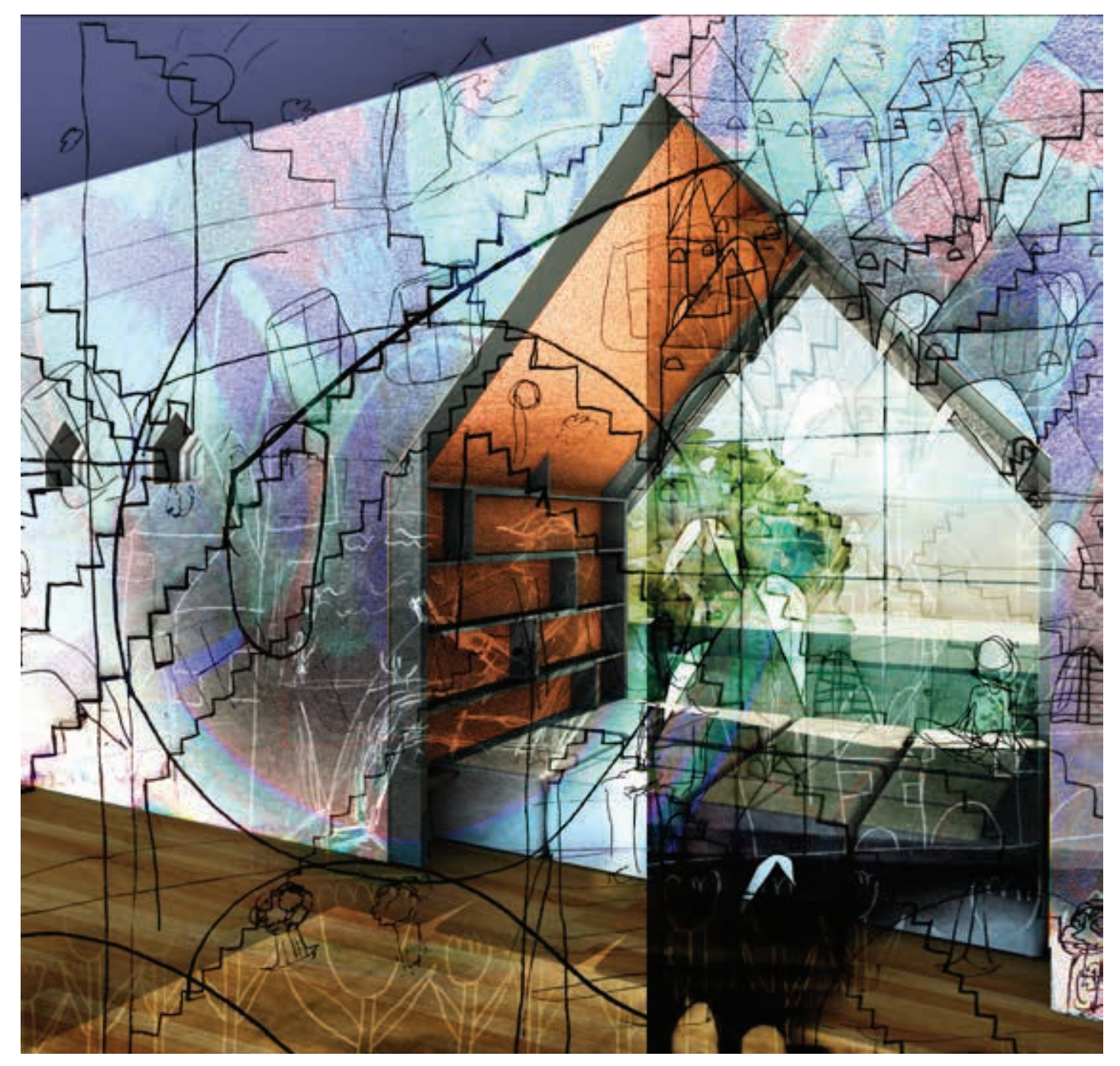

FIGURE 40 


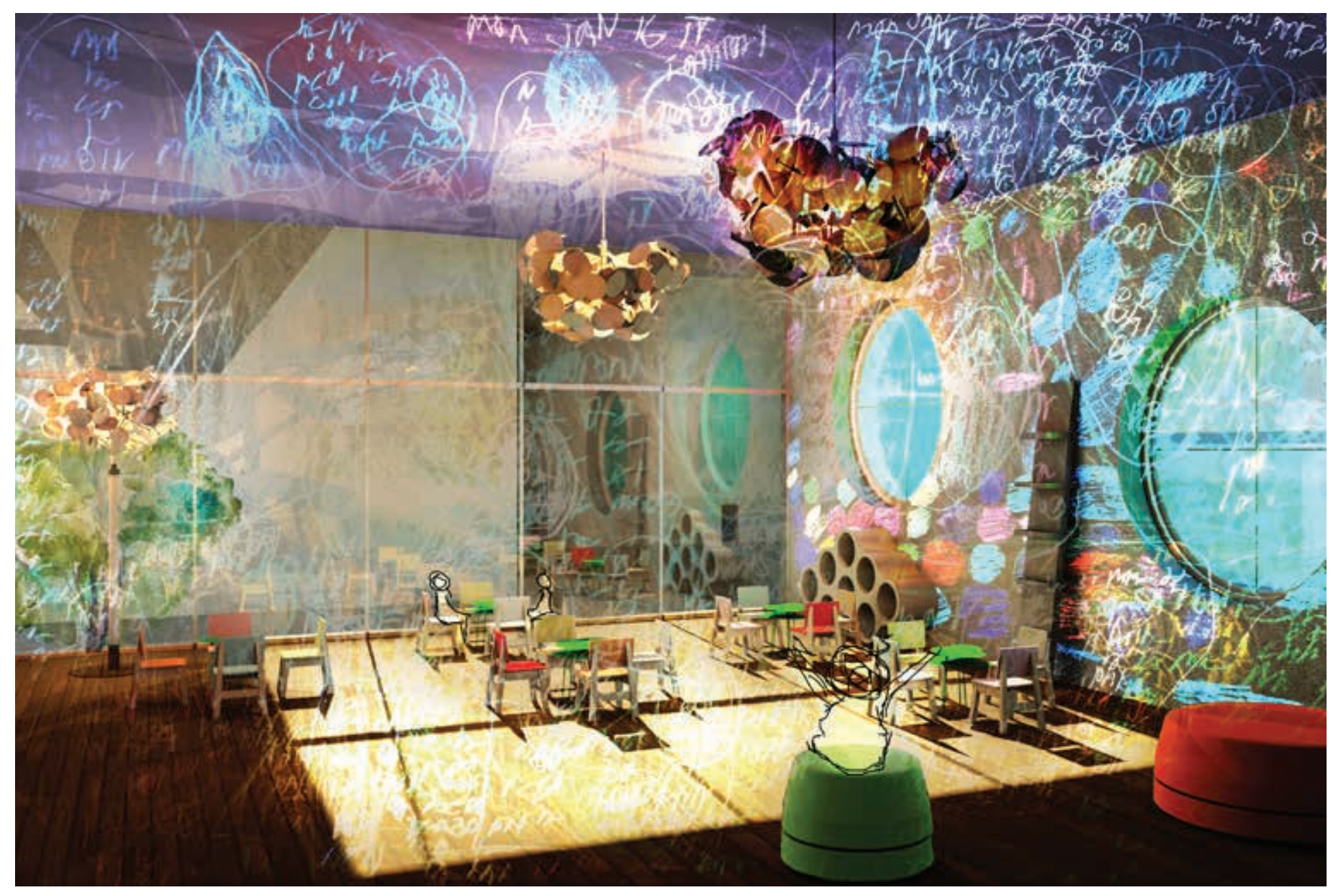




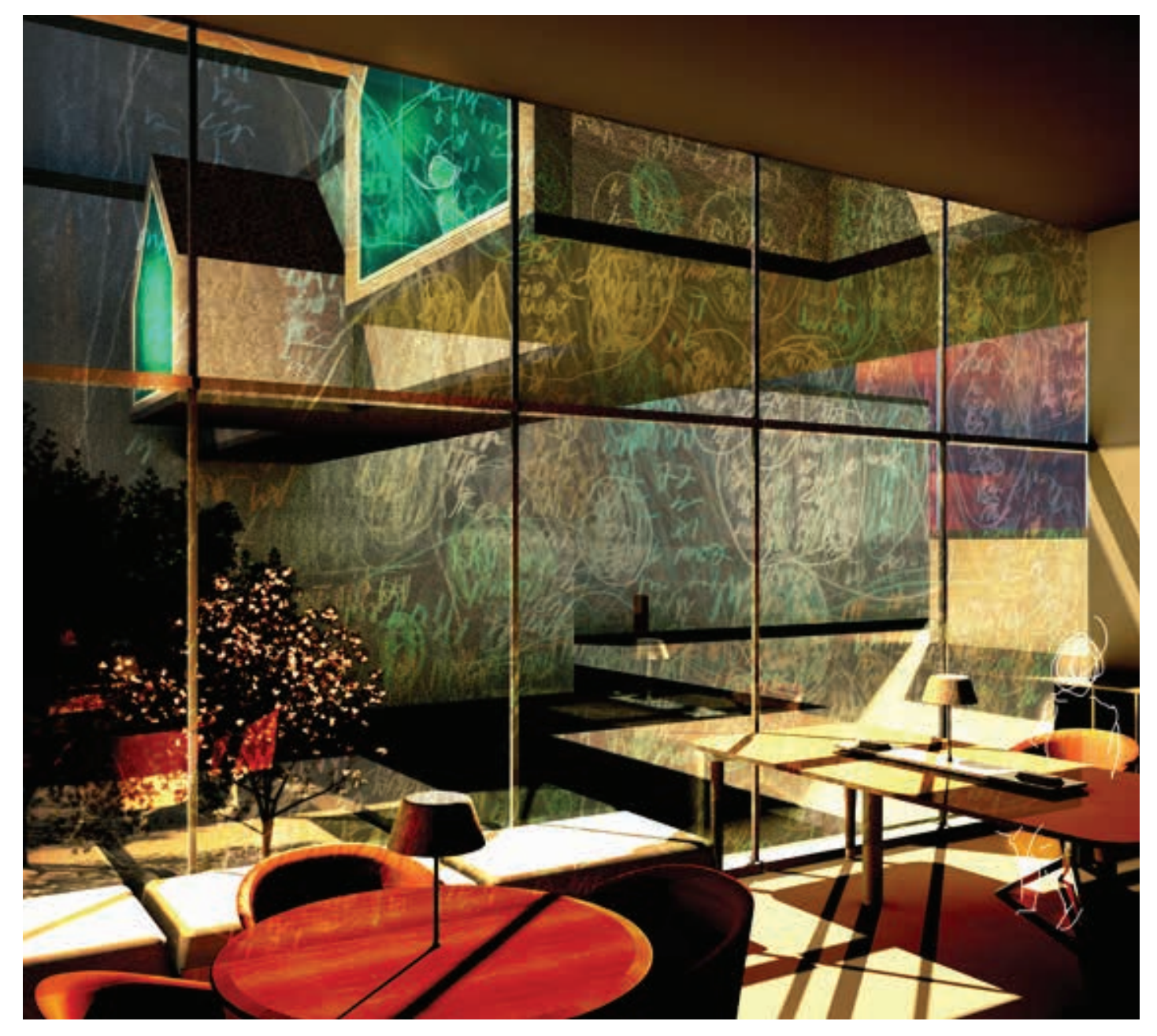

FIGURE 42 


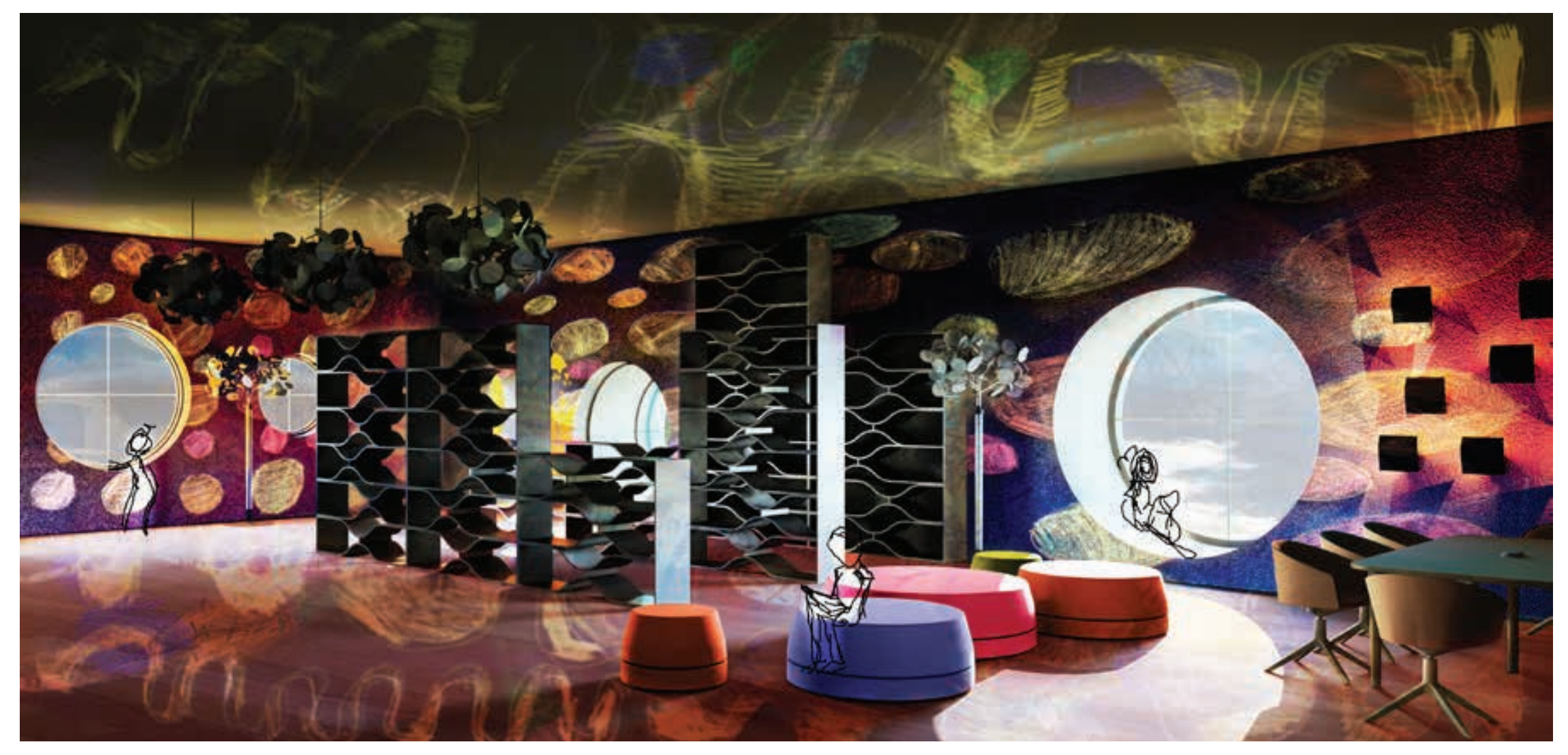

FIGURE 43 


\section{THE ARCHITECTURE OF EMOTIONAL DRAWINGS}

To show every child's hand in the new addition, the drawings being produced in the initial phase, will require archiving, and accordingly a gallery to show a timeline and richness of the process. The addition is the result, as well as the projection of the digital archive of the drawings, thus creating a dynamic architecture of emotional drawings. Throughout the addition there are wall and floor surfaces which lend themselves to the idea of the canvas, as the children draw, their drawings will be digitally archived and projected onto the interior and exterior walls of the addition (Figure 45). The addition is a place to draw and to let the imagination permeate; it is a digital quilt (Figure 46, 47). The drawings produced in the quilt gives the child the ability to step through the threshold between their dreams and the drawing of another. As Marco Frascari said it is in the making of a quilt where many hands are involved; it is a social and collaborative process. Just as in quilt making, the projections of the drawings are a construing; each projection embodies memories of emotion. The digital quilt is stitched from drawing spoils which are translated into a wondrous dimension on the architecture, which carries a new meaning. ${ }^{72}$ 


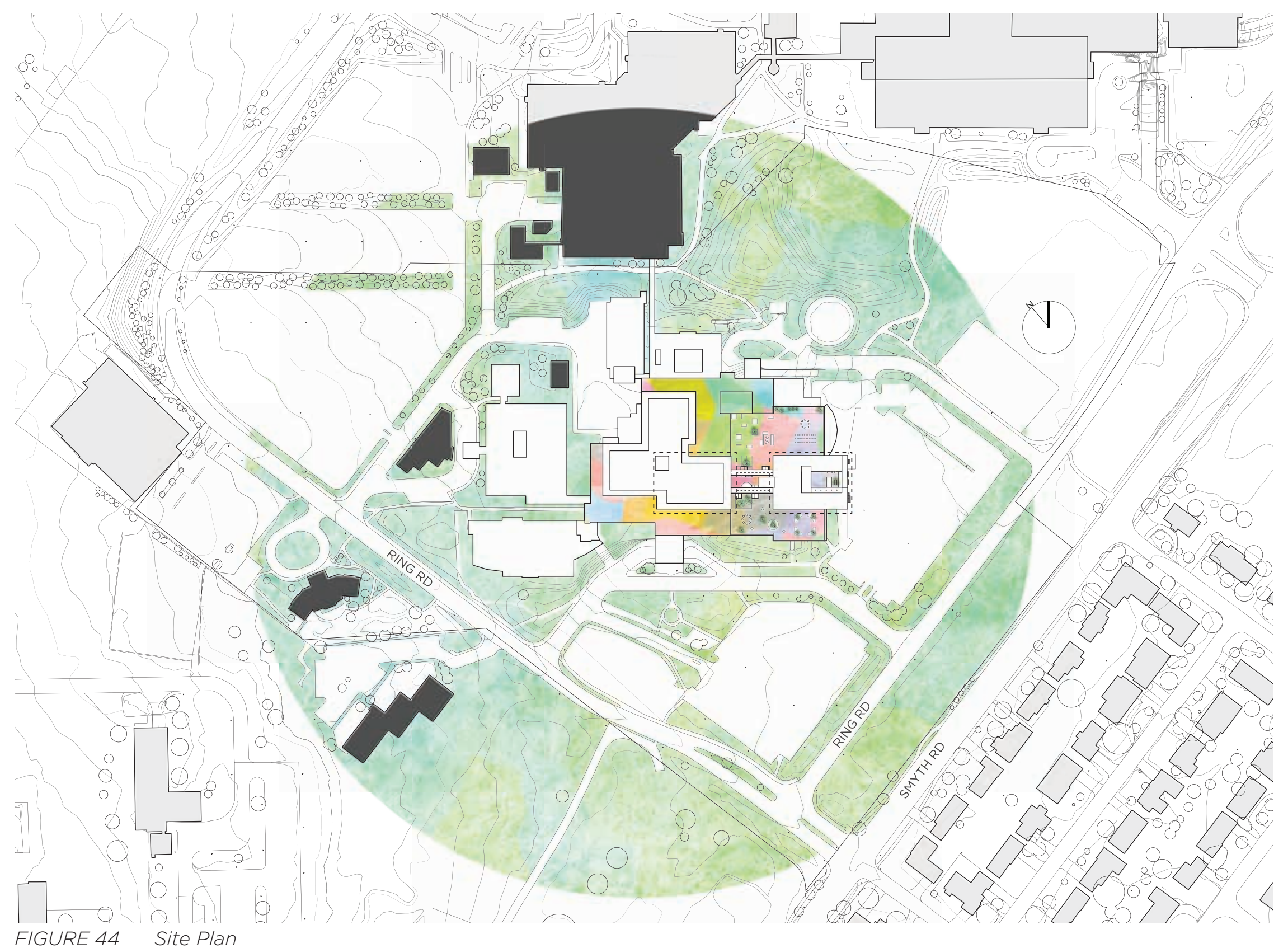




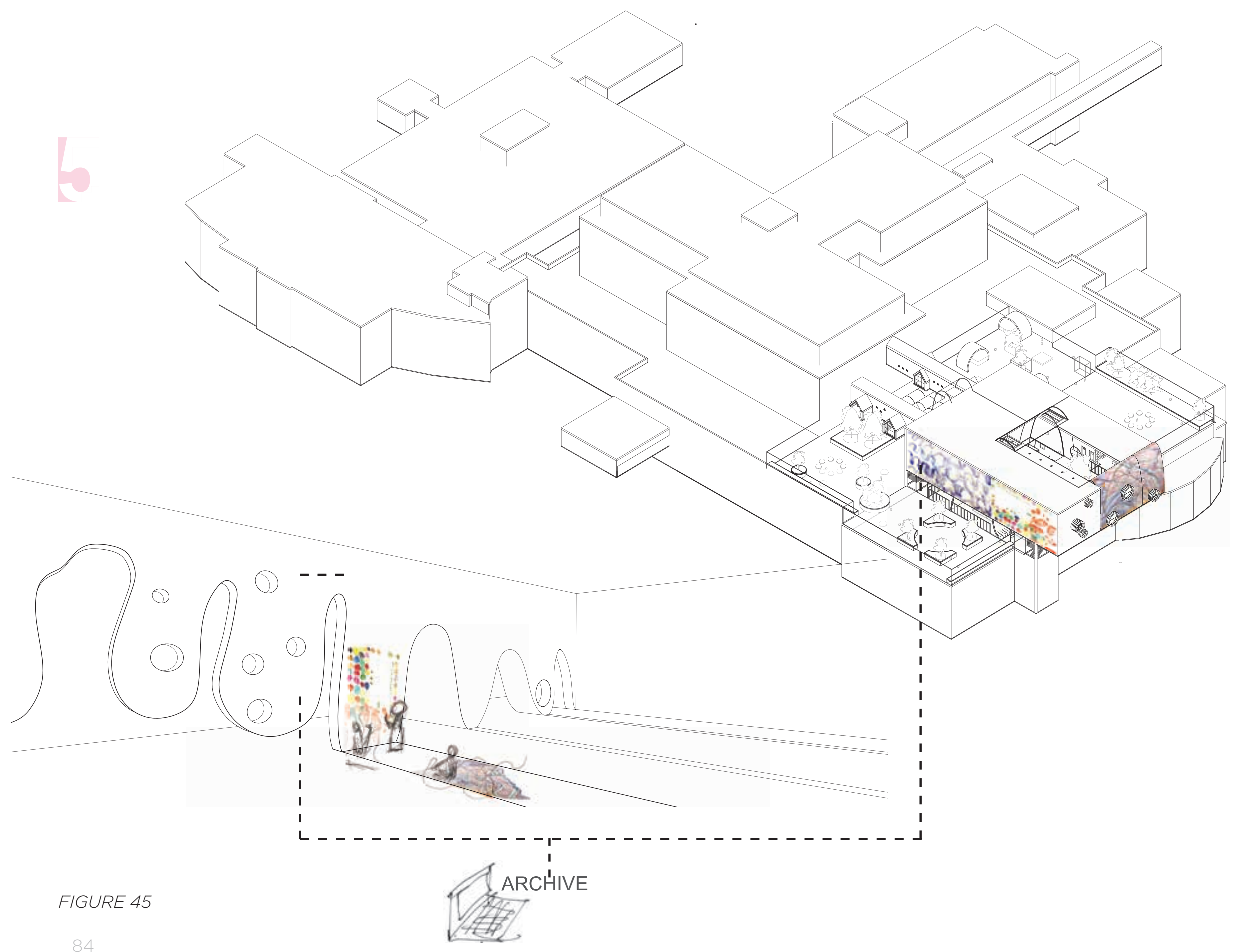



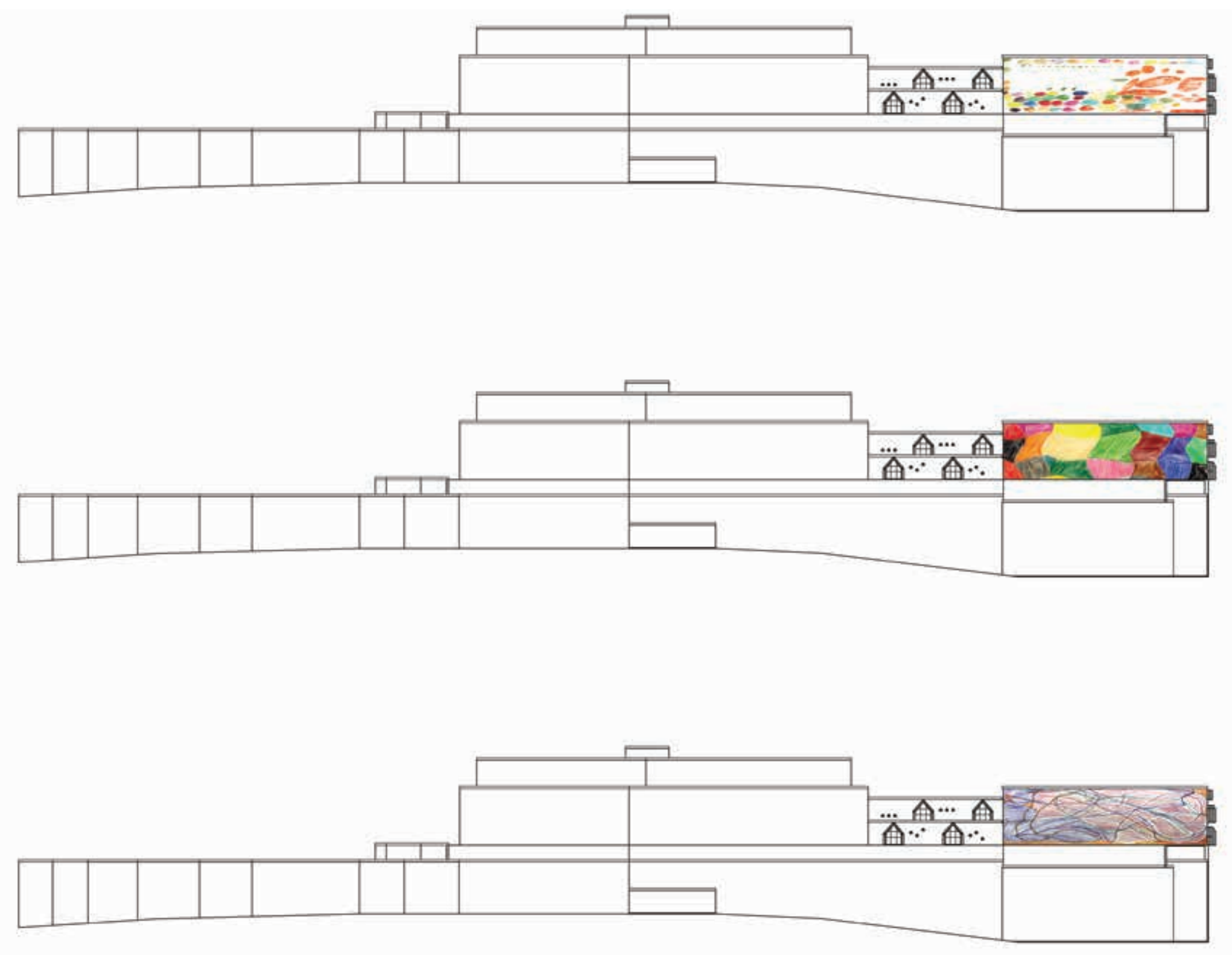

FIGURE 46 

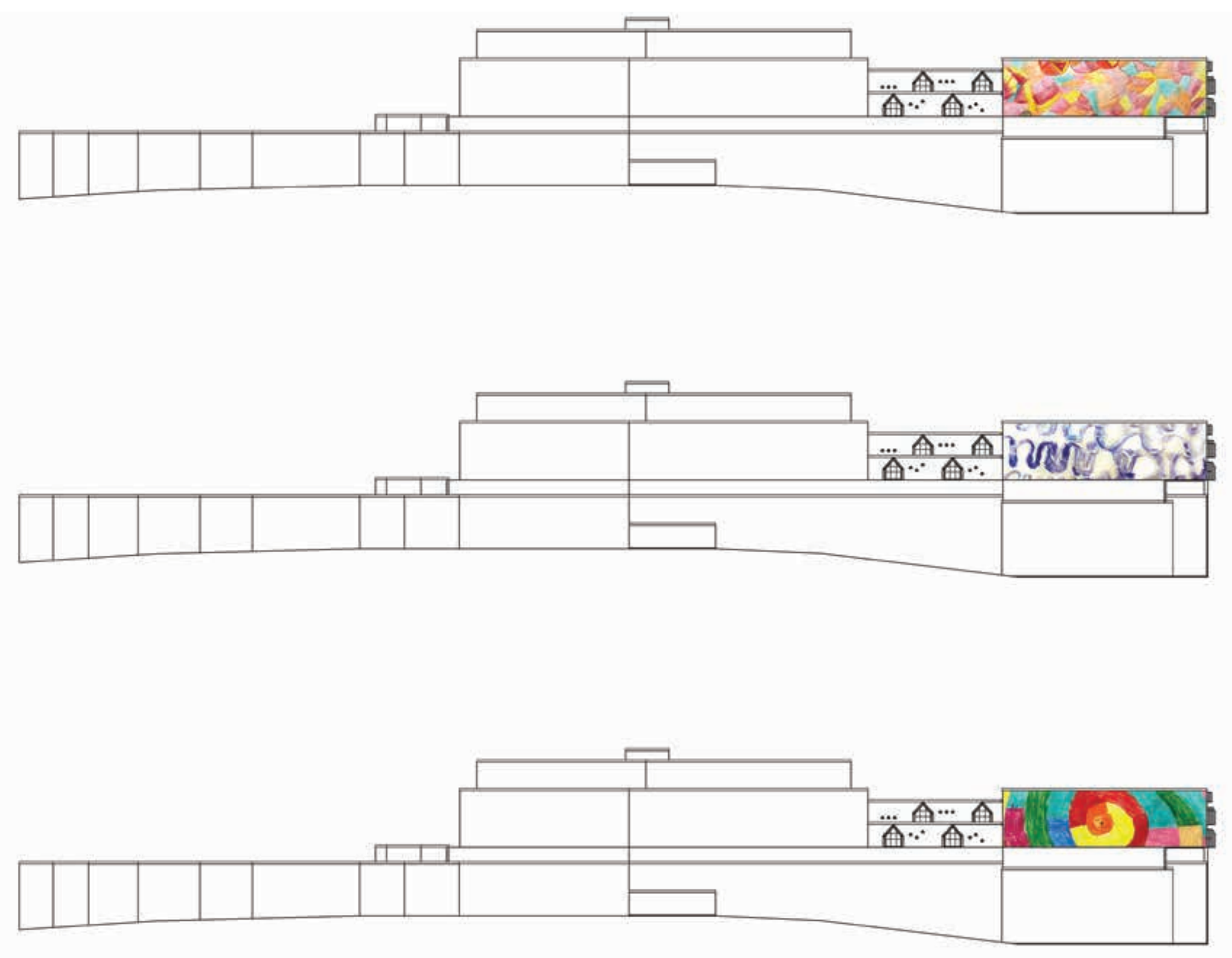

FIGURE 47 
To feel a sense of connection and purpose, everyone should have access to the digital quilt even if they are in their bed for a prolonged period. Thus, every child should be permitted to draw on the whiteboards which are currently in the patient rooms or to have portable drawing tablets which connect to the rest of the drawing quilt (Figure 48). In the same way, the organization Grahamtastic Connection gives technology to children with serious illnesses as they see the importance to keep them connected to the outside world and to continue their education. They believe that it keeps children from feeling isolated, which helps them heal emotionally and physically. ${ }^{73}$ This kind of technology which allows them to draw on surfaces which end up being projected on the walls of the addition gives the children a feeling of control in a time when their world seems out of control.

The addition itself is an elevated uplifting space; it is a separate body hovering on stilts above the existing building, connected by bridges (Figure 49). The bridges carry a transcendence between the two architectural bodies, it is the passage to draw yourself out of the hospital, to leave one's worries behind, and become drawn into one's wondrous imagination-to literally enter the drawing of another (Figure 50). The bridges have tree house pods which allow the children to remove themselves one step further from the hospital. They are intimate places of refuge, calming quiet places amongst the trees in the sky. It is a place of respite for the children and their loved ones. 


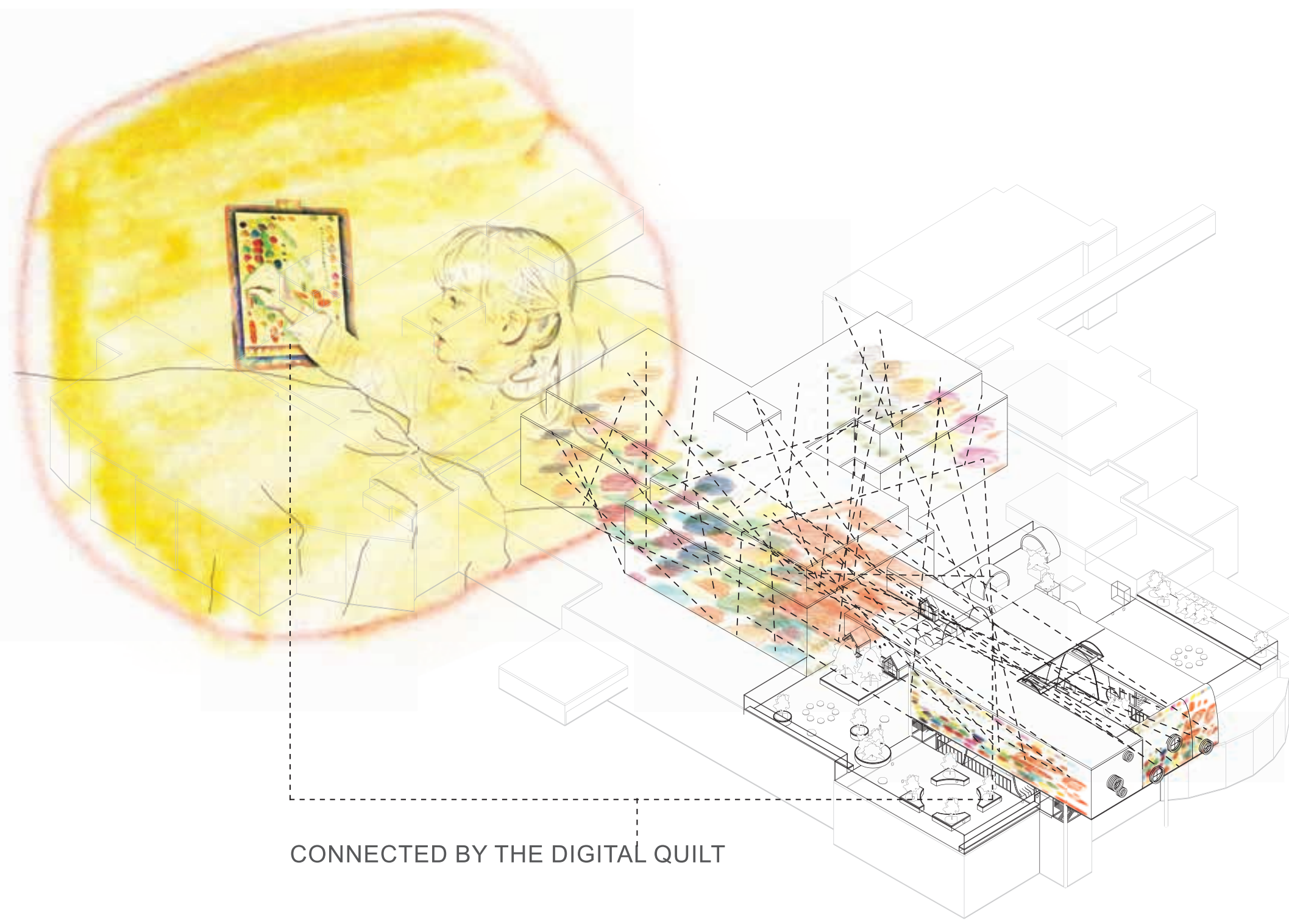

FIGURE 48 


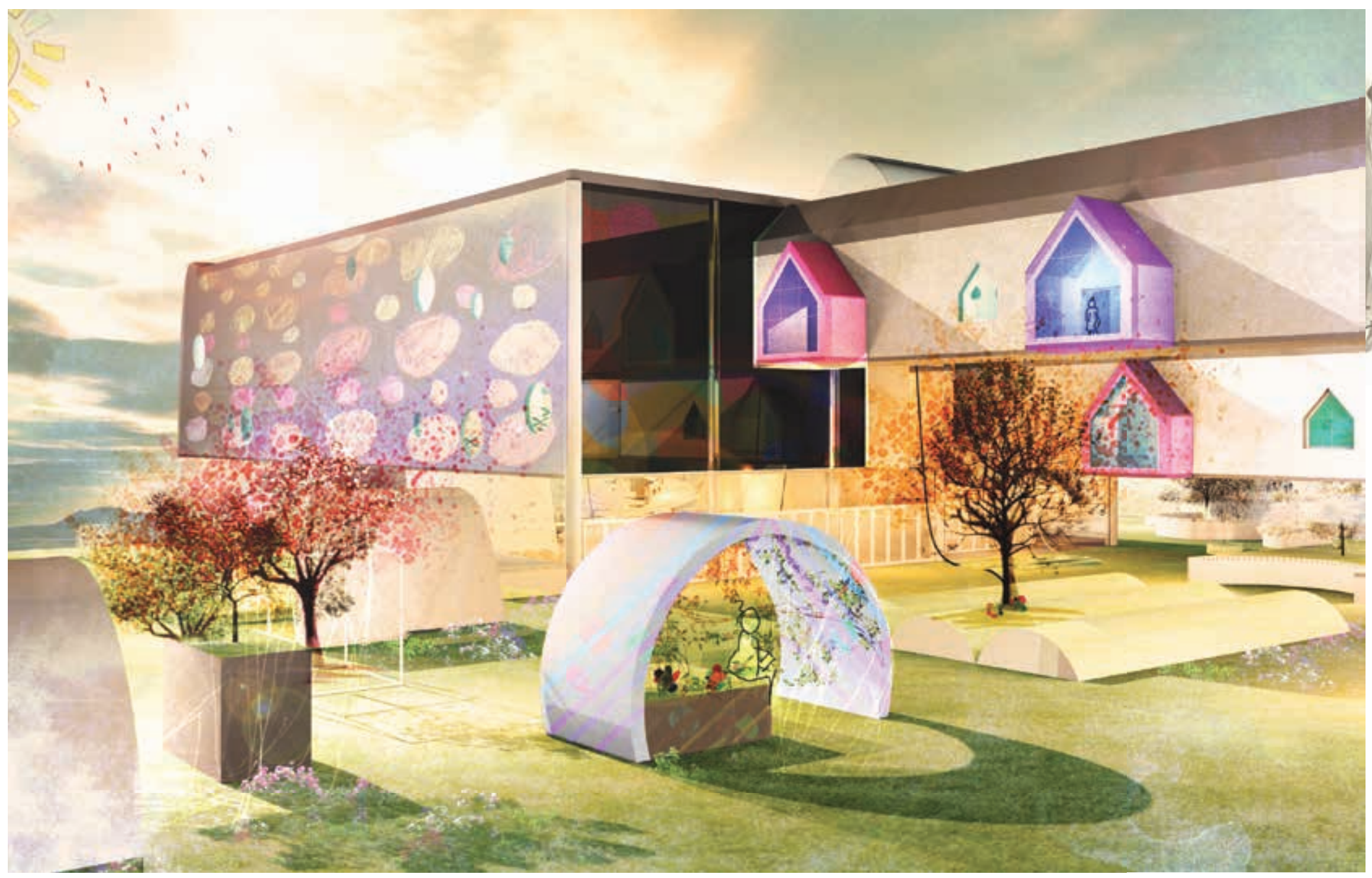

FIGURE 49 


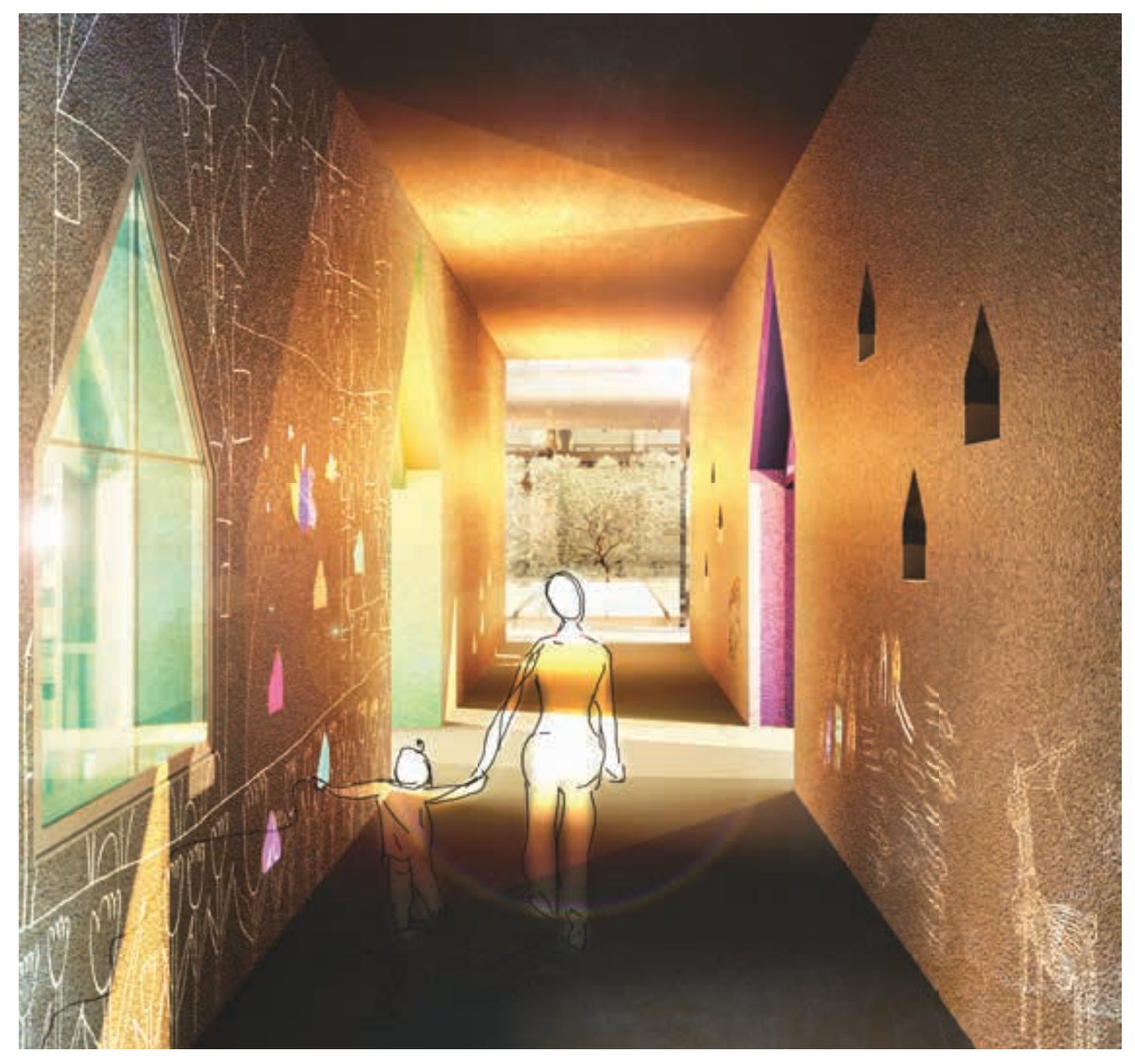

FIGURE 50 


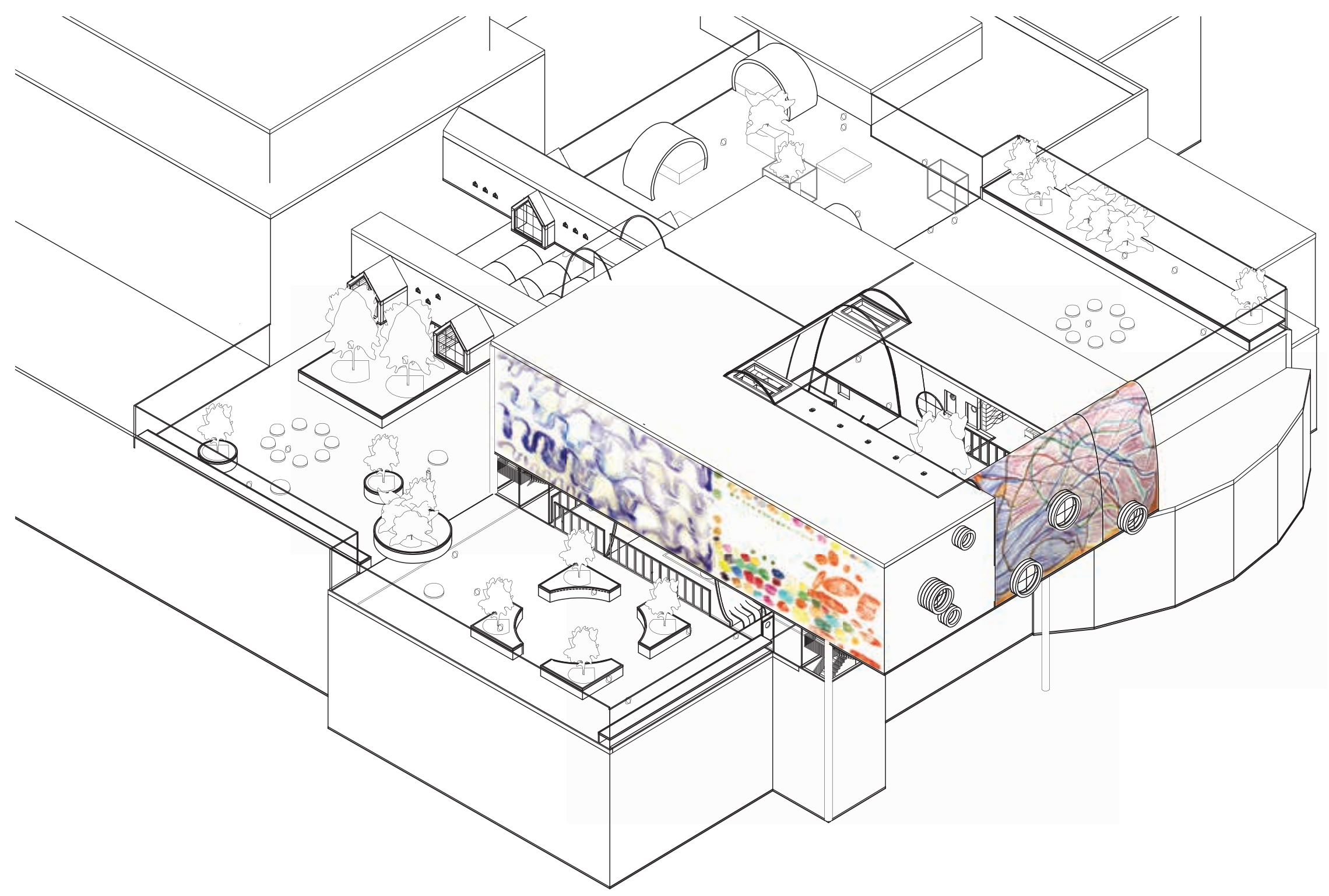

FIGURE 51 Birds Eye View 
The addition naturally creates a covered area on the new green roof allowing for year-round inhabitation, as it has sliding glass windows which can open or close completely. The covered area harmoniously conveys a place suspended between being inside and outside, it becomes the social place. The fourth floor also has a place of performance-- theatre, places to sit and draw (Figure 58). It is where the kids can enjoy CHEO's relocated Zen Garden which spills into the central atrium (Figure 59). Entering from the fifth and sixth floor bridges, one can find the learning center (Figure 60), a gallery, a room of quietness (Figure 61), a place of reading (Figure 64, 65), a technology room, places to draw, all surrounding a central atrium. The atrium connecting all three floors, has a hanging garden (Figure 62) which was inspired by Elaine's drawing of the hanging leaves. In addition, since the sixth floor is the mental health floor and locked down it has its own outdoor garden. Frances' wave drawing inspired the walls and structure of the building. In the section drawing (Figure 55) one can see how the wave like structure creates 'indoor tree pots', this allows for trees to be inside of the architecture. The section shows how the drawings of happiness had a significant role in the design process. 


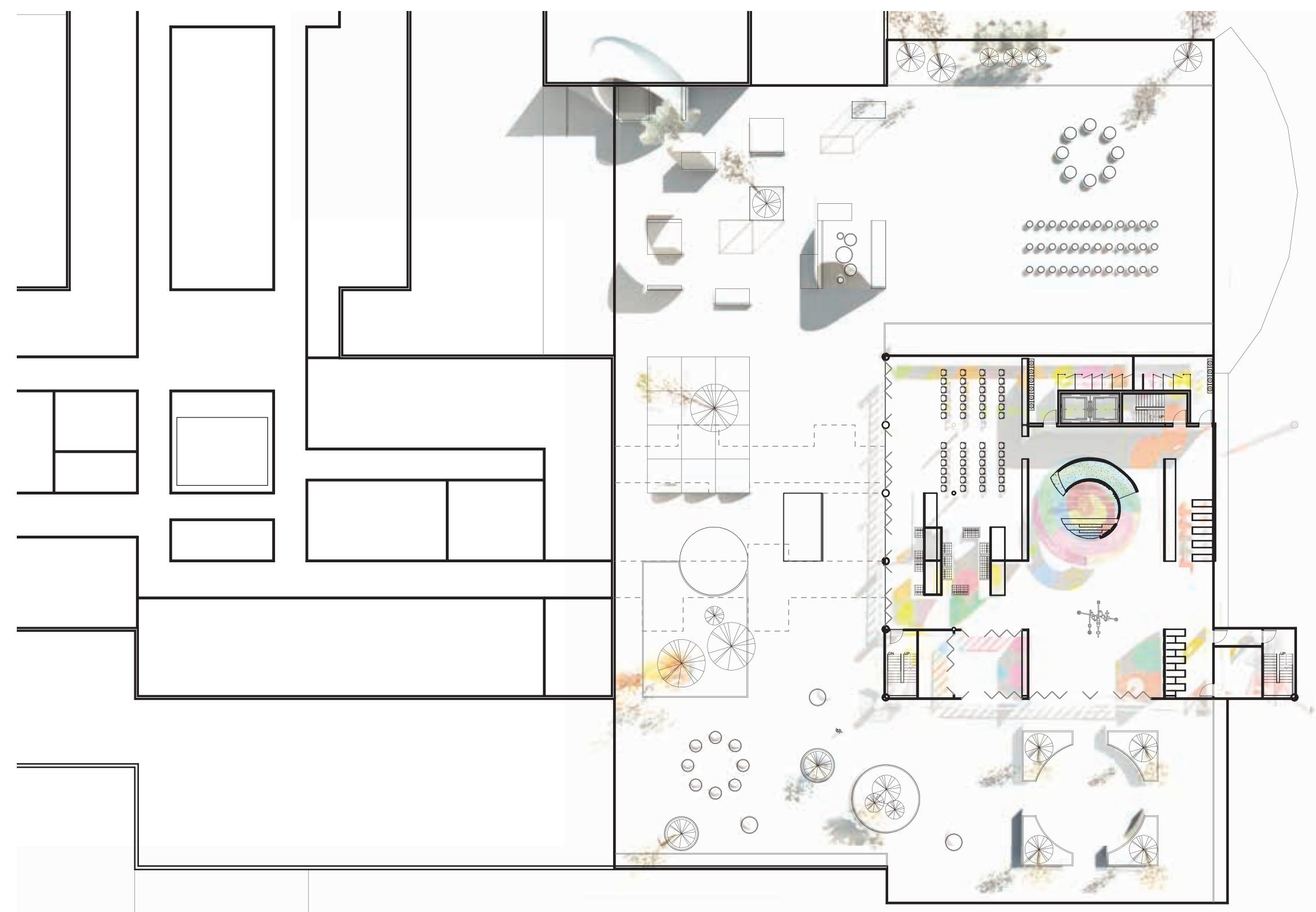

FIGURE 52 Level 4 


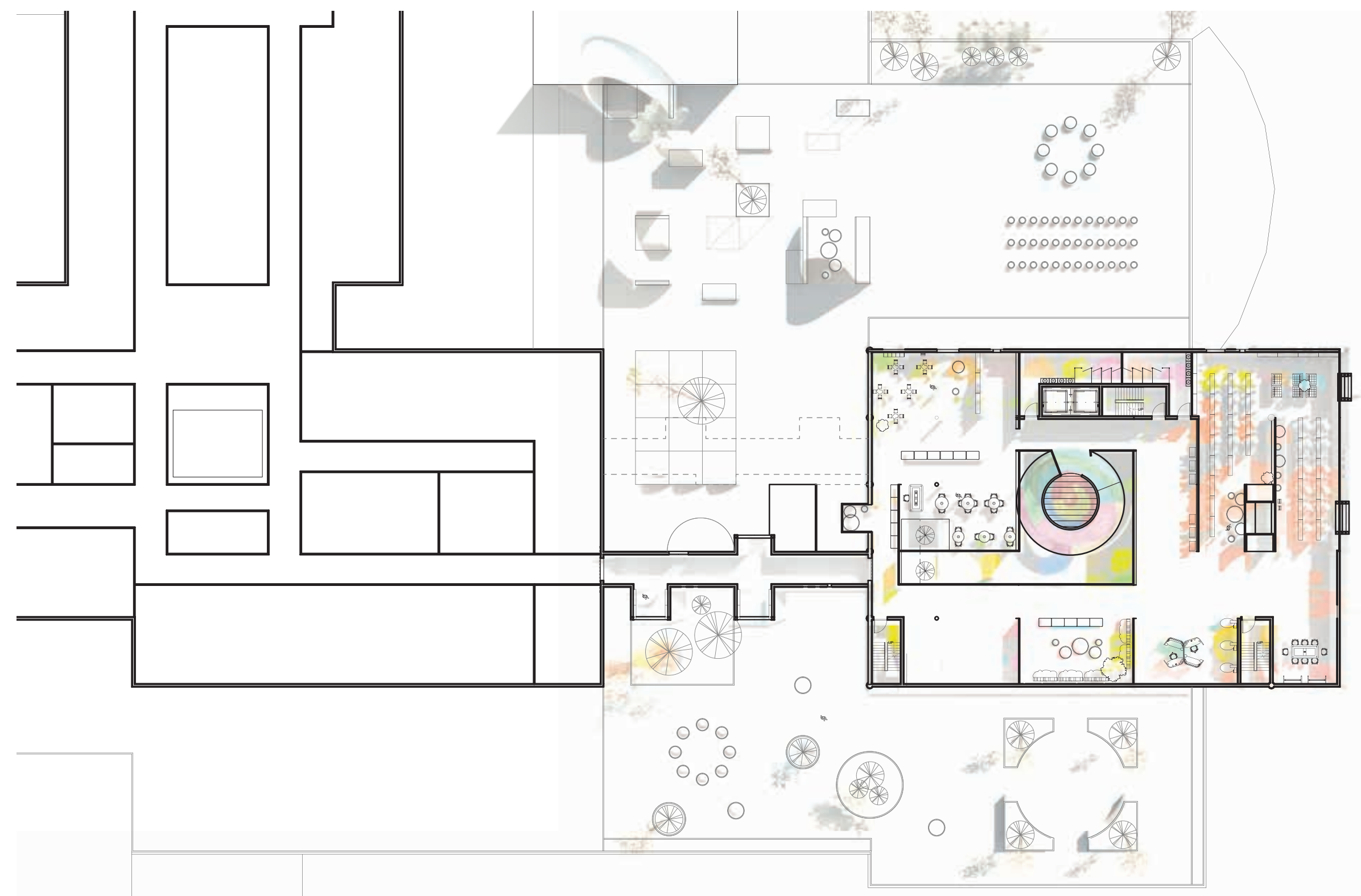

FIGURE 53 Level 5 


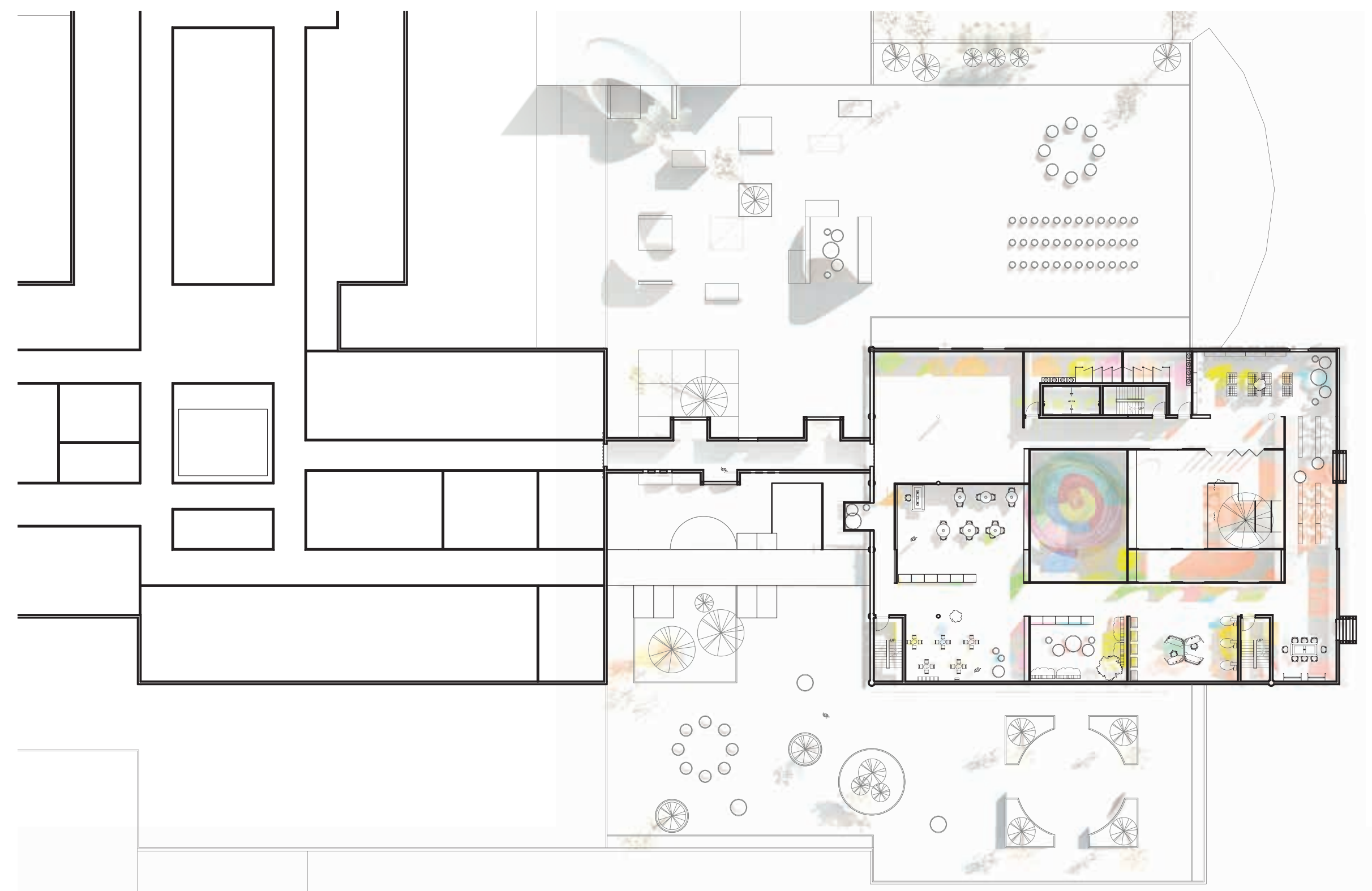

FIGURE 54 Level 6 


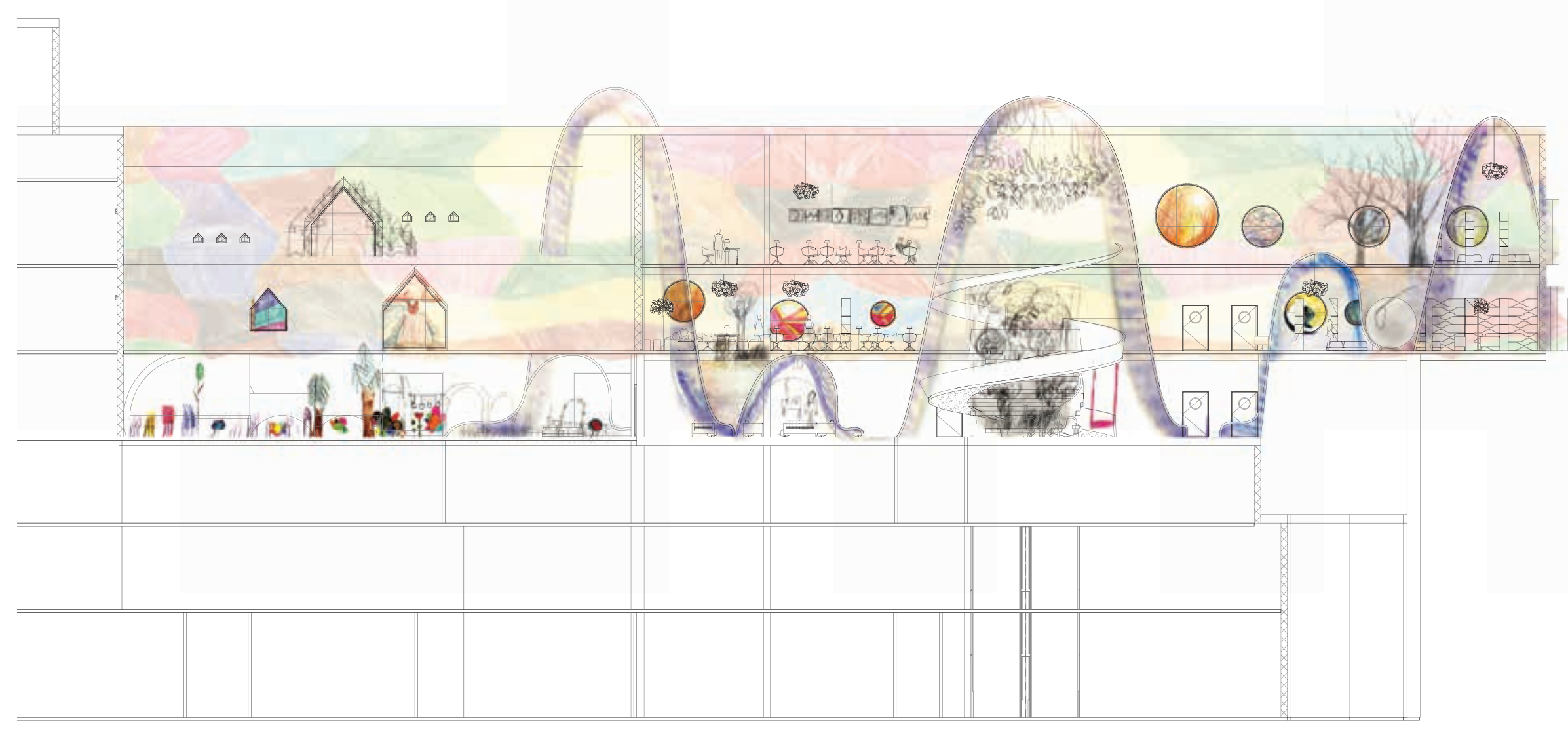

FIGURE 55 Section 

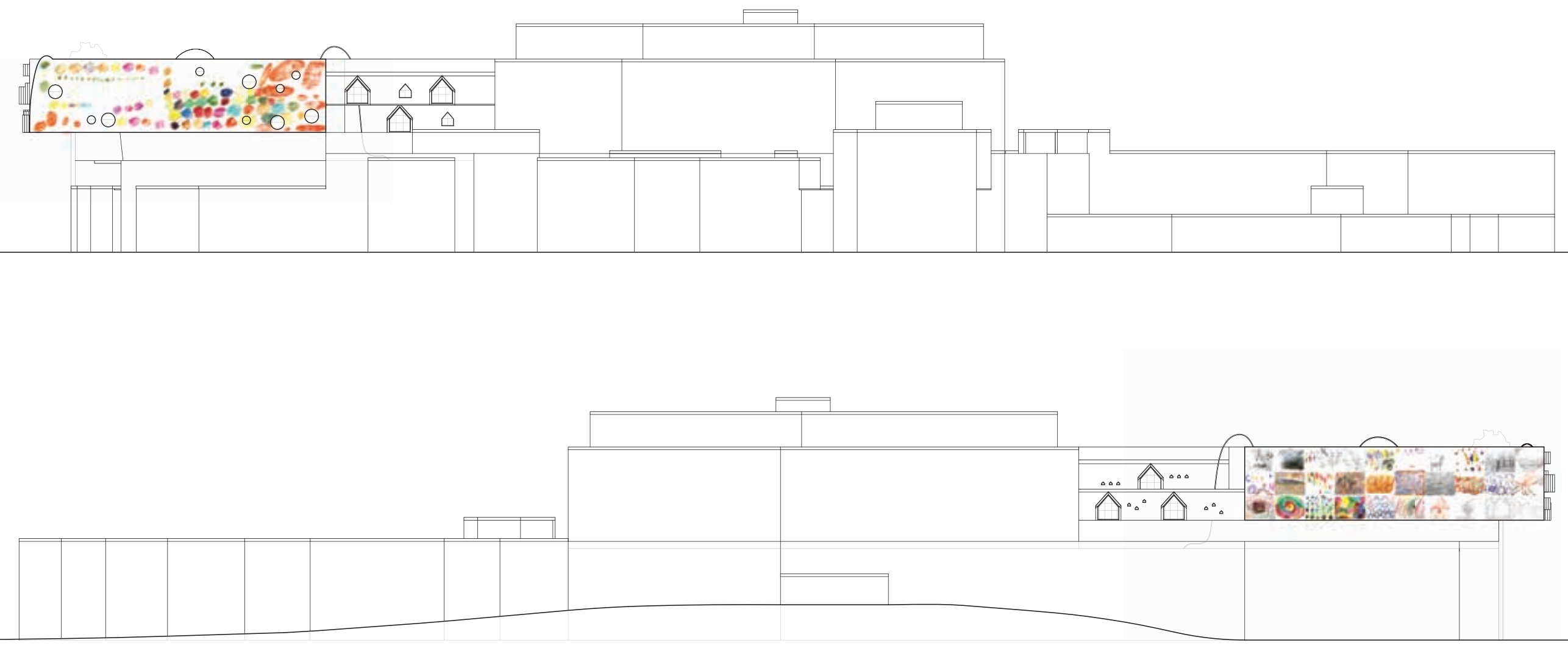

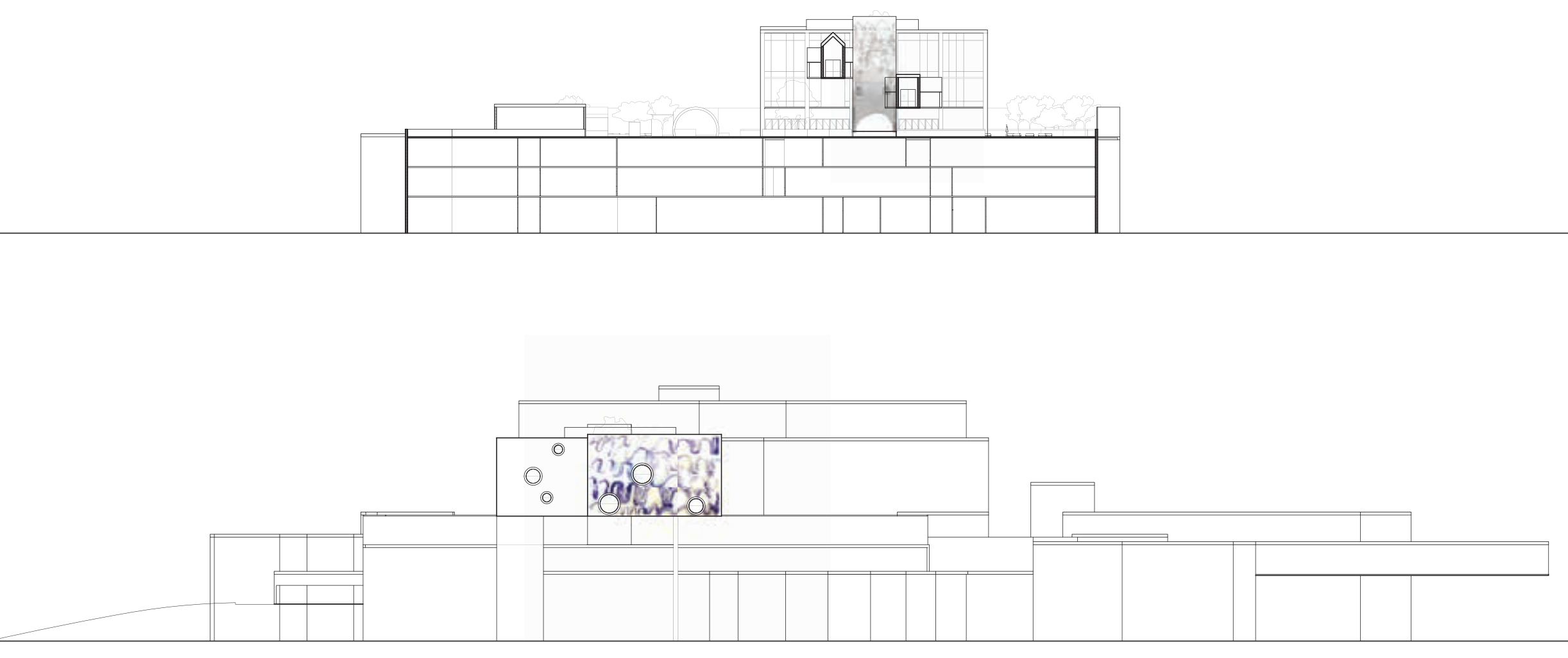


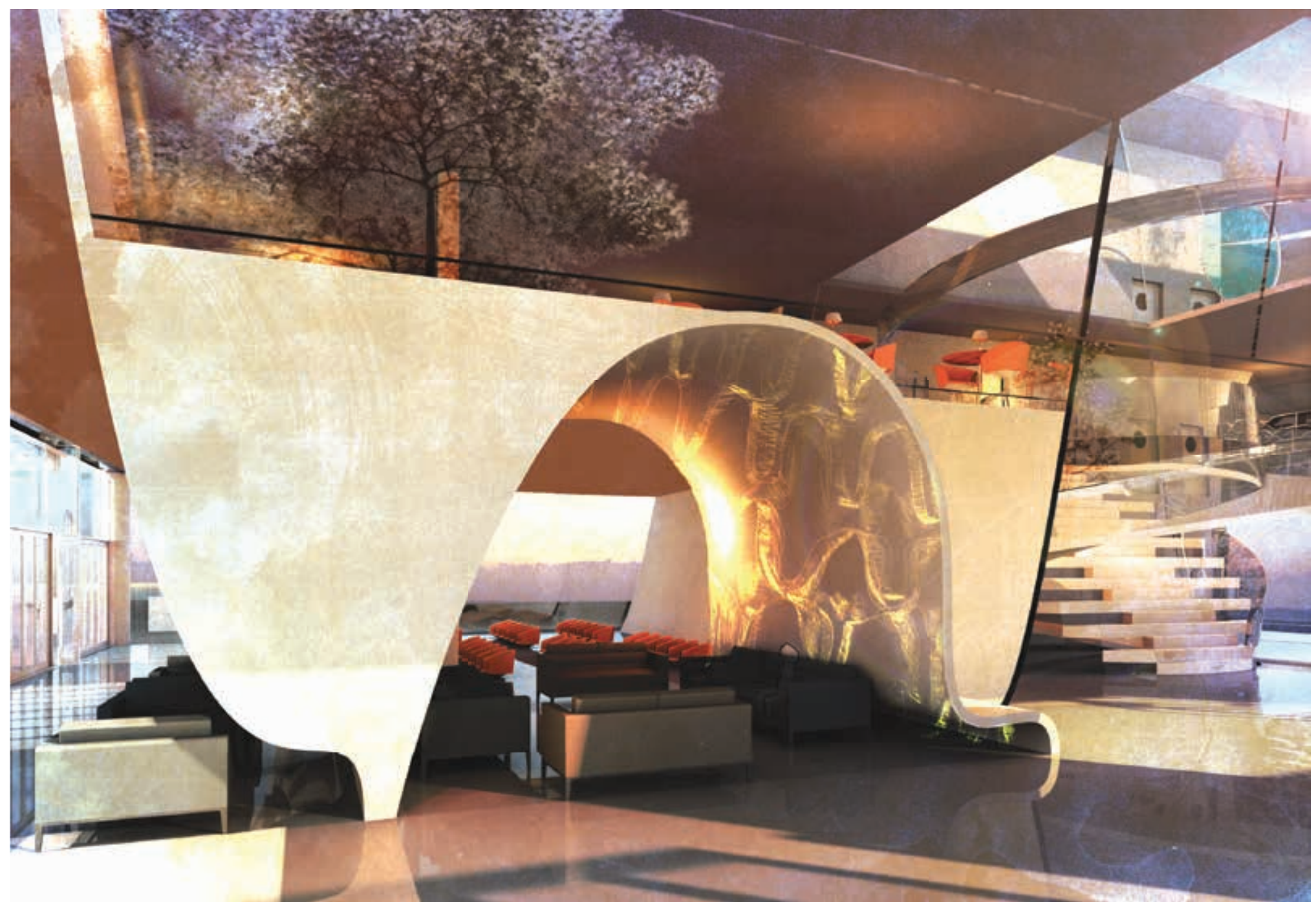

FIGURE 58 


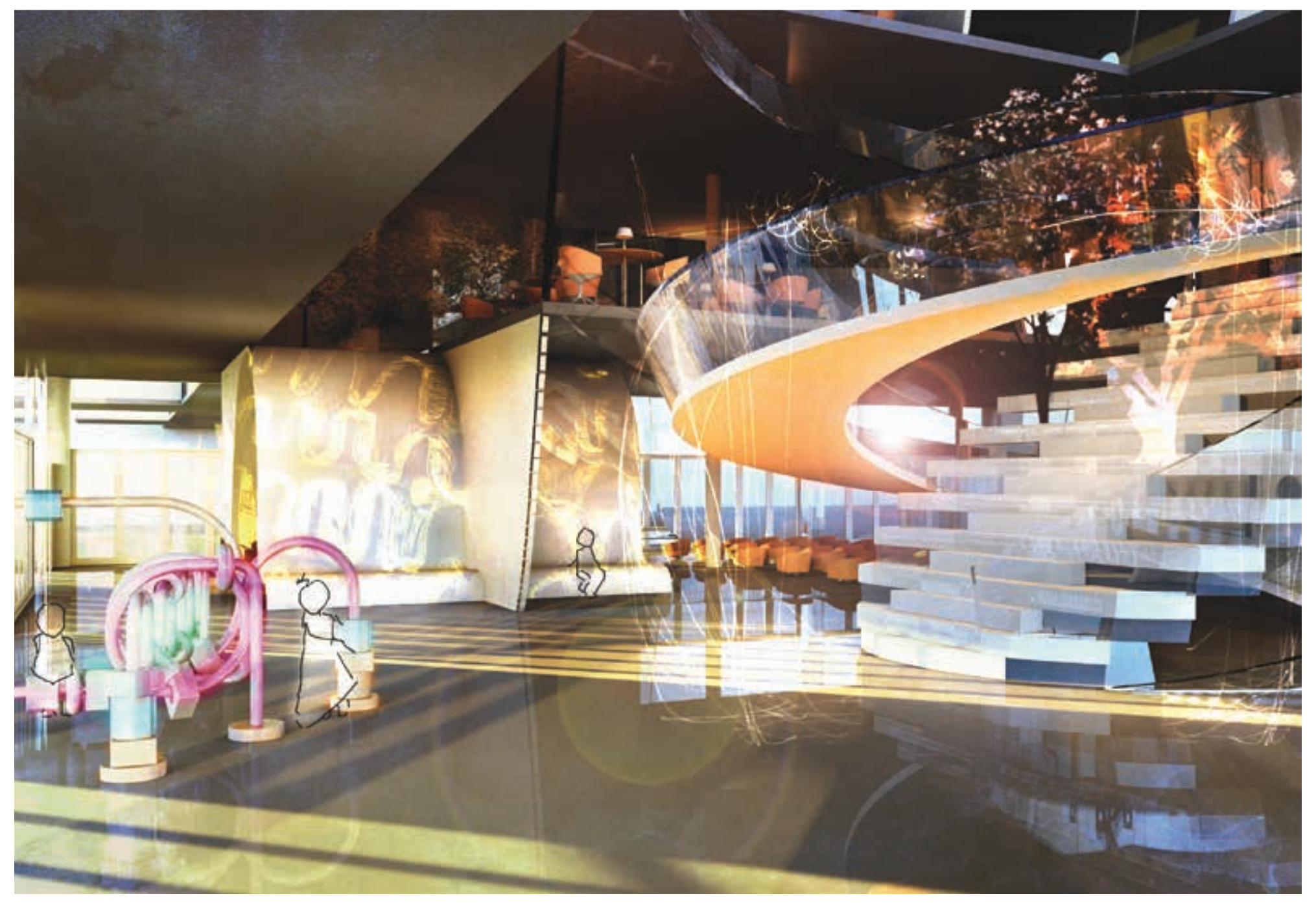

FIGURE 59 


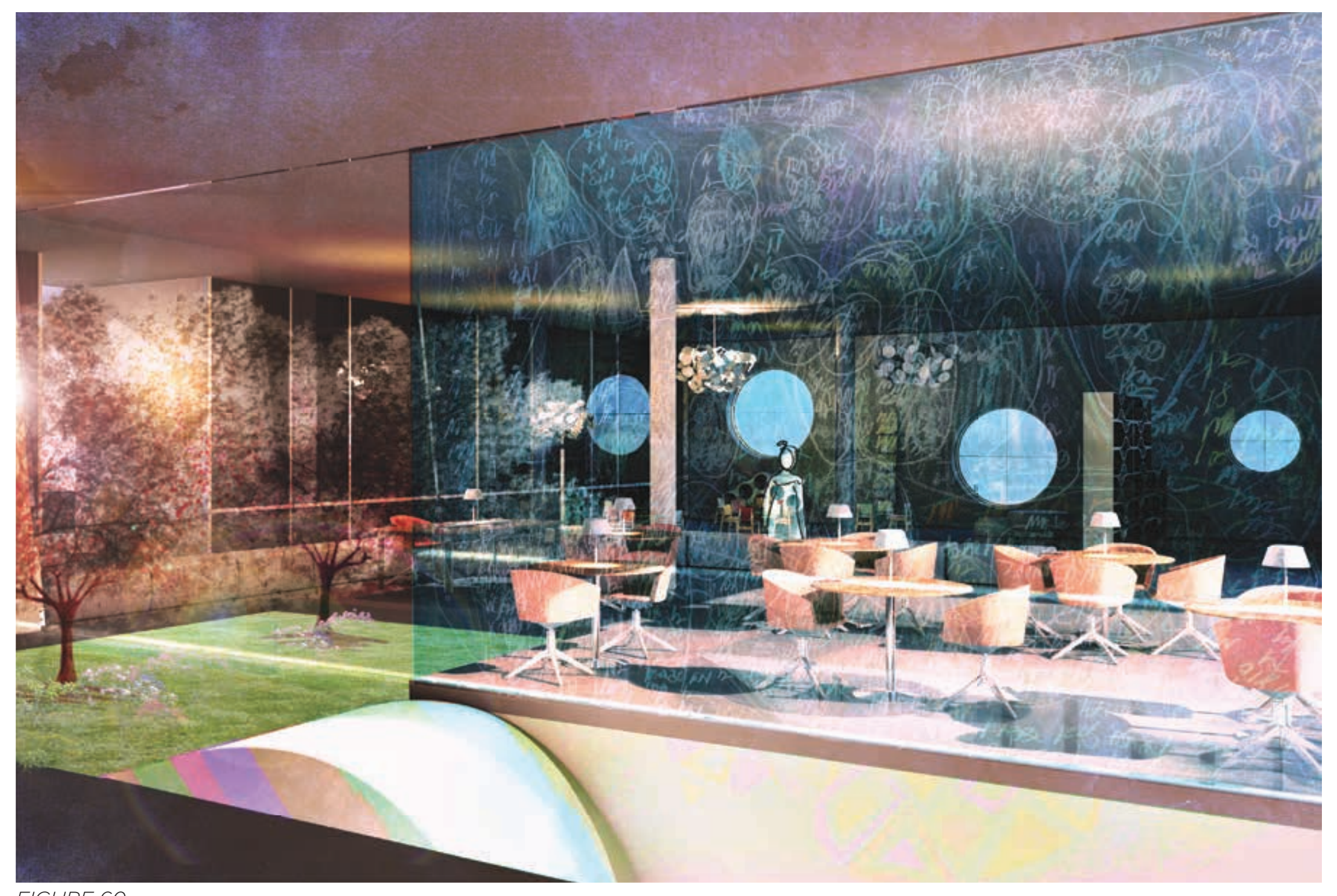




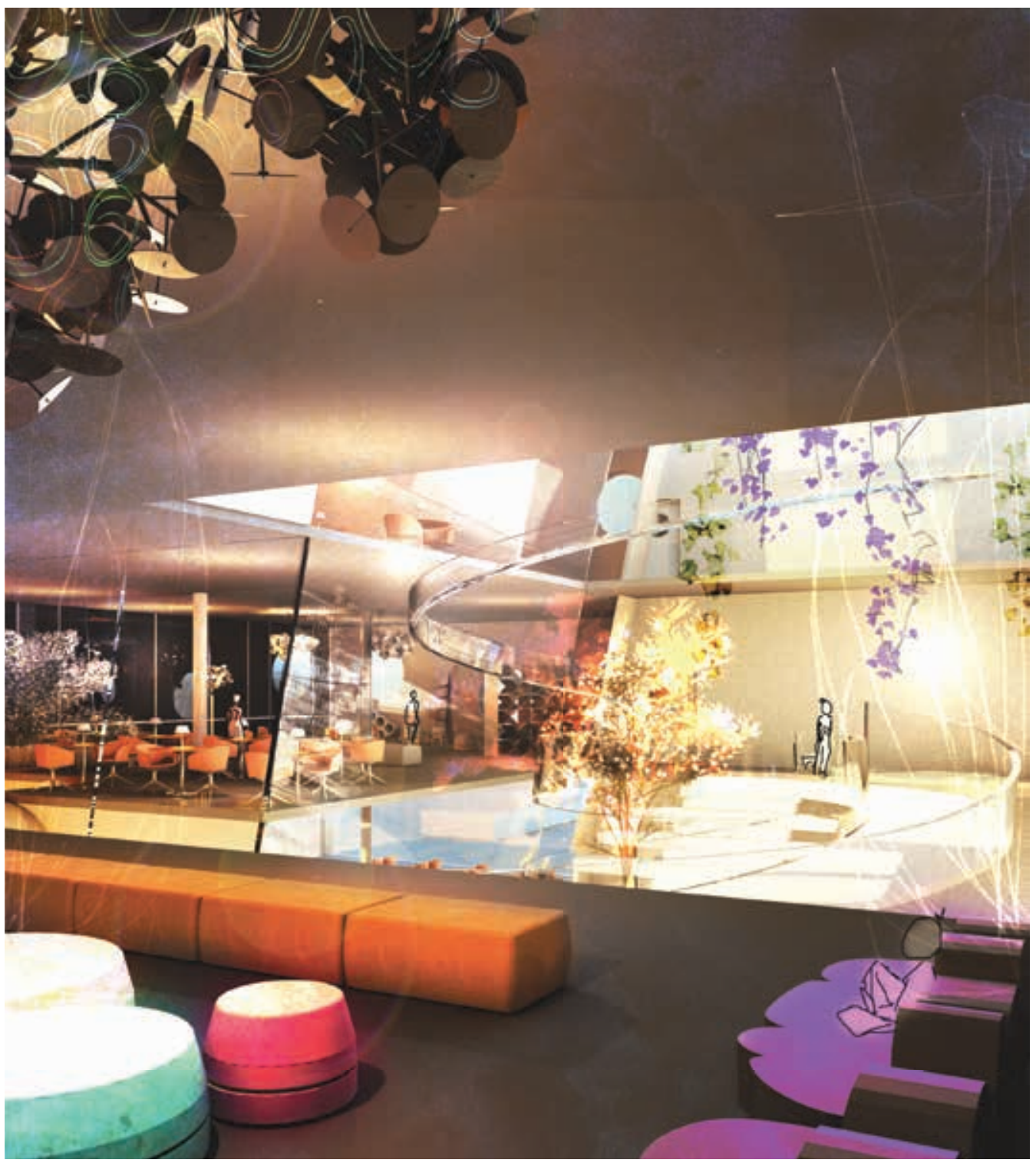

FIGURE 61 


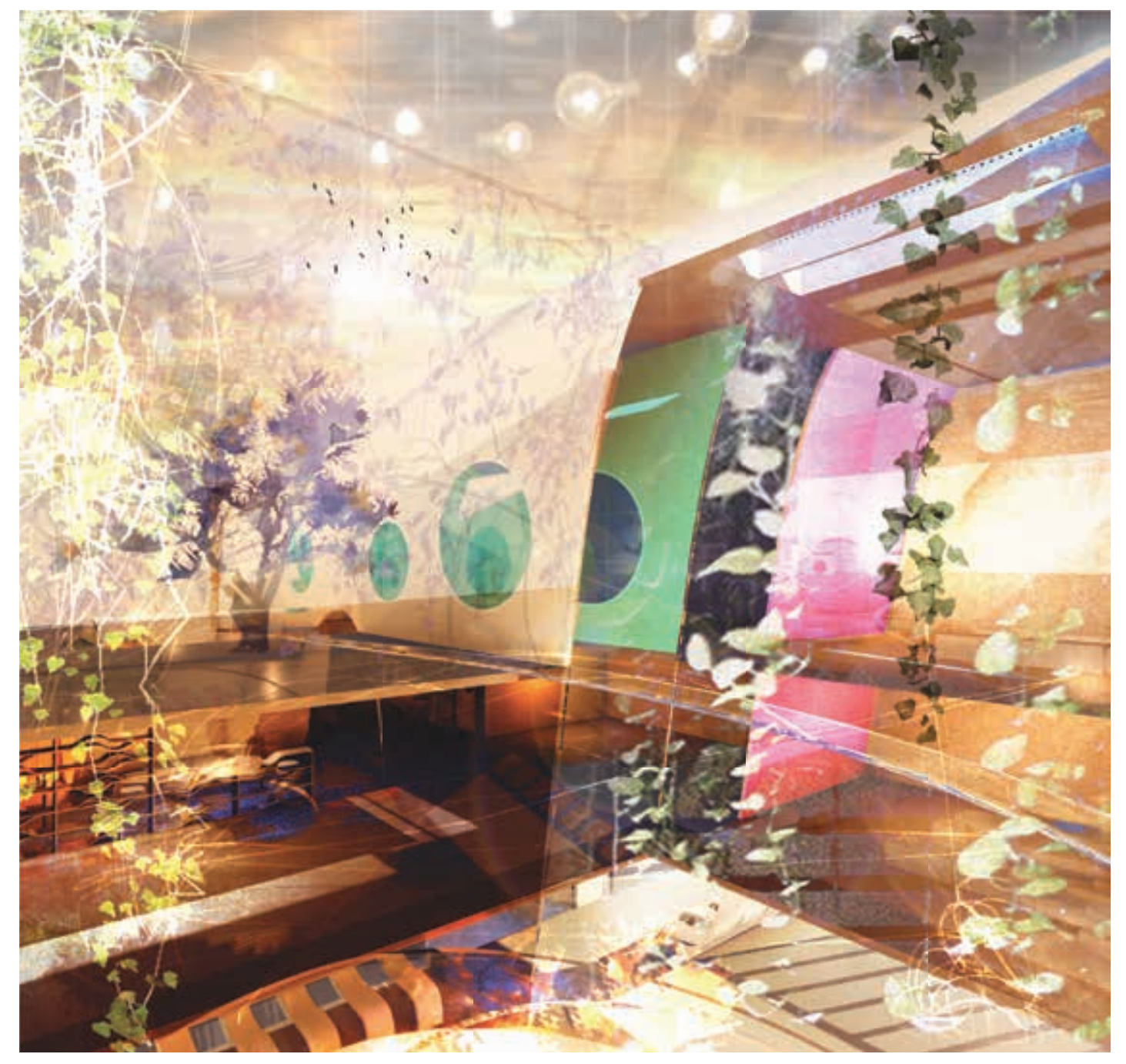

FIGURE 62 


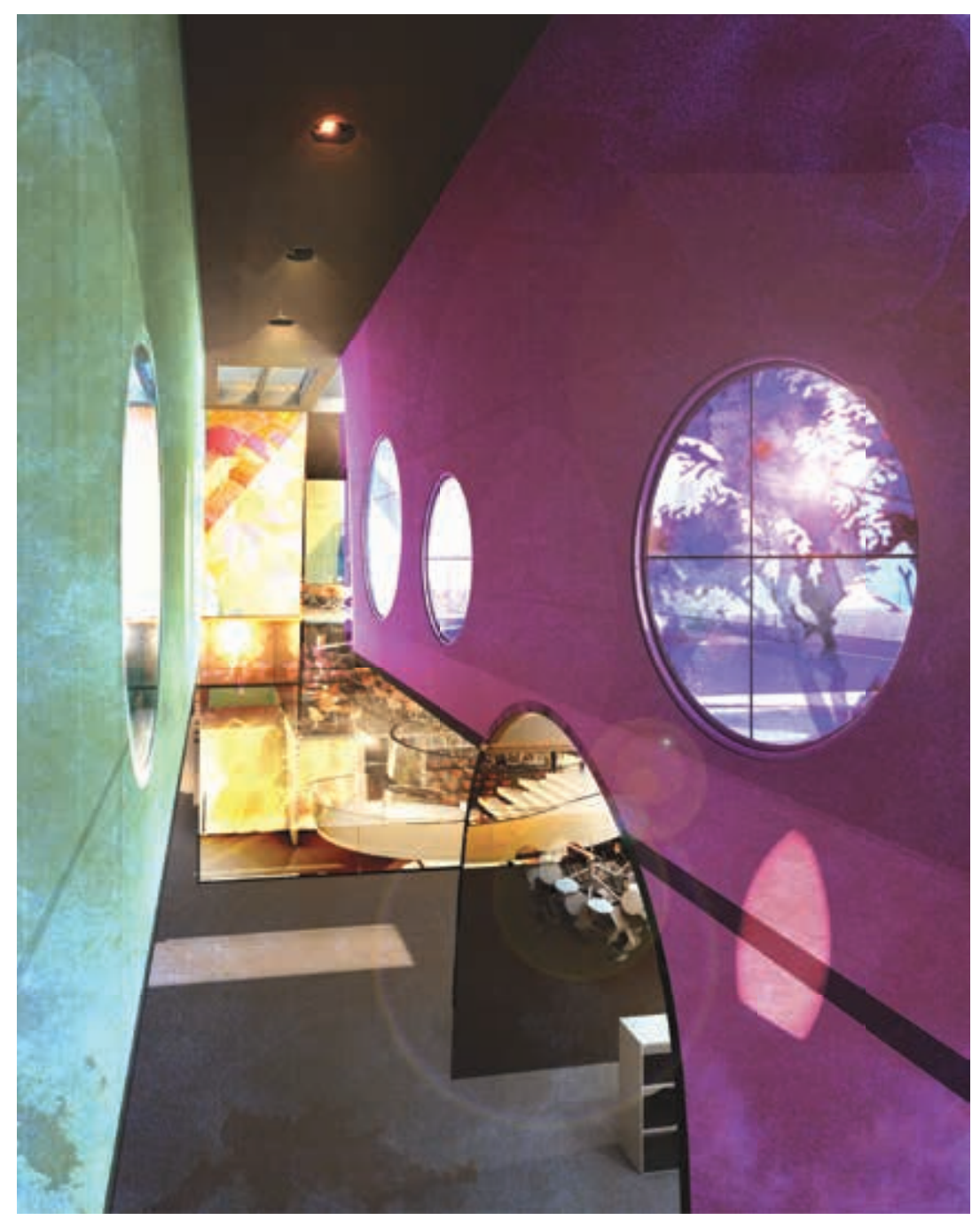

FIGURE 63 


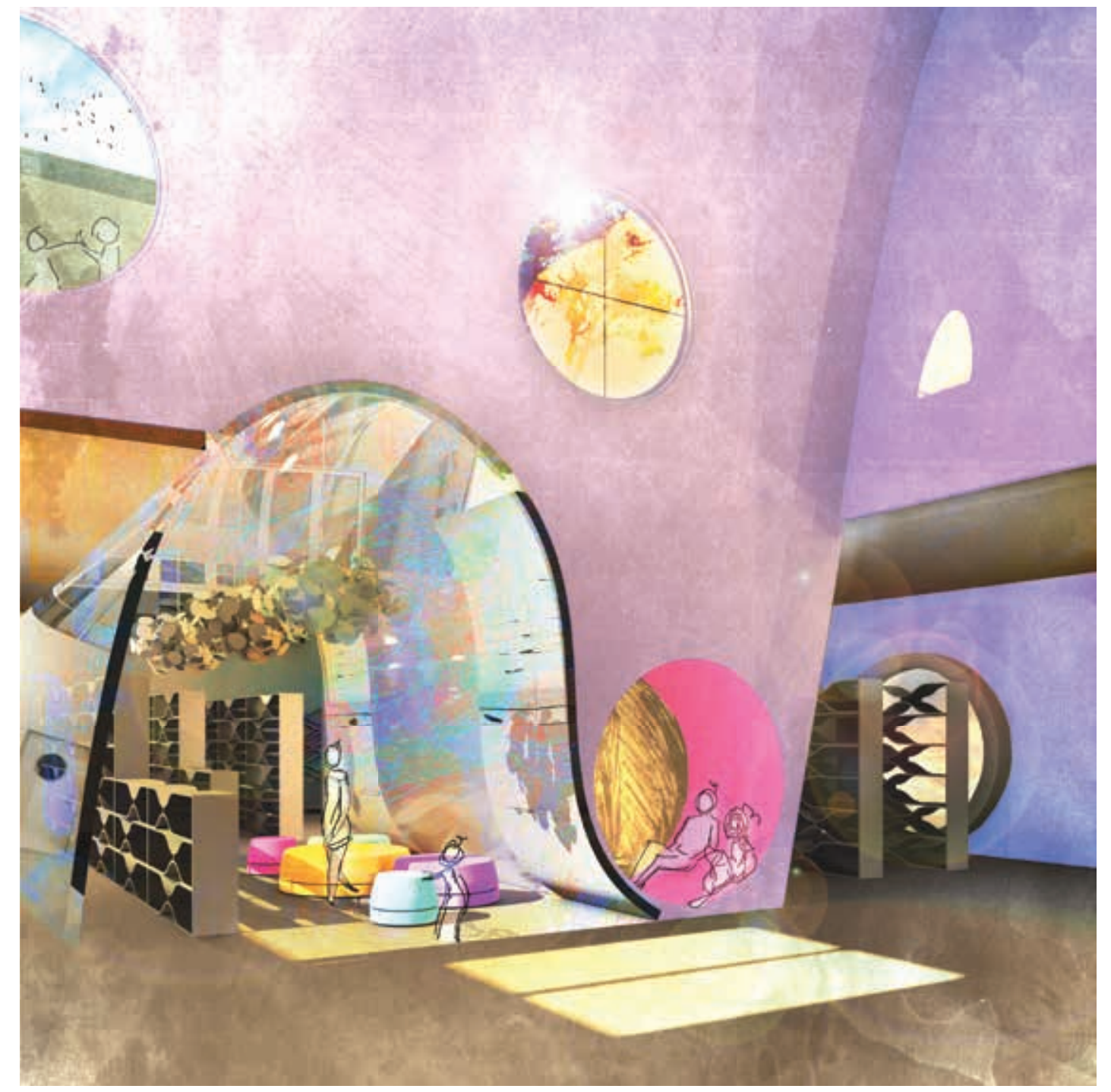

FIGURE 64 


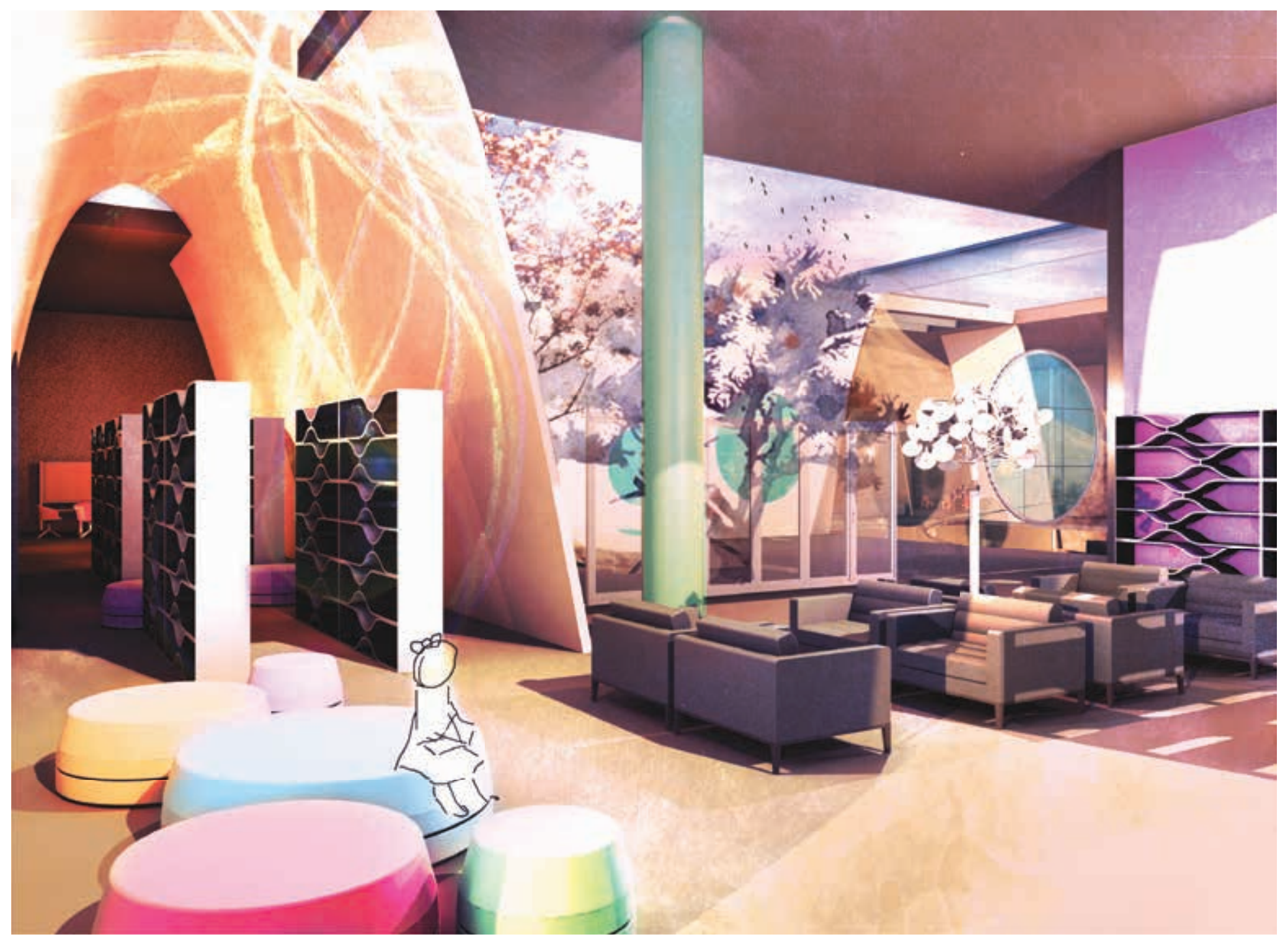

FIGURE 65 


\section{DRAWING A CONCLUSION: A CONTINUOUS DRAWING}

Drawing helps interpret the relationship between space and emotion. Architecture alters our emotions; thus emotion is materialized to create architecture-the architecture of emotional drawings. This thesis explores the interface between architecture and wellbeing through drawings of happiness and relating it to existing research in neuroscience-architecture. The architectural experience affects us both physically and emotionally; drawing happy emotions inspires the design of the architectural experience. The qualities of physical context are reaching a level of understanding through quantitative and qualitative research. Drawing connections between existing quantitative research to qualitative drawing research reframes and reaffirms how happiness and architecture of emotional drawings is experienced. The drawings revitalize the instinct relationship of body and space. They capture the qualitative phenomenological expression of how one experiences happiness. Drawing is the inspiration and means to dream of the new addition at CHEO; a place which can inspire an atmosphere of wellbeing. 
This type of project which addresses mental and physical health issues in a supportive, positive environment can encourage and facilitate empowerment and recovery through creative drawings. ${ }^{74}$ Every architecture embodies the mental orientation of its makers. ${ }^{75}$ Freed from the confines of the page, drawing is everywhere in the interior renovation and the addition at CHEO in which, there is a bodily experience of mark-making in relation to the temporality of drawings and space, a transforming process whereby the tracing of movement approaches space and time. The notion of drawing as process art suggests that drawing involves an oscillation between form and the mind. Drawing records the unfolding of an event, the real and the unreal part of one's mind. ${ }^{76}$ Thus the finished product becomes the evidence of the drawing experience, its visual documentation-the digital quilt. The addition is creating a language to empower people to design their environment, where they can explore and grow; promoting social interaction; making comfortable connections to nature; and creating happy spaces. 
Every moment we experience is precious, and we need to recognize the influence of our buildings and spaces on people's wellbeing. This research was inspired by my perceived experience of space, time, sound, taste and texture-the splendor of the human brain in architecture. Drawing helps me achieve empathy of space where I can literally feel the space. Therefore, getting children and intellectually disabled artists to draw what their happy space looks like and what happiness looks like to them, allowed me to enter their dreams and their drawings to design the architecture of emotional drawings. Architecture is constructed in the wondrous spaces of the mind which is revealed through drawing and the mind is therefore constructed and affected by the architecture. What fragments of the brain respond to precisely what features of architecture? A further possible application of this approach to architecture deals with the relationship between architectural spaces and the way they are experienced through simulation. The experience of the built environment and its affordances is formed through the precognitive activation of motor simulations. The role of embodied simulation in architectural experience becomes even more interesting if one 
considers emotions and sensations. ${ }^{77}$ To study how the drawings of happiness virtually presented within designed architectonic spaces are experienced. To empirically test by recording the mind and bodily responses of subjects perceptually experiencing and exploring virtual architectonic drawings of happiness by means of immersive virtual reality. This experimental approach could qualify us to empirically address significant aspects of architecture. The knowledge acquired through the drawings of happiness being inhabited virtually might provide new insights for the future design of hospitals. It is a way to convey quantitative understanding of the qualitative approach of the drawings of happiness -- to draw and virtually enter the drawings to shape architectural environments that in due course promote wellbeing. 


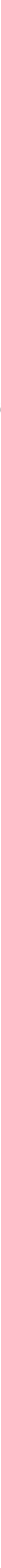


This was the initial design proposal which herein is part of the archive of the design process. The pink volume housed the drawing archive, the gallery and research offices. The blue volume held the creative programs, therapy rooms, learning centers, social spaces, intimate spaces, and play spaces. Consistent with the final design, the green roof remains as the canvas.
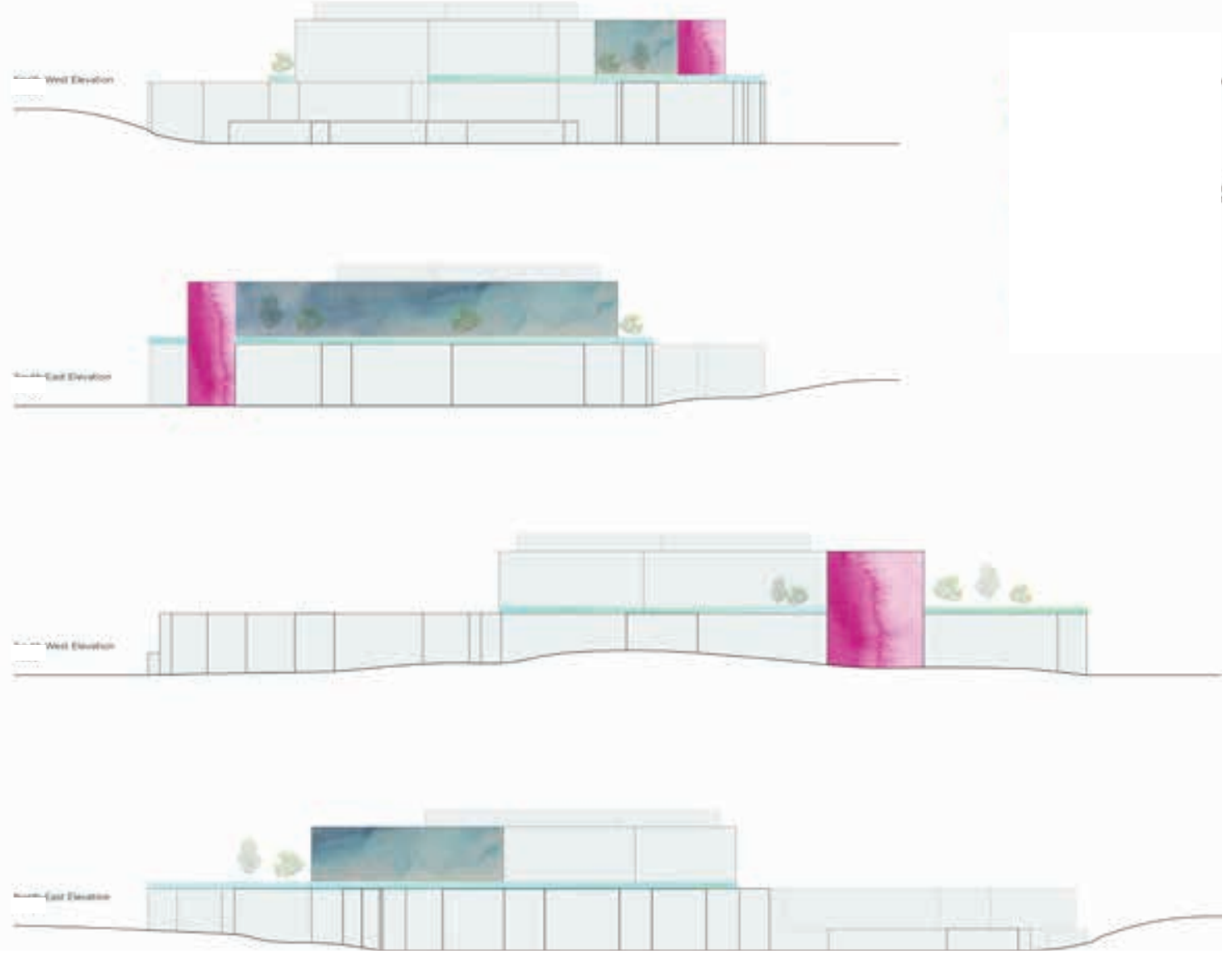

FIGURE 67

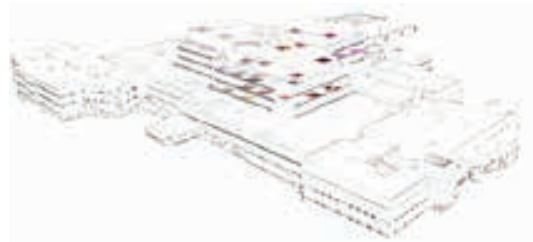

INTERIOR RENOVATION FIGURE 68

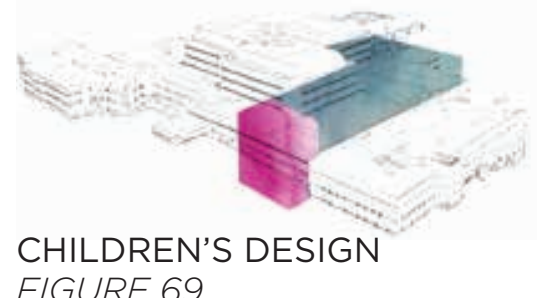

FIGURE 69

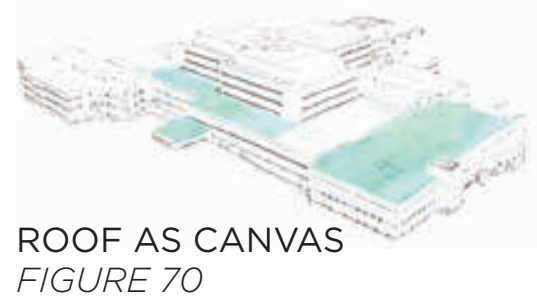




\section{Carleton \\ Canada's Capital University}

Research Compliance Office 511 Tory | 1125 Colonel By Drive | Ottawa, Ontario K1S 5B6

613-520-2600 Ext: 4085

ethics@carleton.ca

\section{CERTIFICATION OF INSTITUTIONAL ETHICS CLEARANCE}

The Carleton University Research Ethics Board-B (CUREB-B) has granted ethics clearance for the research project described below and research may now proceed.

CUREB-B is constituted and operates in compliance with the Tri-Council Policy Statement: Ethical Conduct for Research Involving Humans (TCPS2).

Ethics Protocol Clearance ID: Project \# 106041

Faculty Supervisor: Federica Goffi

Research Team:

Jeniffer Milburn (Student - MA student)

Project Title: The Architecture of Emotional Drawings: A Study on Happiness and Sense of Place [Jeniffer Milburn]

Funding Source (If applicable):

Effective: January 09, 2017

Expires: January 31, 2018.

\section{Restrictions:}

This certification is subject to the following conditions:

1. Clearance is granted only for the research and purposes described in the application.

2. Any modification to the approved research must be submitted to CUREB-B via a Change to Protocol Form. All changes must be cleared prior to the continuance of the research.

3. An Annual Status Report for the renewal of ethics clearance must be submitted and cleared by the renewal date listed above. Failure to submit the Annual Status Report will result in the closure of the file.If funding is associated, funds will be frozen.

4. A closure request must be sent to CUREB-B when the research is complete or terminated. 
5. Should any participant suffer adversely from their participation in the project you are required to report the matter to CUREB-B.

Failure to conduct the research in accordance with the principles of the Tri-Council Policy Statement: Ethical Conduct for Research Involving Humans 2ndedition and the Carleton University Policies and Procedures for the Ethical Conduct of Research may result in the suspension or termination of the research project.

Please contact the Research Compliance Coordinators, at ethics@carleton.ca, if you have any questions or require a clearance certificate with a signature.

\section{CLEARED BY:}

Date: January 09, 2017

Andy Adler, PhD, Chair, CUREB-B

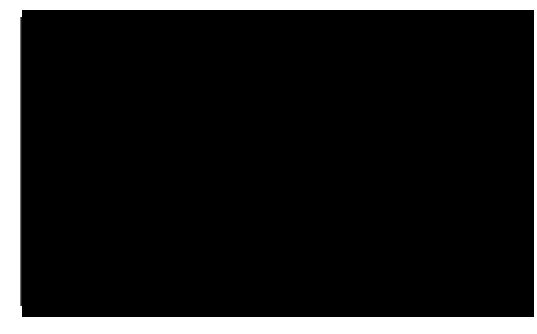

Shelley Brown, PhD, Vice-Chair, CUREB-B

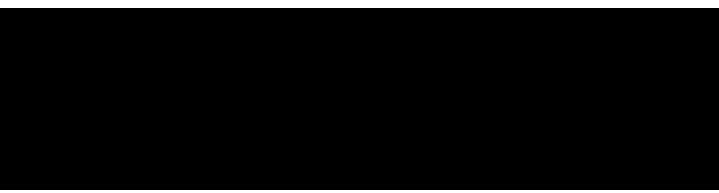




\section{END NOTES}

1 Esther M. Sternberg, Healing Spaces The Science of Place and Well-Being (Cambridge, MA: Harvard University Press, 2009$), 230$.

2 Karen Conty, “Experience,” ARCH 5200 Lecture, Carleton University, Ottawa, Canada, October 21, 2015.

3 Sternberg, Healing Spaces The Science of Place and Well-Being, 20.

4 Sternberg, Healing Spaces The Science of Place and Well-Being, 21.

5 Sternberg, Healing Spaces The Science of Place and Well-Being, 291.

6 Mengfei Huang, “The Neuroscience of Art," Stanford Journal of Neuroscience, (2009), Reviews \& Features, V.2, I:1, 24, Accessed October 8, 2016. https://web.stanford.edu/group/co-sign/Huang.pdf.

7 Saul McLeod, “Qualitative vs Quantitative Data,” Qualitative vs Quantitative Data | Simply Psychology, January O1, 1970, x, accessed January 10, 2017, https://simplypsychology.org/qualitative-quantitative.html.

8 “H'ART OF OTTAWA STUDIO," Upstream Studio - H'Art of Ottawa, x, accessed January 29, 2017, http://www.hartofottawa.ca/.

9 Marco Frascari and Federica Goffi, Marco Frascari's Dream House, A theory of imagination, (New York: Routledge, 2017 ), 1.

10 Frascari and Goffi, Marco Frascari's Dream House, A theory of imagination, 14.

11 Frascari and Goffi, Marco Frascari's Dream House, A theory of imagination, 16.

12 Frascari and Goffi, Marco Frascari’s Dream House, A theory of imagination, 15.

13 Frascari and Goffi, Marco Frascari's Dream House, A theory of imagination, 28.

14 Frascari and Goffi, Marco Frascari's Dream House, A theory of imagination, 32.

15 Frascari and Goffi, Marco Frascari's Dream House, A theory of imagination, 38.

16 Sarah Robinson and Juhani Pallasmaa, Mind in architecture: neuroscience, embodiment, and the future of design; (Cambridge, Mass.: MIT Press, 2015), 150.

17 Kate Macfarlane et al., The drawing book: a survey of drawing: the primary means of expression (London: Black Dog Pub., 2007), 28. 
18 Alex Ashton, "Drawing on the "Lived Experience" -An Investigation of Perception, Ideation and Praxis," Art and Design Review 02, no. 03 (2014): 46, accessed October 13, 2016, doi:10.4236/adr.2014.23007.

19 Wilhelm Dilthey, Rudolf A. Makkreel, and Frithjof Rodi, Understanding the human world, vol. 2 (Princeton, NJ: Princeton University Press, 2010).

20 Alain De Botton and John Armstrong, Art as therapy (London: Phaidon Press Limited, 2016), 47.

21 Botton and Armstrong, Art as therapy, 48.

22 Teel Sale and Claudia Betti, Drawing: a contemporary approach (Belmont, CA: Wadsworth, 2004), 6.

23 Juhani Pallasmaa et al., Architecture and neuroscience (Espoo, Finland: Tapio Wirkkala-Rut Bryk Foundation, 2013 ), 49.

24 Ashton, "Drawing on the "Lived Experience" -An Investigation of Perception, Ideation and Praxis," 46.

25 Adriana Ionascu, "Drawing matter(s)," Drawing: Research, Theory, Practice, vol. 1, no. 2, 2016, p. 163+. Academic,OneFile,proxy. library.carleton.ca, 163.

26 Huang, "The Neuroscience of Art," 24.

27 Huang, "The Neuroscience of Art," 26.

28 Ionascu, "Drawing matter(s)," Drawing: Research, Theory, Practice, 163.

29 Deirdre Heenan, "Art as therapy: an effective way of promoting positive mental health?," Disability \& Society 21 , no. 2 (2006): 1812, doi:10.1080/09687590500498143.

30 Botton and Armstrong, Art as therapy, 65.

31 Robinson and Pallasmaa, Mind in architecture: neuroscience, embodiment, and the future of design, 164.

32 Botton and Armstrong, Art as therapy, 8.

33 Botton and Armstrong, Art as therapy, 32.

34 Botton and Armstrong, Art as therapy, 44.

35 Botton and Armstrong, Art as therapy, 47.

36 Botton and Armstrong, Art as therapy, 59.

37 Heenan, "Art as therapy: an effective way of promoting positive mental health?, 179. 
38 Heenan, "Art as therapy: an effective way of promoting positive mental health?, 184.

39 Botton and Armstrong, Art as therapy, 5.

40 Huang, "The Neuroscience of Art," 26.

41 Robinson and Pallasmaa, Mind in architecture: neuroscience, embodiment, and the future of design, 188.

42 Robinson and Pallasmaa, Mind in architecture: neuroscience, embodiment, and the future of design, 153.

43 McLeod, "Qualitative vs Quantitative Data."

44 Robinson and Pallasmaa, Mind in architecture: neuroscience, embodiment, and the future of design, 51.

45 Robinson and Pallasmaa, Mind in architecture: neuroscience, embodiment, and the future of design, 23.

46 Robinson and Pallasmaa, Mind in architecture: neuroscience, embodiment, and the future of design, 25.

47 Robinson and Pallasmaa, Mind in architecture: neuroscience, embodiment, and the future of design, 34.

48 Robinson and Pallasmaa, Mind in architecture: neuroscience, embodiment, and the future of design, 42.

49 Robinson and Pallasmaa, Mind in architecture: neuroscience, embodiment, and the future of design, 151.

50 Robinson and Pallasmaa, Mind in architecture: neuroscience, embodiment, and the future of design, 192.

51 Robinson and Pallasmaa, Mind in architecture: neuroscience, embodiment, and the future of design, 200.

52 Jamie Huffcut, "Mental Healthcare Design and the Clty," YouTube, August 02, 2015, accessed November 11, 2016, https://www. youtube.com/watch?v=69hesWbRCM8.

53 Robinson and Pallasmaa, Mind in architecture: neuroscience, embodiment, and the future of design, 201.

54 Wendy De Silva, "The London Dialogue: Smart Design from the Hospital to the Streets," YouTube, May 11, 2016, accessed November 11, 2016, https://www.youtube.com/watch?v=w1qcH2FGn48\&list=PLvfJ7m2fAyTWXHZhkavu81jxj8ZnD3pME\&index=2.

55 Robinson and Pallasmaa, Mind in architecture: neuroscience, embodiment, and the future of design, 207.

56 Moshe Bar and Maital Neta, “Humans Prefer Curved Visual Objects," Psychological Science 17, no. 8 (2006): 1, doi:10.1111/j.14679280.2006.01759.x.

57 Bar and Neta, "Humans Prefer Curved Visual Objects," 645. 
58 Bar and Neta, "Humans Prefer Curved Visual Objects," 647.

59 Robinson and Pallasmaa, Mind in architecture: neuroscience, embodiment, and the future of design, 151.

60 Robinson and Pallasmaa, Mind in architecture: neuroscience, embodiment, and the future of design, 62.

61 Robinson and Pallasmaa, Mind in architecture: neuroscience, embodiment, and the future of design, 52.

62 Robinson and Pallasmaa, Mind in architecture: neuroscience, embodiment, and the future of design, 54.

63 Ronald Swaine, "2015-2016 Facts and Tidbits," CHEO - Facts and Figures, accessed September 29, 2016, http://www.cheo.on.ca/ en/FactsandFigures.

64 Sternberg, Healing Spaces the Science of Place and Well-Being, 219.

65 Sternberg, Healing Spaces the Science of Place and Well-Being, 226-7.

66 Sternberg, Healing Spaces the Science of Place and Well-Being, 226.

67 Ronald Swaine, “History,” CHEO - History, accessed September 29, 2016, http://www.cheo.on.ca/en/history1.

68 "Churchill and the Commons Chamber," UK Parliament, accessed October 20, 2016, http://www.parliament.uk/about/livingheritage/building/palace/architecture/palacestructure/churchill/.

69 De Silva, "The London Dialogue: Smart Design from the Hospital to the Streets."

70 "Devon's Story," Childrens Hospital of Eastern Ontario Foundation, accessed December 09, 2016, http://www.cheofoundation. com/stories/videos/.

71 Sternberg, Healing Spaces the Science of Place and Well-Being, 2.

72 Frascari and Goffi, Marco Frascari's Dream House, A theory of imagination, 79.

73 Laura Klairmont, "Robots attend school in place of sick kids," CNN, March 16, 2017, accessed March 16, 2017, http://www.cnn. com/2017/03/16/health/cnn-hero-leslie-morissette-grahamtastic-connection/index.html.

74 Heenan, "Art as therapy: an effective way of promoting positive mental health?, 179.

75 Robinson and Pallasmaa, Mind in architecture: neuroscience, embodiment, and the future of design, 154.

76 Ionascu, “Drawing matter(s)," Drawing: Research, Theory, Practice, 163.

77 Robinson and Pallasmaa, Mind in architecture: neuroscience, embodiment, and the future of design, 175. 


\section{BIBLIOGRAPHY}

Ashton, Alex. "Drawing on the "Lived Experience" - An Investigation of Perception, Ideation and Praxis." Art and Design Review 02, no. 03 (2014): 46-61. Accessed October 13, 2016. doi:10.4236/adr.2014.23007.

Bar, Moshe, and Maital Neta. "Humans Prefer Curved Visual Objects." Psychological Science 17, no. 8 (2006): 645-48. doi:10.1111/ j.1467-9280.2006.01759.x.

Botton, Alain De, and John Armstrong. Art as therapy. London: Phaidon Press Limited, 2016.

"Churchill and the Commons Chamber." Living Heritage Architecture of the Palace. Accessed October 20, 2016. http://www.parlia ment.uk/about/living-heritage/building/palace/architecture/palacestructure/churchill/.

Conty, Karen. "Experience.” ARCH 5200 Lecture. Carleton University. Ottawa. Canada. October 21, 2015.

De Silva, Wendy. The London Dialogue: Smart Design from the Hospital to the Streets. May 11, 2016. Accessed November 11, 2016. https://www.youtube.com/watch?v=w1qcH2FGn48\&list=PLvfJ7m2fAyTWXHZhkavu81jxj8ZnD3pME\&index=2.

“Devon's Story." Children's Hospital of Eastern Ontario Foundation. Accessed December 09, 2016. http://www.cheofoundation.com/ stories/videos/.

Dilthey, Wilhelm, Rudolf A. Makkreel, and Frithjof Rodi. Understanding the human world. Vol. 2. Princeton, NJ: Princeton University Press, 2010.

Frascari, Marco, and Goffi, Federica. Marco Frascari's Dream House, A theory of imagination. New York: Routledge, 2017.

Heenan, Deirdre. "Art as therapy: an effective way of promoting positive mental health?" Disability \& Society 21, no. 2 (2006): 17991. doi:10.1080/09687590500498143.

Huang, Mengfei. "The Neuroscience of Art. Reviews \& Features, Stanford Journal of Neuroscience. Vol. II, Issue 1, Fall 2009.

Huffcut, Jamie. "Mental Healthcare Design and the City." August 02, 2015. Accessed November 11, 2016. https://www.youtube.com/ watch?v=69hesWbRCM8. 
“H'ART OF OTTAWA STUDIO." Upstream Studio - H'Art of Ottawa. Accessed January 29, 2017. http://www.hartofottawa.ca/.

Ionascu, Adriana. "Drawing matter(s)." Drawing: Research, Theory, Practice, vol. 1, no. 2, 2016, p. 163+. Academic,One File,proxy.library.carleton.ca/login?url=http://go.galegroup.com/ps/i.do?p=AONE\&sw=w\&u=ocul_carleton\&v=2.1\&id= GALE\%7CA472989593\&it=r\&asid=e10785bf8fd9d39c3f11dd5d67b73044. Accessed 9 Dec. 2016.

Klairmont, Laura. "Robots attend school in place of sick kids." CNN. March 16, 2017. Accessed March 16, 2017. http://www.cnn. com/2017/03/16/health/cnn-hero-leslie-morissette-grahamtastic-connection/index.html.

Macfarlane, Kate, Charles Darwent, Tania Kovats, and Katharine Stout. The drawing book: a survey of drawing: the primary means of expression. London: Black Dog Pub., 2007.

McLeod, Saul. "Saul McLeod.” Qualitative vs Quantitative Data | Simply Psychology. January 01, 1970. Accessed January 10, 2017. https://simplypsychology.org/qualitative-quantitative.html.

Pallasmaa, Juhani, Harry Francis Mallgrave, Michael A. Arbib, and Philip Tidwell. Architecture and neuroscience. Espoo, Finland: Tapio Wirkkala-Rut Bryk Foundation, 2013.

Robinson, Sarah, and Juhani Pallasmaa. Mind in architecture: neuroscience, embodiment, and the future of design. Cambridge, MA: The MIT Press, 2015.

Sale, Teel, and Claudia Betti. Drawing: a contemporary approach. Boston, MA: Wadsworth Cengage Learning, 2008.

Sternberg, Esther M. Healing Spaces The Science of Place and Well-Being. Cambridge, MA: Harvard University Press, 2009.

Swaine, Ronald. “History." CHEO - History. Accessed September 29, 2016. http://www.cheo.on.ca/en/history1.

Swaine, Ronald. "2015-2016 Facts and Tidbits." CHEO - Facts and Figures. Accessed September 29, 2016. http://www.cheo.on.ca/en/ FactsandFigures.

IMAGES

Google . "CHEO ." Digital image. Google Maps . Accessed October 16, 2016. https://www.google.ca/maps/place/CHEO, Children's Hospital of Eastern Ontario/@45.3996312,-75.6514609,156a,35y,39.45t/data=!3m1!1e3!4m5!3m4!1s0x4cce0f6112ac5b 2b:0x71321aa0a164e5c7!8m2!3d45.401004!4d-75.651373. 